Chronology of middle Holocene hunter-gatherers in the Cis-Baikal region of Siberia:

Corrections based on examination of the freshwater reservoir effect.

\title{
For Quaternary International
}

Andrzej W. Weber ${ }^{1,2}$

Rick J. Schulting ${ }^{3}$

Christopher Bronk Ramsey ${ }^{3}$

Vladimir I. Bazaliiskii ${ }^{4}$

Olga I. Goriunova ${ }^{4,5}$

Natal'ia E. Berdnikova, 5

${ }^{1}$ Department of Anthropology, 13-15 H.M. Tory Building, University of Alberta, Edmonton, Alberta, T6G 2H4, Canada, aweber@ualberta.ca

${ }^{2}$ Laboratoire Méditerranéen de Préhistoire Europe Afrique (LAMPEA) - UMR 7269, AixMarseille Université, 5 rue du Château de l'Horloge - B.P. 647, 13094 Aix-en-Provence Cedex 2, France

${ }^{3}$ Research Laboratory for Archaeology and the History of Art, Dyson Perrins Building, University of Oxford, South Parks Road, Oxford, OX1 3QY, United Kingdom

${ }^{4}$ Department of Archaeology and Ethnography, Irkutsk State University, Karl Marx Street 1, Irkutsk 664003, Russia

${ }^{5}$ Institute of Archaeology and Ethnography, Siberian Branch of the Russian Academy of Sciences, Academician Lavrent'iev Ave. 17, Novosibirsk, 630090, Russia

\begin{abstract}
A dataset of 256 AMS radiocarbon dates on human skeletal remains from middle Holocene cemeteries in the Cis-Baikal region, Siberia, and associated carbon and nitrogen stable isotope values are analyzed for new insights about culture history and processes of culture change. First, based on the typological criteria all dated human burials are assigned to mortuary traditions and typochronological units - Late Mesolithic, Early Neolithic, Late Neolithic and Early Bronze Age. Next, all dates are corrected for the Freshwater Reservoir Effect (FRE) according to the regression equations developed using paired radiocarbon dates on human and terrestrial faunal remains from the same graves (Bronk Ramsey et al., 2014; Schulting et al., 2014; 2015) and examined for chronological trends using a Bayesian approach. While the entire corrected culture historical sequence is younger by roughly 200-400 years relative to the previous model (Weber et al., 2010) the shift of the specific period boundaries is not systematic due to the varying proportion of aquatic food in the diets of the relevant groups. Examination of the dataset subdivided into smaller spatio-temporal units provides additional insights. During the Early Neolithic, in the Angara and Southwest Baikal micro-regions there is a chronological trend toward increased reliance on aquatic food. During the Early Bronze Age in the Little Sea micro-
\end{abstract}


region, there appears to be a trend toward increased reliance on the Baikal seal. This shift, however, can also be interpreted as increasing migration over time of new groups from the Upper Lena. The sample from the Early Neolithic Shamanka II cemetery in Southwest Baikal shows two non-abutting phases of use each displaying a trend toward greater consumption of aquatic foods. These findings provide new chronological framework for the study of other cultural changes affecting middle Holocene hunter-gatherers in the region. The results may also allow better correlation with other sequences, cultural and environmental, that are not affected by the FRE.

\section{INTRODUCTION}

Middle Holocene prehistory of the Cis-Baikal region in East Siberia (Fig. 1) belongs to one of the many cases around the world where examination of materials from mortuary sites has dominated archaeological research. Grave goods and human skeletal remains have been the focus of many studies essentially since the beginning of professional archaeology in the region. Although much has been written about culture history and cultural and biological variation among these groups, many questions regarding the processes of culture change still remain unanswered (e.g., Weber and Bettinger, 2010; Weber et al., 2011). The explicit emphasis on mortuary sites also created an imbalance with regard to dating, both typological and chronometric, as well as the cultural characterization of the different periods and micro-regions. The periods with well-documented cemeteries naturally have been given much attention with many attempts to define them in cultural and chronological terms. In contrast, the periods without cemeteries (e.g., Middle Neolithic and, to a lesser extent, Late Bronze Age) have received much less attention and their cultural characteristics and temporal boundaries remain vague.

Middle Holocene prehistory of Cis-Baikal is also interesting in that it has seen a long debate about its chronology and experienced several fundamental revisions to its culture history (cf. Weber, 1995 for review). To keep the matter brief, the first relatively well-documented model of continuous progression of hunter-gatherer cultures or stages (Khin'-Isakovo-Serovo-KitoiGlazkovo-Shivera; Okladnikov 1950) was criticized by many Siberian scholars and eventually fell apart under the weight of radiocarbon evidence (Konopatskii, 1982; Mamonova and Sulerzhitskii, 1989; Weber, 1995); however, the names of the relevant mortuary traditions are in use to this day without many revisions. According to the new chronological evidence, the Kitoi mortuary tradition is much older than Isakovo and Serovo, which, in turn, appear to be chronologically parallel. The Glazkovo and Shivera traditions, whose typochronological placement was based on the presence of copper and bronze objects, retain their original position at the end of the sequence. A few dates appeared to be quite old, perhaps representing the Late Mesolithic Khin' tradition in the Okladnikov model, but they were either subject to very large measurement errors or their archaeological context was compromised, thus raising doubts about the general archaeological identity of this early mortuary tradition (Weber et al., 2010). 
Further reassessments of this initial radiocarbon evidence and the subsequent accumulation of a much larger set of dates by the Baikal Archaeology Project confirmed the main points of the new culture history model but also led to some revisions (Weber, 1995; Weber et al., 2002, 2006, 2010; Weber and Bettinger, 2010: Table 1). The most important of these was the identification of a roughly millennium-long period with no formal cemeteries at all, thus breaking the chronological continuity of Neolithic mortuary traditions (Weber et al., 2010; Weber and Bettinger, 2010):

\section{Period}

Late Mesolithic (LM)

Early Neolithic (EN)

Middle Neolithic (MN)

Late Neolithic (LN)

Early Bronze Age (EBA)
Mortuary tradition(s)

Lack of archaeologically visible mortuary sites

Kitoi and other micro-regionally specific traditions

Lack of archaeologically visible mortuary sites

Isakovo and Serovo

Glazkovo
Cal BP years

$8800-8000$

$8000-7000 / 6800$

$700 / 6800-6000 / 5800$

$6000 / 5800-5200$

$5200 / 5000-3400$

Following the long-standing Russian school of archaeology, Cis-Baikal's hunter-gatherer culture history is defined on the basis of technological criteria. Thus, changes in the stone industry (i.e., mostly proliferation of the microlithic technique) define the Mesolithic, the bow and arrow, ground stone tools, and ceramics identify the Neolithic, and objects of copper and bronze the Bronze Age. Further divisions within Neolithic are based mainly on the characteristics of the mortuary protocol (see below for more detail) while within the Bronze Age on the appearance of new forms of metal artefacts. Since animal and plant domesticates were introduced into the region only during the Iron Age and historical times, respectively, subsistence of all preceding groups was based on various combinations of game and seal hunting, fishing and gathering.

The work reported in this paper represents the next step in the revisions to the middle Holocene culture history in Cis-Baikal. While the changes may at first appear as less dramatic than those associated with earlier applications of radiocarbon dating in the region, it will become evident later in the paper that they are perhaps even more important. The matter regards corrections based on the identification of a Freshwater Reservoir Effect (FRE) impacting the radiocarbon ages of human skeletal remains on which our understanding of the culture history and process of middle Holocene Cis-Baikal relies to a substantial extent.

While the marine reservoir effect has been known for some time and from many archaeological and environmental settings around the world, the importance and complexity of the FRE has been only recently recognized (e.g., Ascough et al., 2012; Cook et al., 2001; Lillie et al., 2009; Olsen et al., 2010; Higham et al., 2010; Wood et al., 2013). Its presence suspected for some time (e.g., Prokopenko et al., 1999), a FRE has also been confirmed in the aquatic system of Lake Baikal based on the comparison between dates obtained on bones from terrestrial herbivores and the Baikal seal representing the same stratigraphic units at the multilayered archaeological campsite Sagan-Zaba II on Lake Baikal (Nomokonova et al., 2013). Since the diets of middle Holocene foragers in the region included spatially and temporally variable 
amounts and kinds of aquatic foods (Weber et al., 2011), radiocarbon determinations made on human skeletal remains are likely to overestimate their true age to correspondingly variable degrees. To assess the extent of FRE impact on the radiocarbon age of human osteological remains, paired dating of human and animal terrestrial herbivore skeletal material from the same grave was implemented (Bronk Ramsey et al., 2014; Schulting et al., 2014; 2015). Separate correction equations were developed for the entire Cis-Baikal region as well as for its constituent micro-regions: the Angara River combined with Southwest Baikal, the Little Sea area and the Upper Lena (Fig. 1).

The primary goal of this paper is a preliminary assessment of the revisions to the regional

culture history resulting from the corrections to the ${ }^{14} \mathrm{C}$-dates available for middle Holocene hunter-gatherers from Cis-Baikal. An investigation of temporal dietary trends is our secondary goal. After these introductory notes, we present the available set of radiocarbon dates generated for Cis-Baikal and review the principles of typological dating of Cis-Baikal mortuary assemblages. We follow with the introduction of the FRE correction equations used in the paper and explain the methods of analysis. The discussion of the results is divided into two parts. Part one is an assessment of Cis-Baikal middle Holocene culture history as a whole and part two is organized by micro-regions, where more specific chronological patterns are examined. The paper ends with a summary of the findings and a number of conclusions of broader archaeological relevance.

\section{MATERIALS}

The study is based on radiocarbon dates obtained for 256 individuals from the Cis-Baikal region. All dating was conducted at the Oxford Radiocarbon Accelerator Unit (ORAU) at the University of Oxford, UK, with stable carbon and nitrogen isotope ratios, collagen yields and $\mathrm{C} / \mathrm{N}$ ratios reported at the same time (Fig. 2, Supplement 1). Analytical precision for $\delta^{13} \mathrm{C}$ and $\delta^{15} \mathrm{~N}$ is \pm 0.2 and $\pm 0.3 \%$, respectively. With the exception of the 48 dates included in the paired dating project (Bronk Ramsey et al., 2014; Schulting et al., 2014; 2015) and some reported in the monograph of the Kurma XI cemetery on Lake Baikal (Weber, 2012), the ORAU data have not yet been published. Prior to the dating program implemented at ORAU, 335 radiocarbon dates (with some overlap with ORAU) were undertaken at the Isotrace Laboratory, the University of Toronto, Canada, while carbon and nitrogen stable isotopes for the same individuals were analyzed by Dr. M.A. Katzenberg at the University of Calgary (Weber et al., 2006; 2011). Although Isotrace did not provide stable isotope measurements, it would still be possible to correct these dates for the FRE using the stable isotope results from Calgary, enabling their inclusion in the analysis alongside the ORAU dates and thus making the dataset substantially larger. Aside from some additional difficulties related to the fact that in a number of instances different skeletal elements were tested in the labs, the main problem is that the ORAU and Isotrace dates appear to be incompatible. For example, for the EN Shamanka II cemetery on Southwest Baikal, there are currently four individuals (Burials No. 16, 24.02, 30 and 32) dated at both laboratories (Supplement 1; Weber at al., 2006: Table 2) but in no case do these pairs pass the $\chi^{2}$ test of the 
R_Combine function in OxCal 4.2.4 (Ward and Wilson, 1978). In every instance the Isotrace date is significantly younger than the ORAU measurement. This difference may relate to the improved removal of contaminants provided by the use of $30 \mathrm{kD}$ ultra-filters at Oxford (Brock $e t$ al., 2010). As all Shamanka II individuals dated at Isotrace have been since reanalyzed at ORAU, the Isotrace dates are omitted from analysis.

There are around 200 individuals from a number of cemeteries across the entire region without an ORAU date but readily available for analysis. The majority derive from the following cemeteries: EN Lokomotiv, the LN and EBA components of Ust'-Ida I - both in the Angara valley, and EBA Khuzhir-Nuge XIV in the Little Sea micro-region. Furthermore, there are still many skeletons from the older excavations along the Angara and Upper Lena Rivers (Okladnikov, 1974; 1975; 1976; 1978; Svinin, 1981) and in the Little Sea (Masson, 1991); however, at present, their number is difficult to assess. While a few of these sites have been dated at ORAU to some extent, plans to analyze the remaining extant individuals are under development. In addition, some 45 individuals from Shamanka II are also still without a date.

\section{TYPOLOGICAL DATING}

The matter of typological dating of the relevant mortuary traditions requires some attention. The substantial body of data provided by approximately 184 cemeteries, 1026 graves and 1182 individuals (Weber and Bettinger, 2010: Table 3), relatively well-documented in various publications and reports, and the equally substantial amount of regional and micro-regional variation in mortuary characteristics, make the typological classification of Baikal's middle Holocene mortuary assemblages a relatively complex exercise (Bazaliiskii, 2010; Weber and Bettinger, 2010). Unsurprisingly perhaps, this material has never been systematically analyzed as a whole and doing so would be beyond the scope of this study. Consequently, it is not possible to provide a complete list of traits defining relevant chronological and territorial groups nor is it possible to give new quantitative results regarding geographic distribution and prevalence of these traits based on the entire corpus. Instead, what follows is a summary of several standard diagnostic characteristics as per the available literature. Unfortunately, quantitative evidence to support many of these claims is sparse. When practical, similarities and differences between the micro-regions as well as exceptions to general patterns are noted.

\subsection{Late Mesolithic}

Okladnikov originally assigned the Khin' mortuary tradition to the Mesolithic (Okladnikov, 1950). Represented in his dataset by two graves (Pad' Khin'skaia and Pad' Chastye) excavated in the Angara valley in the 1930s, subsequent fieldwork has produced only two additional graves, one each in the Angara (Ust'-Griaznaia) and the Upper Lena valleys (Rytvinka), matching the typological criteria of the Khin' mortuary protocol (Bazaliiskii, 2010). Grave No. 8 from Lokomotiv-Raisovet is excluded as its initial assignment to the LM was based not on the typological characteristics but rather on the radiocarbon date (Bazaliiskii, 2010; Weber et al., 2006) which we now know was affected by the FRE. A dozen or so other graves from several 
cemeteries across much of Cis-Baikal have been recently assigned by Bazaliiskii (2010) to the Final Mesolithic based on a combination of typological and radiocarbon criteria. Since both groups are not very numerous to begin with and, furthermore, represented in this study by even smaller number of dated burials, they are treated here as one Late Mesolithic typochronological group.

The Late Mesolithic mortuary tradition appears highly variable. Body position is mostly flexed while extended burials have been observed only in a few cases, the orientation is to N, $\mathrm{NW}$, or E, use of red ochre ranges from isolated spots to full coverage (e.g., Khotoruk), and grave goods are generally small in number but relatively diverse. Grave accoutrements show similarities with the Mesolithic (prismatic blades and points on prismatic blades) and the EN (fishing tackle including mostly fishhook shanks but also a barb and a leister). Ornaments are not common and when they do occur there are beads, red deer canine pendants and a boar tusk pendant - the kinds known also from EN, LN and EBA graves. Bazaliiskii (2010) defines these graves in terms of the absence of pottery and bifacially formed arrowheads but, to be sure, many other categories relatively frequent among EN, LN, and EBA graves are lacking too (e.g., green or white nephrite tools and ornaments, composite tools, bone points, etc.)

\subsection{Early Neolithic}

The Kitoi mortuary tradition is known primarily from a few large cemeteries located in the Angara valley (Lokomotiv, Kitoi, Galashikha, and Ust'-Belaia) and one (Shamanka II) on the southwest tip of Lake Baikal as well as from a number of isolated graves scattered along the banks of the Angara river (Fig. 1; Bazaliiskii, 2010). The ubiquitous use of copious amounts of red ochre is perhaps the most distinctive mortuary characteristic of this tradition. According to Bazaliiskii (2010), in the Angara valley $96 \%$ of Kitoi graves show this trait. Additionally, body position is predominantly extended, but flexed or bundled burials occur occasionally, and there are a few prone interments. The head is generally oriented to the north, graves with more than one interment are common and in many such cases the burials are arranged head-to-toe and on different stratigraphic levels, suggesting successive interments. Some burials have missing skulls and graves generally lack stone structures.

Grave goods are the most variable in kind and number of all middle Holocene mortuary traditions documented in the region, featuring as many as 60-65 categories (Bazaliiskii, 2010). Most common are composite lithic fishhook shanks and bifacial arrowheads but many other kinds are well-represented, including an array of stone, bone and antler tools (unilateral harpoons and a range of points and shafts or handles of composite tools), objects made of green nephrite (knives and adzes), ornaments (rings, beads, red deer canine pendants, bone pendants, mother-ofpearl pendants and boar tusk pendants) and objects of zoomorphic art depicting terrestrial (moose) and aquatic fauna (fish and seal). Pottery is very rare; however, when it does occur, complete mitre-shaped pots with net impressions on the outside surface are found. Within any given cemetery, the distribution of these diverse grave goods is highly variable: some burials are accompanied by hundreds of items while many others have very few or none at all. 
Outside of the Angara valley and Southwest Baikal, the EN graves are best characterized as displaying variants of the 'classic' Kitoi package: a small number of Kitoi traits might be present but others are lacking. Furthermore, other traits usually show little patterning making it difficult to present this variation in a systematic way. Since Bazaliiskii (2010) and Weber and Bettinger (2010) have discussed the matter in detail, we can limit ourselves to a few examples. At Fofanovo, on the lower Selenga River, all graves have copious amounts of red ochre but the bodies display flexed legs and southeast orientation of the head and the composite fishhooks of the Kitoi type are absent (Gerasimov and Chernykh, 1975; Bazaliiskii, 2010). At Kurma XI in the Little Sea micro-region, all burials have the N orientation and some show red ochre but the grave good assemblage - a total of five prismatic blades from six graves - is clearly not EN but rather Mesolithic in character (Weber et al., 2012). However, such lithics would not be out of place as part of a larger EN, LN or even EBA mortuary assemblage. At Khotoruk, in the same micro-region, all graves have red ochre and the burials show the $\mathrm{N}$ orientation but the body position is flexed. Only one grave has fishhooks, there are no bifacial arrowheads and the remaining grave goods are not particularly diagnostic. The same situation, i.e., the lack of pattern, prevails on the Upper Lena, where every cemetery classified as EN seems to be different from the other one, and, of course, from the Angara and Little Sea micro-regions. Here, ironically, it is the Turuka cemetery near Ust'-Kut in the north, geographically the most distant from the 'classic' Kitoi, that shows most resemblances to it (Fig. 1; Bazaliiskii and Ineshin, 1995; Bazaliiskii, 2010). For the record, a few seemingly Kitoi graves in the Angara valley pose similar classificatory ambiguities (Bazaliiskii, 2010).

This lack of clear pattern, of course, causes difficulties and disagreements about chronological classification of this group of graves. The presence of, for example, composite fishhooks or red ochre may be sufficient to place them in the EN; however, it is also possible to place more emphasis on the differences than the similarities and assign them to the LM. For example, Khotoruk has been placed in the Final Mesolithic by Bazaliiskii (2010), but in the EN by Konopatskii (1982). Weber et al. (2012) classified such graves from Kurma XI as EN, though based on Bazaliiskii's criteria they should rather belong to the LM.

\subsection{Middle Neolithic}

Since the reassignment of the Serovo graves-MN in Okladnikov's model (1950) - to the LN at the turn of the last century (Mamonova and Sulerzhitskii, 1989; Weber, 1995; Weber et al., 2002, 2006), there is currently no other archaeologically visible mortuary tradition associated with this period. Consequently, the $\mathrm{MN}$ is frequently referred to as representing a discontinuity in the use of formal cemeteries in the region.

\subsection{Late Neolithic}

Two main mortuary traditions have been proposed for the LN: Isakovo and Serovo, both first described by Okladnikov (1950). Okladnikov dated Isakovo to the EN and Serovo to the MN but since the introduction of radiocarbon dating, the consensus has been that both belong to the same 
LN period (Mamonova and Sulerzhitskii, 1989; Weber, 1995; Bazaliiskii, 2010; Weber and Bettinger, 2010). In the Angara valley, Isakovo and Serovo graves co-exist at many cemeteries (e.g., Serovo, Ponomarevo, and Bratsk). Okladnikov (1978) and, more recently, Bazaliiskii (2010) proposed a local version of the Serovo mortuary protocol for the Upper Lena microregion, referring to it as Archaic or Verkholensk, respectively. Bazaliiskii (2010) also identifies a separate Serovo group in the Little Sea micro-region. It seems, however, that the range of similarities and differences displayed by Serovo graves in these three micro-regions fully warrants their combined treatment, a decision that has limited impact on this study because, for the reasons discussed below, EN and LN dates from the Upper Lena are excluded from analysis.

The Isakovo mortuary tradition was identified by Okladnikov (1950) on the basis of 12 graves only, all from the Angara valley. Subsequent fieldwork has substantially expanded the body of data, mostly in terms of the number of sites and graves but much less in geographic distribution. Today, the Isakovo mortuary tradition is still known exclusively from the Angara valley. Isakovo graves feature surface stone structures, orientation parallel to the Angara River with the heads pointing upstream (generally S). Most graves are single inhumations but multiple interments are not uncommon. Subadult individuals account for an unusually large proportion of all burials (Bazaliiskii, 2010).

Grave inclusions are less diverse in the Isakovo than in the Kitoi mortuary tradition, with 20 25 categories represented (Bazaliiskii 2010). Mitre-shaped clay vessels with net impressions and round pits along the rims, recorded in $70 \%$ of graves, are among the most ubiquitous grave goods. Other frequently found objects include a range of bone and antler points, bone or antler shafts of double-sided composite tools (daggers and spears) and harpoons. Large lithic bifaces, common in the Serovo mortuary protocol, have been found only in three Isakovo graves. Fishing gear is rare and so are objects of art, with only a few anthropomorphic items known. Overall, Okladnikov's original portrayal of this mortuary tradition as displaying little variation in terms of grave architecture, body treatment and kind and number of grave goods seems to hold as much today as it did then.

The Serovo tradition is known from the Angara, Little Sea and Upper Lena micro-regions and this broad geographic distribution subsumes variation with regard to many aspects of the mortuary protocol. On the Angara, burials are in extended supine position, perpendicular to the river with the head pointing away from it. It is this referencing relative to the river that sets Serovo fundamentally apart from Isakovo. On the Angara, Serovo graves feature stone structures both on the surface as well as in grave pits. Red ochre is relatively frequent but its use is limited to small and isolated patches. Most graves have single interments and grave goods are more numerous and more variable than in the Isakovo tradition, with 30-35 categories of grave goods (Bazaliiskii 2010). Stone, bone and antler tools, and pottery are among the most common. In the Angara valley, egg-shaped pots, invariably present in all Serovo graves, and large bifacially formed points (spearheads) also distinguish Serovo assemblages from other mortuary traditions in this micro-region. Two-sided composite inset points differ morphologically from Isakovo points, but fishing gear, featured by several bone and antler harpoons and two stone fish-lures, 
does not and is equally rare. Portable art, represented by single examples of anthropomorphic and zoomorphic figurines, and a few unique bird carvings, is also rare. Graves with rich grave good assemblages are apparently more common than in the Isakovo tradition.

With a few exceptions, much of the Angara Serovo pattern is repeated in the Little Sea and on the Upper Lena (Bazaliiskii, 2010). Grave architecture, use of ochre, number of individuals per grave, body position, and orientation relative to water are similar in all three micro-regions, although in the Little Sea water referencing may lead to confusion. Due to the geographic orientation of the lake's coastline, the placement of the deceased's head away from Baikal in many instances effects the $\mathrm{N}$ orientation of the interments, the same as in EN burials. In absence of other diagnostic traits (and ${ }^{14} \mathrm{C}$ dating), this creates ambiguity and potential for missclassification.

Further, many burials on the Upper Lena and in the Little Sea are covered or wrapped in birch bark and many skeletons are affected by fires set inside grave pits. Fishing tackle is rare in the Little Sea and slightly more frequent on the Upper Lena. In the Little Sea clay vessels are quite common (31 pots in 19 graves) and they appear to be of the egg-shape form. On the Upper Lena, however, clay vessels - mitre-shaped as the Isakovo pots on the Angara - have been found in only about 50\% of the graves (Bazaliiskii, 2010). Ground stone adzes or axes and composite knives are also typologically similar to the specimens found in Isakovo graves. Antler picks appear to be documented so far only on the Upper Lena while grave goods from the Little Sea do not show any specifically local characteristics.

\subsection{Early Bronze Age}

Currently, the Glazkovo mortuary tradition is the only one that is known from all four microregions (Okladnikov, 1955; Svinin, 1981; Konopatskii 1982; Weber et al., 1995; Kharinskii and Sosnovskaia 2000; Goriunova, 2002; Turkin and Kharinskii, 2004; Weber et al., 2008;

Goriunova and Novikov, 2010; Weber et al., 2012). Although on the regional scale, and to an extent also micro-regionally, it displays relatively substantial variation in terms of presence and absence of various mortuary characteristics, for the purpose of this study it is not necessary to analyze the Glazkovo tradition in such detail. Copper and bronze objects define the chronological placement of this group relative to the others, but since metals are generally quite rare, it is primarily the orientation of graves and burials that sets Glazkovo apart. Although variable between the micro-regions, these two characteristics work well within each area. On the Angara, Glazkovo graves, like the LN Isakovo, are parallel to the Angara but the heads are oriented downstream (generally $\mathrm{N}$ ), that is, in the opposite direction than seen in the Isakovo. In the Upper Lena micro-region Glazkovo graves are parallel to the rivers but since they flow in different directions, the orientation of the Glazkovo burials relative to cardinal directions naturally differs. In the Little Sea, where there is no large river and the coastline is quite irregular, referencing relative to water does not work in the same way but the graves are typically oriented along the SW-NE axis (generally parallel to the long axis of Baikal) with heads pointing SW. 
On Southwest Baikal, Glazkovo graves are known so far from only one cemetery, Shamanka II. Here, to complicate matters further, the graves are oriented N-S or NW-SE with the heads pointing $\mathrm{N}$ or $\mathrm{NW}$ and, so it seems, the water-referencing rule does not apply. In this area, which lacks a large river, the lake's coast runs in various directions as it curves around its southwest end. Fortunately, due to the obvious differences regarding other aspects of the mortuary protocol, mainly the profuse use of red ochre, it is difficult to confuse EBA with Kitoi graves, numerically the dominant component at Shamanka II. At Fofanovo, on the lower Selenga, Glazkovo graves, like on the Angara, are also parallel to the river, but the heads point $E$ thus upstream rather than downstream as on the Angara (Gerasimov and Chernykh, 1975).

Such characteristics as grave architecture (i.e., use of stones), number of interments per grave (predominantly one), and body position are similar in all four micro-regions and are also similar to Isakovo and Serovo groups. Red ochre occurs rarely, mostly, as in the LN, in isolated spots, but in the Little Sea there are a few burials entirely covered by this pigment (e.g., Graves 14 and 17 at Kurma XI; Weber et al., 2012). Also in the Little Sea, many graves have been disturbed in the past and many skeletons are charred from fires set inside grave pits. Assortment of grave goods, by and large, repeats many categories found in LN Isakovo and Serovo graves but differ from them in detail (adzes and axes, composite tools, harpoons, bone points, arrowheads, bifaces, etc.). New, or at least much more common than earlier, are objects made of white nephrite (disks and rings) but artefacts made of green nephrite also occur. Entirely new are the seated burials and, of course, the metals. Utilitarian objects (e.g., knives, needles and fishhooks) are the most common but ornaments, mostly rings, or other kinds such as the unique medallion from Grave 1 at Kurma XI (Weber et al., 2012: Photos 17 and 22) are known too. Clay pots are rare and fishing gear (fishhook shanks and barbs and harpoons) is even less common. Such nondiagnostic ornaments as boar tusk pendants, red deer canine pendants and small beads are known from numerous Glazkovo graves across Cis-Baikal. Lastly, at many cemeteries LN and EBA graves co-exist side by side, the older rarely disturbed by the younger, implying that the latter were somehow marked in ways that persisted over the intervening centuries.

\subsection{Summary of typological dating}

The overview presented above should help the reader navigate through the radiocarbon dates and the accompanying archaeological information compiled in Table 1 and Supplement 1. Regardless of the variation present in this material, including the exceptions, ambiguities and inconnsistencies in the selection and description of mortuary traits, as long as they display at least some combination of the standard diagnostic characteristics, most graves are relatively easy to assign to a specific mortuary tradition. The problems, however, arise when they do not and in such instances additional criteria are taken into consideration, not always in a systematic manner. In some cases, research agenda, intuition or presence of other graves at a given cemetery, that are less ambiguous become decisive factors. Clearly, in such cases errors and disagreements are likely to appear. Overall, typology seems to work relatively well but mainly as a coarse dating tool. It is, perhaps, because of this relatively low resolution that, so far, there have been no 
successful attempts to use typology toward developing a more detailed sequence for any of the periods, mortuary traditions, micro-regions or large cemeteries.

Based on the typological criteria summarized above all dated human burials have been assigned to a specific "Typological period" (Supplement 1). In the absence of published work, information provided by the excavators was used instead. In those instances where surface finds were dated, the column shows values expected based on the typological profile of the entire cemetery. For the typologically contentious graves from the Khotoruk and Kurma XI cemeteries "LM or EN" has been entered. Only in one instance was the published typological classification overwritten based in part on the re-evaluation of the archaeological context and in part on the radiocarbon date (Supplement 1). Grave 22 from Sarminskii Mys in the Little Sea, with no grave goods in it, was originally classified as LN Serovo due to the $\mathrm{N}$ orientation of the burial consistent with the other Serovo graves from this and other LN cemeteries in the vicinity, most with some grave goods (Goriunova, 1997). However, this orientation and the lack of grave goods are equally consistent with those displayed by similar graves from the Khotoruk and Kurma XI cemeteries, none of which appear to be LN. The corrected radiocarbon date for Sarminskii Mys Grave 22 falls within the LM.

\section{METHODS}

\subsection{Correction of the freshwater reservoir effect}

As mentioned above, a substantial freshwater reservoir offset in radiocarbon age between terrestrial herbivores and aquatic fauna of Lake Baikal from the same archaeological layers has been recently identified by Nomokonova et al. (2013). In order to correct for this offset, 42 pairs of dates on human bone and terrestrial herbivore bone or tooth samples, each from the same grave, were analyzed. This dataset represents five major middle Holocene cemeteries in the CisBaikal region: Lokomotiv (EN) and Ust'-Ida I (LN and EBA) in the Angara valley, Shamanka II (EN) on Southwest Baikal and Khuzhir-Nuge XIV and Kurma XI (both EBA) in the Little Sea (Fig. 1). Paired dates for a series of smaller cemeteries were also obtained from the Upper Lena micro-region: Popovskii Lug 2, Turuka, Zakuta, Ust'-Iamnaia and Makrushino (Fig. 1).

The regression equations use the human ${ }^{14} \mathrm{C}$ date and the $\delta^{15} \mathrm{~N}$ value for each tested individual and, in the case of the Little Sea and Upper Lena micro-regions, also the $\delta^{13} \mathrm{C}$ measurement. Two different approaches were used to correct the human ${ }^{14} \mathrm{C}$ dates. While details of these two techniques are given in dedicated publications, it is important to emphasize that both, i.e., the Bayesian approach (Bronk Ramsey at al., 2014) and the linear regression method (Schulting et al., 2014; 2015) generated very similar corrections. Bronk Ramsey et al. developed a regional correction model and Schulting et al. worked out regional and micro-regional models. In the present study we use the two regression models developed by Schulting et al.: 


\begin{tabular}{llrrrr} 
Regression model & Equation $^{1}$ & \multicolumn{1}{c}{$S$} & \multicolumn{1}{c}{$r^{2}$} & \multicolumn{1}{c}{$p$} & $n$ \\
\hline Southwest Baikal \& Angara & $Y=-1388.8522+125.4503 \times \delta^{15} \mathrm{~N}$ & 64.1 & 0.814 & $<0.000$ & 15 \\
Little Sea & $Y=-3329.5361-125.5967 \times \delta^{13} \mathrm{C}+95.1091 \times \delta^{15} \mathrm{~N}$ & 51.8 & 0.859 & $<0.000$ & 16 \\
Upper Lena (all) & $Y=-7364.1880-402.3963 \times \delta^{13} \mathrm{C}$ & 183.6 & 0.490 & 0.016 & 11 \\
Upper Lena (EBA) & $Y=-4289.8916-211.1860 \times \delta^{13} \mathrm{C}+45.3842 \times \delta^{15} \mathrm{~N}$ & 40.3 & 0.840 & 0.030 & 6
\end{tabular}

Where, $Y$ is the predicted offset between the conventional (measured) and terrestrial (atmospheric) ${ }^{14} \mathrm{C}$ age for an individual and $\delta^{15} \mathrm{~N}$ is the nitrogen stable isotope value for the dated individual. The corrected ${ }^{14} \mathrm{C}$ age of an individual is then obtained by subtracting the offset value $(Y)$ from the conventional radiocarbon age while the standard deviation of the corrected date is calculated according to the following equation:

$$
\sqrt{ }\left(\text { s.d. }{ }^{2}+S^{2}\right) \text {, where }
$$

s.d. is the error associated with the conventional ${ }^{14} \mathrm{C}$ measurement and $\mathrm{S}$ is the standard deviation of residuals from the linear regression.

The first equation appears to work quite well for the Southwest Baikal and Angara microregions combined. Although the equation using $\delta^{15} \mathrm{~N}$ alone leaves some $20 \%$ of the observed variation in ${ }^{14} \mathrm{C}$ offsets unaccounted for (including the $\delta^{13} \mathrm{C}$ value does not improve the predictive value of the model for these micro-regions), it does account for $\sim 80 \%$ of that variation $\left(r^{2}=0.814\right)$ which is a substantial improvement over no correction at all (Schulting et al., 2014). The regression model developed for the Little Sea, which employs both stable isotope signatures $\left(\delta^{13} \mathrm{C}\right.$ and $\left.\delta{ }^{15} \mathrm{~N}\right)$ performs even better, accounting for $\sim 86 \%$ of the variation in ${ }^{14} \mathrm{C}$ offsets in this micro-region $\left(r^{2}=0.859\right)$ Still, it must be kept in mind that for some of the dates in the dataset the regression model does not work as well as it does for the majority and it is difficult at this time to identify such dates.

Two additional regression equations were calculated for the Upper Lena micro-region (Schulting et al., 2015). The first is applicable to all chronological periods but its predictive value $\left(r^{2}=0.490\right)$ is somewhat low and its associated error $(\mathrm{S}=183.6)$ is rather high. Interestingly, in this case the correction is based on the $\delta^{13} \mathrm{C}$ signature rather than on $\delta^{15} \mathrm{~N}$. Limiting the Upper Lena dataset to two EBA cemeteries (Ust'-Iamnaia and Makrushino) in the southern part of the micro-region substantially improves the predictive power of the correction equation $\left(r^{2}=0.840, \mathrm{~S}=40.3\right)$ bringing it to the same level as obtained for the other two microregions. In this instance, the main correction comes from the $\delta^{13} \mathrm{C}$ values with $\delta^{15} \mathrm{~N}$ being of significant but secondary value. Since the predictive strength of the general Upper Lena correction is much lower relative to the other three equations, all LM, EN and LN dates from this micro-region are excluded from analysis, pending further work.

Because the Angara and Little Sea regression equations rely to a large extent on the $\delta^{15} \mathrm{~N}$ value, they cannot be applied to those individuals whose $\delta^{15} \mathrm{~N}$ is affected, in addition to the aquatic diet, by other factors such as nursing. This applies to the EBA sample for the Upper Lena

\footnotetext{
${ }^{1}$ Although regression equations are normally presented with one or two decimal places, here we show four as provided by the regression analysis and as employed in the calculation of the corrected dates. The rounding of the obtained products was done only at the very completion of the entire procedure rather than at each step.
} 
although to a lesser extent because the correction there is based mainly on the $\delta^{13} \mathrm{C}$ value. While it would be possible to subtract from the given isotopic measurement the assumed trophic level effect of 3-5\%, it is not clear whether the entire value should be applied. It would be unrealistic to expect lack of variation in the onset and nature of weaning (Weber et al., 2002; Waters-Rist $e t$ al., 2011) and subtract a fixed number depending on the age of an infant, for example 3\%o from $\delta^{15} \mathrm{~N}$ value of a 1-year-old, $2 \%$ from a 2-year-old, etc. Besides, skeletal age determinations of young children and the 3-5\% trophic level fractionation both carry their own uncertainties (e.g., Reynard and Tuross, 2015). Based on our current knowledge about the onset of weaning among Cis-Baikal's middle Holocene foragers, and taking a conservative stance, radiocarbon dates of children assessed to be 5 years old or younger are not corrected.

Thus, results for 32 children from the Angara, Southwest Baikal and Little Sea micro-regions and for 2 additional infants from the Upper Lena have been omitted from this preliminary examination, though the matter will be revisited in the future. It must be kept in mind, however, that in individual cases some residual nursing effect might still be present in children older than 5 years. In these cases, the elevated $\delta^{15} \mathrm{~N}$ value may over-correct the radiocarbon determination thus resulting in a corrected date that is too young. Since in the present dataset there are only five children aged between 5 and 7 years old and two more aged broadly from 0 to 7 years, but probably closer to the upper boundary, this is unlikely to bias the overall analysis.

It can be argued that the animal dates from the paired dating program could be preferentially used over the corrected human bone dates, thus avoiding altogether the FRE for these burials. However, for consistency with graves that do not contain animal remains, we apply the regression equations for the FRE to all dated humans over the age of 5 years, including those in the paired dating program from which the corrections were developed.

\subsection{Conventions}

The radiocarbon determinations reported in this paper undergo a sequence of corrections and analyses and the following terms and acronyms are used to ensure clarity:

(1) The ${ }^{14} \mathrm{C}$ determinations provided by ORAU are referred to as conventional, uncorrected, or simply ${ }^{14} \mathrm{C}$ or radiocarbon dates and they are presented in years BP.

(2) ${ }^{14} \mathrm{C}$ dates transformed with the linear regression equations are referred to as corrected ${ }^{14} \mathrm{C}$ dates and they are also presented in years BP.

Only the corrected ${ }^{14} \mathrm{C}$ dates are calibrated and analyzed further using Bayesian statistics, generating two calibrated age estimates:

(3) Each corrected ${ }^{14} \mathrm{C}$ date has a counterpart in the mean $(\mu)$ with standard deviation $(\sigma)$ and median cal BP age of the highest posterior distribution (HPD) interval (Table 1); it is the means that are principally used for further quantitative analysis.

(4) Groups of dates (events) are used to calculate durations of relevant archaeological intervals such as periods (phases) and their boundaries; these are presented in the text and graphs generated by OxCal as HPD intervals in cal BP years, Table 3 and graphs 
providing the $68.2 \%$ and $95.4 \%$ confidence levels and probability distributions; following accepted practice, all modelled dates are presented in italics.

\subsection{Combining radiocarbon dates}

The entire set of ORAU radiocarbon determinations from the Baikal region used in this study, each with complete chemical data and relevant archaeological information, is presented in Supplement 1 . The total number of dates was actually much higher than the 256 individuals included in the Bayesian analysis because in a number of cases the same burial was dated multiple times (Supplement 1). In most instances, this is a product of ORAU's routine internal checks involving repeat measurements. In other cases, the same sample or a different one from the same individual was submitted for analysis for additional checks, in some cases prompted by apparently errant results obtained on the first measurement. Such multiple dates representing the same individual were combined in the following manner:

1. Method 1: Dates on the same sample and on the same collagen extraction (indicated by the same "P" number) were first combined using an error-weighted mean as implemented in the R_Combine function of OxCal and next the resulting product was FRE-corrected. Dates on the same sample but on different extractions (indicated by different "P" numbers) were processed in the same fashion.

2. Method 2: Dates on two different samples (i.e., skeletal elements) were first FREcorrected to account for the potentially slightly different turnover rates in the examined elements and next the resulting products were combined using the R_Combine function in OxCal.

3. Method 3: Sets of dates (usually three or more), which included repeats on the same and different sample, were transformed using a combination of these two methods.

4. The use of Methods 2 and 3 meant that in 14 instances we did not generate a combined radiocarbon determination before FRE correction and the associated field was left blank (Table 1). In these cases only the FRE-corrected dates were combined before calibration.

5. The chemical data, including the $\delta^{13} \mathrm{C}$ and $\delta^{15} \mathrm{~N}$ values, were averaged over such multiple runs to supply the data for the FRE correction (Table 1).

To combine the multiple dates available for some individuals, we chose to combine before rather than after calibration (i.e., using the R_Combine method of OxCal rather than the Combine method). The Combine method in OxCal allows combination of dates derived from different methods or from radiocarbon dates with different known age offsets; it assumes that each date and calibration provides completely independent information. In general, R_Combine method gives wider errors because it accommodates the fact that the uncertainty associated with the calibration of the different combined dates is highly correlated; it is intended for dates where the true age of the samples dated is the same within the resolution of the calibration curve (here effectively decadal). Although in this case there may be slight offsets on the dates on the same individual due to bone collagen turnover differences, these differences are likely to be small and in any case are not quantified. For this reason we conclude that combination before calibration (using R_Combine) is more appropriate and also more conservative, generating wider calendar range estimates.

\subsection{Quantitative methods}


Selection and implementation of quantitative analytical methods is driven by research goals and the kind of data analyzed. As mentioned, the main goals of this study are two: (1) reassess the middle Holocene culture history at the scale of entire Cis-Baikal based on the evidence of FREcorrected and calibrated radiocarbon dates; and (2) search for specific micro-regional dietary trends and patterns using the same radiocarbon evidence and the associated carbon and nitrogen stable isotope ratios.

The first goal (regional culture history) is approached mainly with Bayesian modelling done in OxCal 4.2.4 using the IntCal-13 dataset (Reimer et al., 2013; Bronk Ramsey, 2009; 2014). We are aware that this material lends itself to a variety of approaches to Bayesian analysis both in terms of units of analysis and functions used. In addition to the entire Cis-Baikal region, the micro-regions, mortuary traditions, separate cemeteries—large and small—or the distinct spatial formations within them such as clusters or rows of graves are all viable units of analysis. There are also graves with multiple individuals arranged horizontally on the same level (side-by-side) or vertically on different layers in some cases separated by a layer of sediment, as well as some graves that disturb one another. Lastly, changes in the temporal distribution of mortuary traits within various spatial units could also be examined. While some of this work is already in progress (Weber et al., n.d.) it is clear that delving into even a few of these options in sufficient detail would be well beyond the scope of this preliminary study.

Bayesian modeling is guided by the following assumptions about the nature of the mortuary record in question:

1) Based on the archaeological data, i.e., typology and the previous radiocarbon record, regardless of the FRE, the general chronological sequence of the dated mortuary traditions should be as follows (from oldest to youngest): LM (including the undifferentiated LM and LM or EN) > EN (Kitoi) > MN (lack of formal cemeteries) > LN (Isakovo, Serovo) > EBA (Glazkovo).

Further, there are no empirical or theoretical grounds to assess:

2) Whether the period transitions (i.e., LM > EN Kitoi or LN Isakovo, Serovo > EBA Glazkovo) were overlapping, abutting or non-abutting.

3) The tempo (e.g., abrupt vs. gradual) of any of these transitions including the end of EN Kitoi, which is not followed by any archaeologically recognizable mortuary tradition.

4) Population models for the relevant groups (e.g., constant population or population growth - peak — decline, etc.) and resulting deposition rates regionally, micro-regionally or within each larger cemetery separately.

5) The extent to which period boundaries or cultural transitions (e.g., $\mathrm{LN}>\mathrm{EBA}$ ) were more or less contemporaneous across micro-regions.

Considering the above, two models were employed. The first builds on OxCal's default assumption of a uniform distribution of dated events (human burials in this case) within archaeological periods (phases) and thus invokes potentially relatively abrupt transitions. The uniform distribution model employs the following commands:

- Sequence to order events within a phase (group of events); 
- Boundary to model start and end of various groups (phases) of events;

- Span to define temporal span of the dated events; and

- Interval to define phase durations.

However, in the context of the prior knowledge listed above, a model that allows some overlap between phases and gradual changes in deposition rates of the dated events may be a more realistic approach. In OxCal 4.2.4 it is the trapezium distribution that accommodates these conditions (Lee and Bronk Ramsey, 2012), congruent with the fact that the archaeological processes examined here are all population level changes and, as such, should be gradual, although the tempo may vary, and cumulative rather than abrupt and transformative. The trapezium model, in addition to the functions listed above, requires that the Boundary command be used in conjunction with the following three functions:

- Transition to allow a Boundary to have a none-instantaneous transition period as this function creates trapezium shaped distributions; and

- Start and End to find the start and end of a Boundary with a gradual transition period, respectively.

Both models, populated with the data from Table 1, were submitted to OxCal for analysis. The input files themselves are included as Supplements 2 and 3. The subsequent discussion is based primarily on the results from the trapezium distribution model but the outcome of the uniform model is invoked to note significant differences between them. Table 1 and Fig. 3A-B display results of the trapezium model only while Table 3 summarizes both.

In the uniform model the Spans are, as expected, always shorter than the Intervals, while this is not the case in the trapezium model where the Spans are sometimes longer than the Intervals (Table 3). This is because in the uniform model the Interval measures the length of the phase and is thus always longer than the Span. On the other hand, in the trapezium model the Interval command measures the distance between the mid-points of the phase transitions and so will in some cases be slightly shorter than the Span of dated events which will include those in the overlap-period between phases in the tails of the single trapezium distribution.

Our second goal involves the search for more specific temporal patterns. The data were divided into a number of archaeologically meaningful units of analysis based on "Micro-region" and "Typological period" (Table 2). The resulting numbers of dates representing such units, however, are quite variable, as some units have no dates at all and others have only very few dates. Therefore, while examination of culture history within Cis-Baikal as a whole employs the entire set of 256 dates, examination of micro-regional trends is applied to the following four units which are large enough to search for meaningful insights: EN Angara $(n=50)$, EN Southwest Baikal $(n=83)$, EBA Little Sea $(n=49)$ and EBA Upper Lena $(n=27)$.

This aspect of our analysis employs Bayesian modelling when applicable, but mainly Pearson product-moment correlation coefficients (PCC) between the conventional ${ }^{14} \mathrm{C}$ dates, means and medians of HPD intervals and $\delta^{13} \mathrm{C}$ and $\delta{ }^{15} \mathrm{~N}$ - the critical dietary variables in this examination. The means and medians of HPD regions were provided by the results from both trapezium and uniform distributions. Since in all cases the results were essentially the same, only 
correlations with the means of HPD regions from the trapezium distribution model are reported in the paper. Scatter plots and descriptive statistics are also used, the former mostly for illustrative purposes and identification of non-linear relationships between relevant variables.

\subsection{Data assessment}

Of the 36 individuals with multiple ${ }^{14} \mathrm{C}$ determinations, 33 passed the $\chi^{2}$ test (Ward and Wilson 1978), while two cases failed by only a small margin and were retained in the Bayesian analysis; the final case failed by a large margin and was removed from the analysis (Table 1). However, stable isotope results for this last individual (LOR_1997.011 ${ }^{2}$ ) are presented in scatter plots (Fig. 2A).

Since the PCC analysis is quite sensitive to outliers, all datasets suitable for examination of chronological trends were screened using the outlier labeling technique (Hoaglin et al., 1986; Hoaglin and Iglewicz, 1987). Only one individual, SHA_2004.042.02 from the Shamanka II cemetery, failed this test due to its low $\delta^{15} \mathrm{~N}$ value of $10.4 \%$ (Table 1, Fig. 2A). While this value is not unusual for the entire Cis-Baikal, it is clearly the lowest measurement from the EN Shamanka II and Angara datasets. It is unlikely that this is a matter of measurement error because two different samples were analyzed at ORAU, both giving essentially the same result, and yet another sample measured previously at the University of Calgary produced a value of 11.1\%, the lowest in the Calgary dataset and also an outlier (Weber et al., 2011: Table 9). The low $\delta^{15} \mathrm{~N}$ signature suggests a diet with much less contribution from aquatic food and, together with the $\delta^{13} \mathrm{C}$ measurement of $-17.7 \%$, implies an origin different than either Southwest Baikal or the Angara River. If so, the regression formula developed for the Angara and Southwest Baikal micro-regions may not be applicable. Consequently, the radiocarbon date and stable isotope results for this individual are excluded from Bayesian modelling and PCC tests, respectively, but the isotopic values are presented in the graphs (Fig. 2A). Weber et al., (n.d.) provide additional justification for the temporary exclusion of this case from chronological analysis. One other individual from Shamanka II (SHA_2003.026.02), with the second lowest low $\delta^{15} \mathrm{~N}$ value of $12.0 \%$ in this sample (Supplement 1, Fig. 2A), passed the test marginally and is therefore retained in the analysis.

SHA_2008.106 is also excluded from analysis, although still displayed in stable isotope scatter plots (Fig. 2B), but merely because it belongs to the Late Bronze Age (LBA), a culture historical period represented only by this single case. This burial produced a very late uncorrected radiocarbon date congruous with the typological dating of the grave good assemblage that included three tri-lobe bronze arrowheads with long, tapered stems.

Data for 16 LM, EN and LN individuals from the Upper Lena micro-region are also excluded from the chronological analysis, although their stable isotope signatures are presented in graphs for comparative purposes (Fig. 2). Finally, results for 34 young children from the entire Cis-

\footnotetext{
${ }^{2}$ Each individual analyzed by the Baikal-Hokkaido Archaeology Project is assigned a master identification number, which includes the following information: abbreviated site name (e.g., LOK for Lokomotiv), excavation year (e.g., 1997) and grave number (e.g., 011). In graves with more than one interment, the grave number is followed by an extension indicating its number as in SHA_2004.042.02 (i.e., Shamanka 2004 excavation, grave 42, individual 2).
} 
Baikal whose $\delta^{15} \mathrm{~N}$ signatures are potentially subject to the nursing effect are removed from analysis altogether and thus are not included in Supplement 1.

While radiocarbon dating of skeletal remains of middle Holocene hunter-gatherers from CisBaikal continues, the current spatio-temporal distribution of $256{ }^{14} \mathrm{C}$-dated LM, EN, LN and EBA interments from all four micro-region is seen as sufficiently representative for the goals of this exploratory study (Table 2). Examination of more specific trends will commence once more data are available regionally or for specific cemeteries.

\section{DISCUSSION: REGIONAL CHRONOLOGY}

The benefit of starting the discussion with an assessment of regional chronology is that it lessens, to a certain extent, the biases resulting from the uneven representation of the various spatiotemporal units in our current dataset (Table 2). Also, examination of regional chronology permits a focus on the general picture without the need to discuss the micro-regional peculiarities for which the evidence is not yet adequate. These biases and idiosyncrasies will become more evident within each separate micro-region and will thus be discussed later. Another advantage is that on the regional scale the main culture historical units - excepting the MN of course - are represented in the dataset, albeit with variable numbers, and this permits assessment of required revisions to their temporal boundaries, the main goal of this study. Lastly, while it is not necessarily expected that the boundaries of the relevant culture historical periods are the same from one micro-region to another, the frequently small sample sizes prevent examination of each micro-region in detail.

\subsection{Late Mesolithic: from $8277 \pm 176$ to $7503 \pm 14$ mean HPD cal BP}

Despite the introduction of radiocarbon dating into Cis-Baikal archaeology, the chronological position of this group of graves remained ambiguous for a long time (Weber et al., 2010), essentially until this study. Included in the current project is the original skull from Pad'Khin'skaia, the eponymous site in the Angara valley (PKH_1936.001; Table 1, Supplement 1), recently rediscovered in the Kraevedcheskii Muzei in Irkutsk.

Our results confirm the presence of graves pre-dating the EN Kitoi in Cis-Baikal. The LM group $(n=10)$ includes the two burials originally classified as "LM" and an additional eight interments classified as "LM or EN" (Tables 1-2). The corrected dates for the eight "LM or EN" graves place them either well before the EN Kitoi on the Angara and Southwest Baikal or within its beginning. Interestingly, the grave from Ershi, classified by Bazaliiskii (2010) as Final Mesolithic, is the youngest of all graves in this group and its corrected ${ }^{14} \mathrm{C}$ determination postdates the oldest EN Kitoi burials by $\sim 50$ years. In the trapezium model, the LM starts and ends much later though with roughly similar duration ( $774 \pm 176$ years) as in a previous assessment of 8800-8000 cal BP (Weber et al., 2010: Table 2.3). In the uniform distribution model, the LM is $\sim 140$ years longer mostly due to its earlier beginning (Table 3 ).

These early graves appear across the entire region but are quite rare, and the sites are rather different from one another and from any of the later well-known mortuary traditions. LM 
cemeteries are invariably small, the largest being Khotoruk and Kurma XI on Lake Baikal with seven and six graves, respectively. However, while originating within the LM, both cemeteries appear to have been used sporadically and continued into the EN. It is doubtful that many more graves and cemeteries dating to this period will be found in the region. Therefore, the LM lower boundary will likely continue to be defined only in approximate terms but the upper boundary seems to be established quite firmly, at least on the regional scale, due to the abundant radiocarbon record from the EN Kitoi mortuary tradition that provides a constraint for Bayesian modelling.

\subsection{Early Neolithic: from $7503 \pm 14$ to $7027 \pm 33$ mean HPD cal BP}

The EN is the best represented of all archaeological periods in our current dataset $(n=133)$. The dates come from a dozen or so cemeteries, small and large, from two micro-regions (Table 1 and 2, Supplement 1). Admittedly, the dataset is dominated by two cemeteries-Lokomotiv, in the Angara valley, and Shamanka II, Southwest Baikal — but this situation is unlikely to change as the dominant Kitoi mortuary tradition of this period is mainly known from there. Of the other large EN cemeteries, Vitkovskii's $(1982,1989)$ materials from the eponymous Kitoi cemetery are not available for analysis, and while dating of Ust'-Belaia (Georgievskaia, 1989) will somewhat rectify this imbalance, dating of the rest of Lokomotiv burials will skew the imbalance back in favour of the large cemeteries. In the Little Sea and on the Upper Lena EN graveswhether of the Kitoi tradition or otherwise - are rare and this is unlikely to change. Still, the 133 dates for $418 \mathrm{EN}$ burials (32\%) currently known from the entire region provide a very good sample (Weber and Bettinger, 2010: Table 3).

Due to the large number of dates and to their consistency the temporal parameters of the EN (i.e., upper and lower boundaries and duration) are rather sharply defined (Table 3, Fig. 3) both at the $68.2 \%$ and $95.4 \%$ probability levels. According to the results of the trapezium distribution model, these parameters differ considerably from the previous model (Weber et al., 2010: Table 2.3). Instead of the estimated 1000-1200 years long, the EN now appears to be only $476 \pm 37$ years in duration (or $711 \pm 36$ years long in the uniform distribution model), mostly as a result of its much later start ( $\sim 500$ years). This asymmetric shift is attributable to a combination of two factors: (1) different typochronological grouping of the graves and (2) the impact of Bayesian modelling. Regarding the first, in the previous assessments, some of the dates (e.g., from Khotoruk and Kurma), assigned here to the LM, were grouped with the EN thus shifting the start of this period back in time. Regarding the second factor, Bayesian analysis was not employed at the time of the previous chronological study.

Continued dating of EN mortuary assemblages is unlikely to change substantially the chronological parameters of this period, which, at this point, depend more on how this dataset is analyzed. However, additional dating, and further refinement of spatial and temporal variation in the FRE, will be critical for better assessment of the larger cemeteries' internal chronology and use patterns as well as for understanding the temporal relationships between individual cemeteries within and across micro-regions. 


\subsection{Middle Neolithic: from $7027 \pm 33$ to $5571 \pm 88$ mean HPD cal BP}

Because of the complete lack of dated mortuary assemblages, the $\mathrm{MN}$ is defined by the upper and lower boundaries of the temporarily adjacent groups of dated EN and LN graves, respectively (Weber et al., 2010). To make this matter clear, it is not necessarily the case that people largely abandoned Cis-Baikal at the end of EN, only that the EN socio-economic model(s), Kitoi or otherwise, was rearranged into a system that did not include formal cemeteries, and did not see continued use of those established in the EN.

In comparison to the previous model, according to which the MN was 1000-1200 years long (Weber et al., 2010: Table 2.3), the trapezium and uniform distribution models suggest 1456 \pm 94 and $1300 \pm 66$ year durations, respectively (Table 3 ). The longer duration of the MN is primarily accounted for by the shortened EN interval and by the much later start of the LN. However, it must be kept in mind that the LN is represented in the current study by fewer dates than in the previous analysis. To be sure, there is much that we do not yet know about the cause and mechanism of this transition or about the socio-economic system that developed across the entire Cis-Baikal during the MN. These questions still require much thought and fieldwork to search for isolated MN burials and assemblages at campsites.

\subsection{Late Neolithic: from $5571 \pm 88$ to $4597 \pm 76$ mean HPD cal BP}

Relative to what has been excavated and published so far, the LN mortuary traditions are not very well represented in our dataset (Weber and Bettinger, 2010: Table 3). Of the $227 \mathrm{LN}$ burials reported, we have radiocarbon dates for only $22(10 \%)$ and this situation is unlikely to improve any time soon for two reasons. First, the current location of most of the materials from Okladnikov's early field campaigns and from those conducted on the Angara later in the 1950s and 1960s, when the dams in Irkutsk and Bratsk were being constructed, is difficult to establish (Okladnikov, 1974, 1975, 1976). The one skull from the Isakovo cemetery, found recently in the Kraevedcheskii Muzei, and dated for this study (ISA_1932.002) is only a minor consolation with little impact. Second, LN cemeteries elsewhere in Cis-Baikal appear to be rare and rather small with the largest being Verkholensk on the Upper Lena (20 graves; Okladnikov, 1978) and Sarminskii Mys in the Little Sea (13 graves; Goriunova 1997; 2002). Continued dating of Isakovo graves from the Ust'-Ida I cemetery will provide more data but will not address the imbalance in geographic distribution in the Angara valley, where the Isakovo and Serovo traditions have been documented at 27 locations along the $700 \mathrm{~km}$ long stretch of the river between Baikal and Bratsk. An additional disadvantage of the current $\mathrm{LN}$ dataset is the complete absence of dates for Serovo graves from the Angara micro-region.

Due to the relatively small sample size the temporal parameters of the LN are not as sharply defined as for the EN (Table 3, Fig. 3). Bayesian modeling of the FRE-corrected dates affects the $\mathrm{LN}$ chronological parameters differently relative to the EN. The length of the LN appears roughly the same $-973 \pm 126$ years now (Table 3, Fig. 3) vs. 800-1000 years previously (Weber at al., 2010: Table 2.3) - but the period starts and ends a few hundred years later, as a direct 
result of the FRE correction. The main difference with the parameters from the uniform distribution model is in the earlier end of the LN by 300 years which also makes its duration correspondingly shorter. Additional dating of LN graves may push the lower boundary further back in time and extend its duration. It may also affect the upper boundary, and thus the temporal overlap with the following EBA.

\subsection{Early Bronze Age: from $4597 \pm 76$ to $3726 \pm 34$ mean HPD cal BP}

On the regional scale, the EBA is represented by 91 dated burials of the 520 currently known (18\%), presenting a reasonably sized sample. Their geographic distribution, however, is rather uneven. The Little Sea and Upper Lena South are well represented but the Angara is not (Table 2). Of the 204 EBA burials recorded in the Angara valley, few are available for analysis for the same reasons as outlined above for the LN. Lastly, although we only have six dates from Southwest Baikal, there are only additional five individuals to be dated, all from Shamanka II, the single EBA cemetery to have been documented in this micro-region (and possibly reflecting one or two violent episodes rather than a normal cemetery; see Bazaliiskii et al., 2001; Lieverse et al., 2012).

Even though the number of EBA dates is over four times that of the LN, the differences between the relevant chronological parameters at the $68 \%$ and $95 \%$ probability levels are higher than for the LN (Table 3). According to the trapezium model, the EBA starts $~ 400-600$ years later, ends $~ 200$ years earlier and is only about 871 \pm 91 years long, thus 600-800 years shorter, when compared with the previous chronology (Weber at al. 2010: Table 2.3). In the uniform distribution model the EBA starts about 300 years earlier than in the trapezium model, thus affecting its longer overall duration (1204 \pm 41 years). Modelling of the transition between LN and EBA periods suggests continuity and overlap between them. The current dataset does not allow assessment of the relationship between the EBA and the following LBA period, which is represented in this study by only one burial from Shamanka II (SHA_2008.106) with a corrected date roughly 800 years younger than the latest date in the EBA sequence. While it makes sense to expect continuity between these two periods, assessment of this transition with radiocarbon dates will be difficult because LBA graves, for unknown reasons, are as rare as those from the LM. Future dating may bring about adjustments to the upper boundary of the EBA.

\section{DISCUSSION: MICRO-REGIONAL PATTERNS}

In order to avoid unnecessary repetition this section focuses on detection of dietary patterns and trends that are specific to each micro-region and which might be less clearly visible on the regional scale. Consequently, the analysis is limited to those datasets that are large enough to provide meaningful insights. Transitions between periods is another topic potentially suitable for examination at the micro-regional level; however, the frequently insufficient samples sizes force us to leave this matter aside until more data are available.

\subsection{Early Neolithic Angara}


The Angara valley is the micro-region with the longest history of research on Holocene huntergatherers in Cis-Baikal and is also the area that provided the bulk of the archaeological materials analyzed by Okladnikov in his synthesis $(1950,1955,1974,1975,1976)$. Unfortunately, for the reasons mentioned earlier, of 536 interments documented to date most are no longer available for research and only 76 have been included in this analysis (Weber and Bettinger, 2010: Table 3). Of these, only the EN sample with 50 dated burials (i.e., 26\% of the 194 known) from seven cemeteries is sufficiently representative for further examination.

The corrected ${ }^{14} \mathrm{C}$ dates range from $6559 \pm 81 \mathrm{BP}$ (LOR_1991.007.01) to 5939 $\pm 74 \mathrm{BP}$ (ROZ_2008.003, Table 1). On average, the entire sequence of corrected dates is $465{ }^{14} \mathrm{C}$ years younger than the uncorrected series with the lowest and highest corrections for the FRE being $350{ }^{14} \mathrm{C}$ years for LOK_1990.043.02 (6555 $\left.\pm 73 \mathrm{BP}\right)$ and $651{ }^{14} \mathrm{C}$ years for ROZ_2008.003 $(5939 \pm 74 \mathrm{BP})$, respectively (Table 1$)$.

In search for chronological trends scatterplots of mean HPD cal BP dates and associated carbon and nitrogen stable isotope values were explored and correlations (PCC) between these three variables were calculated. While the mean HPD cal BP dates and $\delta^{13} \mathrm{C}$ values show no temporal pattern (PCC, $r=0.103, p=0.478, \mathrm{n}=50$ ), $\delta^{15} \mathrm{~N}$ values display a strong negative relationship with the mean HPD dates: the isotope values get higher as the dates become younger (Fig. 4; PCC, $r=-0.711, p<0.000, \mathrm{n}=50$ ). This suggests a temporal shift in diet toward greater reliance on aquatic foods toward the end of the EN relative to its beginning. This is an entirely new and very important finding. It is unlikely that this trend is an artefact of the transformation of the uncorrected dates based on the regression analysis even though it makes the individuals with high $\delta^{15} \mathrm{~N}$ values archaeologically younger. The reason for this is that the trend is not invariably seen in other micro-regions where $\delta^{15} \mathrm{~N}$ values are equally or even more variable (e.g., Little Sea). Also, the chronological position of each individual in the sequence still depends to a great extent on the conventional ${ }^{14} \mathrm{C}$ date. Interestingly, the three Angara LM individuals appear to extend the beginning of this trend back in time by about 1000 years. Prior to their FREcorrection, the Angara EN radiocarbon dates still show a statistically significant, albeit moderate, negative correlation with $\delta^{15} \mathrm{~N}$ values (PCC, $r=-0.402, p=0.004, \mathrm{n}=49$ ).

The relatively tight clustering of both carbon and nitrogen values ( $2 \%$ on either scale; Fig. $2 \mathrm{~A})$ suggests correspondingly homogenous values in the aquatic food sources contributing to the diet of the EN groups in the Angara valley. This practically eliminates Lake Baikal as the potential source of these foods because of the substantial isotopic variability seen there. More specifically, Baikal's various fishes and the lake's endemic seal (Phoca sibirica) cover together a wide range in $\delta^{13} \mathrm{C}$ and $\delta^{15} \mathrm{~N}$ values from about $-25 \%$ to $-10 \%$ and $10 \%$ to $16 \%$, respectively (Weber et al., 2011: Table 4 and 5). Any significant dietary contribution of the seal would be relatively easy to detect because of its low $\delta^{13} \mathrm{C}$ values (about $-22 \%$ ). Adding this food item to the diet mix would result in more ${ }^{13} \mathrm{C}$-depleted human values and individual variation would result in a more scattered distribution of the Angara EN sample. This is what we see in the EN sample from the Southwest Baikal and in the EBA sample from the Little Sea (Fig. 2A and 2B) but not in the EN Angara sample. Thus, the clustered distribution of EN human stable isotope 
values from the Angara valley is more consistent with procurement of the local sources where the fishes are expected to show a much narrower range of $\delta^{13} \mathrm{C}$ and $\delta^{15} \mathrm{~N}$ values and the Baikal seal is absent. In sum then, the EN diachronic trend in human $\delta^{15} \mathrm{~N}$ results on the Angara is best accounted for by an increased reliance on riverine resources.

\subsection{Early Neolithic Southwest Baikal}

Despite the fact that archaeological finds dating to the middle Holocene have been reported from the area extending westward from the southwest tip of Lake Baikal toward Lake Hovsogol in Mongolia, Shamanka II is the only currently known mortuary site in this micro-region. With no LN graves and only six EBA and one LBA dated burials from Shamanka II, our sample is heavily biased toward the EN. The corpus of EN geochemical data from Shamanka II is a subject of a separate study on which the following summary is based (Weber et al., n.d.). Excluding SHA_2004.042.02, the remaining 83 corrected $\mathrm{EN}{ }^{14} \mathrm{C}$ dates from Shamanka II range from $6653 \pm 70$ BP (SHA 2006.066.01) to 5835 \pm 75 BP (SHA_2005.059.01; Table 1). The corrected sequence is on average $456{ }^{14} \mathrm{C}$ years younger than the uncorrected series and the lowest and highest corrections recorded are $117{ }^{14} \mathrm{C}$ years for SHA_2003.026.02 (6373 $\left.\pm 73 \mathrm{BP}\right)$ and $693{ }^{14} \mathrm{C}$ years for SHA_2006.083.02 (6402 \pm 74 BP), respectively (Table 1).

Chronologically, the Shamanka II sequence generally parallels the sequence of mean HPD cal BP dates currently available for the Angara valley although the Shamanka II series appears to start roughly 40 years earlier and to end 70 years later than the Angara sequence. Note, however, that there are still many more EN graves from the Angara valley to be dated than there are from Shamanka II and this may affect these differences. A more important and better documented difference between the two micro-regions seems the temporal gap of about 200 years in the distribution of mean HPD dates at Shamanka II between 7123 \pm 94 cal BP (SHA_2007.086.01) and $6918 \pm 83$ cal BP (SHA_2004.049.01) (Table 1). The relevant portion of the middle Holocene calibration curve features a few flat or even reversed sections, the product of variations in the ${ }^{14} \mathrm{C} /{ }^{12} \mathrm{C}$ ratio of the Earth's atmosphere. However, while the gap partly coincides with one such section on the calibration curve, visible roughly between 7150 and 7050 cal BP, Bayesian modelling confirms that the discontinuity in the dates is real rather than a product of the variation in atmospheric ${ }^{14} \mathrm{C}$ production over time.

This provides initial evidence for the presence of two EN phases of cemetery use at Shamanka II: Phase 1 (longer) and Phase 2 (shorter). Such discontinuity is neither visible in the Angara valley taken as a whole, nor in the dates from Lokomotiv only. Interestingly, Phase 2 at Shamanka II appears to continue after the termination of the Kitoi mortuary tradition on the Angara. Given that as many as $\sim 45$ individuals from Shamanka II - most of them adults - have not yet been dated these results could potentially fill the gap in the distribution of the calibrated dates. However, the presence of two phases is supported by additional evidence regarding the changes in how the cemetery was used during Phase 2 relative to Phase 1 . This matter, discussed in more detail in a separate study (Weber et al., n.d.), will be assessed further once the dating of Shamanka II is completed. 
Returning to the issue of the dietary trend at Shamanka II, the set of $83{ }^{14} \mathrm{C}$ dates and associated stable isotope results shows no correlation with $\delta^{13} \mathrm{C}$ and only a small negative association between the mean HPD cal BP dates and $\delta^{15} \mathrm{~N}$ values, neither statistically significant (PCC, $\delta^{13} \mathrm{C}, r=0.033, p=0.764, \mathrm{n}=83 ; \delta^{15} \mathrm{~N}, r=-0.143, p=0.196, \mathrm{n}=83$ ). However, calculating correlations by phase gives quite different results and reveals trends similar to that found on the Angara (Fig. 5):

- Phase 1: PCC, $\delta^{13} \mathrm{C}, r=-0.021, p=0.865 ; \delta^{15} \mathrm{~N}, r=-0.360, p=0.002 ; \mathrm{n}=70$; and

- Phase 2: PCC, $\delta^{13} \mathrm{C}, r=0.355, p=0.235 ; \delta^{15} \mathrm{~N}, r=-0.914, p=0.000 ; \mathrm{n}=13$.

The resulting Phase 1 correlation is only moderate while Phase 2 association is strong and exceeds the value observed on the Angara. That the correlation within the entire dataset at Shamanka II is much weaker - and statistically insignificant - than within each phase separately is explained partly by the fact that at the beginning of Phase 2 the $\delta^{15} \mathrm{~N}$ values appear to return to a level comparable to the beginning of Phase 1, i.e., to relatively less reliance on aquatic foods and partly by the more diverse diets of Phase 1 individuals relative to Phase 2 (Fig. 5).

Another point to address is why the dietary trend toward increased reliance on aquatic foods during Phase 1 is less clearly expressed than for Phase 2. The reason for this appears to be, as examined in detail by Weber et al. (n.d.), that Phase 1 is composed of four dietary groups: one displaying no change in diet over time and three other showing dietary trends each emphasising different sources of freshwater food such as the shallow water fishes of the nearby Kultuk Bay, Lake Baikal seal, and the fishes of surrounding rivers. Since these food groups display quite different carbon and nitrogen stable isotope values, combining them into one analytical unit results in much weaker relationships between the relevant variables.

Unfortunately, at this point we do not have a readily available explanation for both the twopulse pattern and the diversity of dietary trends during Phase 1 and their detailed exploration goes beyond the scope of this paper (cf. Weber et al., n.d. for some suggestions in this regard). Overall, as argued above in the section on the Angara EN chronology, we feel confident that the trends are real rather than a product of the regression analysis. Still, these patterns at Shamanka II are being investigated further through additional paired dating, to refine the FRE regression equation for this site specifically.

Overall, the most interesting finding from the examination of radiocarbon measurements and the carbon and nitrogen stable isotope ratios for the Shamanka II cemetery is that there are chronological trends involving increased reliance on aquatic foods, mostly fish, and that these changes parallel a similar trend found among the neighbouring Angara EN groups.

For the record, correlations prior to date correction are just the inverse of the results after the FRE transformation and would suggest decreased over time reliance on aquatic foods:

- Phase 1: PCC, $\delta^{13} \mathrm{C}, r=0.232, p=0.065 ; \delta^{15} \mathrm{~N}, r=0.393, p=0.001 ; \mathrm{n}=64$; and

- $\quad$ Phase 2: PCC, $\delta^{13} \mathrm{C}, r=0.377, p=0.253 ; \delta^{15} \mathrm{~N}, r=0.937, p=0.000 ; \mathrm{n}=11$.

\subsection{Early Bronze Age Little Sea}


Of the roughly 277 middle Holocene burials known from the Little Sea micro-region (Weber and Bettinger, 2010: Table 1), 64 (23\%) have been dated for this study. Although this dataset is clearly biased toward the EBA, the low numbers of LM, EN and LN dates seem to reflect the general rarity of those graves there (Table 2). Since the relative frequencies of culture historical designations of the burials that can still be dated are similar to the sample examined in this study, these proportions are not expected much to change. The currently available sample of dated humans comprises 49 of the 203 (24\%) documented EBA individuals in this micro-region.

The Little Sea features a level of isotopic complexity that needs to be taken into consideration. Previous work identified two different diets - game-fish-seal (GFS) and game-fish (GF), and two different groups of people-locals and non-locals (Weber and Betttinger, 2010; Weber at al. 2011; Weber and Goriunova, 2013). The diet types were identified on the basis of carbon and nitrogen stable isotope data and the origin of the individuals was established on the basis of strontium isotope ratios measured in first molars (Haverkort et al., 2008). It is believed that the locals were born within the geographic confines of the Little Sea and they are assumed to have spent most of their lives in this micro-region. The diet of these locals was found to be invariably GFS. The non-locals appear to have been born outside of the Little Sea, possibly on the Upper Lena, and moved to the northwest coast of Lake Baikal later in their lives. The diet of the non-locals was found to be either GF or GFS, in roughly equal proportions (Weber and Goriunova, 2013). In other words, many people in the Little Sea micro-region displaying the local GFS diet appear to be of non-local origin. These individuals earlier in their lives probably consumed a GF diet, perhaps on the southern reaches of the Upper Lena. This matter, however, requires further investigation in light of the results of the paired dating programme for that micro-region (Schulting et al., 2015).

Although this dietary distinction was made on the basis of stable isotope data obtained from the University of Calgary in collaboration with Dr. M.A. Katzenberg, the current set of stable isotope results from ORAU shows the same pattern (Fig. 2B). Since, for the most part, different sets of burials were analyzed in the two laboratories this pattern seems quite robust. While in the Calgary dataset, individuals with GF diet were found in all three periods (EN, LN and EBA; Weber et al., 2011: Table 7, Fig. 4C), the ORAU dataset currently shows individuals with GF diets only in the EN and EBA (Supplement 1, Fig. 2). Considering the Calgary and ORAU datasets together, the GFS diet dominates the EBA sample roughly by 3 to 1 .

These two distinctions - GFS vs. GF diets and locals vs. non-locals - are important because they affect the definition of analytical units. For example, the relative continuity of LN and EBA may suggest that these two periods should be analyzed together. Doing so, however, would skew the correlation results because in the ORAU dataset the GF diet is currently absent in the LN sample while present in the EBA sample. This would very likely suggest a trend from greater to lesser reliance on aquatic foods across the combined LN-EBA period (Fig. 6). For this reason, the analysis is limited to the EBA sample, which is complicated enough due to the dietary and provenance differences mentioned above. Furthermore, it would be preferable to divide the GFS 
group into two units: GFS-local and GFS-non-local. This, however, is not possible at the moment due to the lack of strontium data for most of the individuals displaying the GFS diet.

The corrected ${ }^{14} \mathrm{C}$ dates for the EBA group range from 4410 \pm 43 BP (SHM_1975.001) to 3474 \pm 60 BP (SHM_1973.003.01; Table 1). For the GFS dataset $(\mathrm{n}=39)$, the minimum, maximum, and average FRE corrections are 262 (KHA_2010.015, 3849 660 BP), 536 (SHM_1973.003.01, 3774 $\pm 60 \mathrm{BP}$ ), and $406{ }^{14} \mathrm{C}$ years, respectively, while for the individuals with the GF diet $(\mathrm{n}=10)$ these figures are $14\left(\mathrm{~K} 14 \_2000.077,3776 \pm 56 \mathrm{BP}\right), 362$ (KUR_2002.019, 3759 \pm 58 BP), and $200{ }^{14} \mathrm{C}$ years, respectively (Table 1). The relatively large FRE corrections for the GFS group are also important because in a few instances the conventional ${ }^{14} \mathrm{C}$ date would put the dated individual in the wrong culture historical period, i.e., the LN (Supplement 1). Correction for the FRE and Bayesian modelling, however, supports the original typological assignment as EBA.

The results of the correlation analysis between mean HPD cal BP dates and stable isotope values for the 49 EBA individuals from the Little Sea are as follows:

- GFS individuals: PCC, $\delta^{13} \mathrm{C}, r=0.329, p=0.041 ; \delta^{15} \mathrm{~N}, r=0.142, p=0.389 ; \mathrm{n}=39$;

- GF individuals: PCC, $\delta^{13} \mathrm{C}, r=-0.255, p=0.477 ; \delta^{15} \mathrm{~N}, r=-0.216, p=0.549 ; \mathrm{n}=10$; and

- GFS and GF individuals together: PCC, $\delta^{13} \mathrm{C}, r=0.344, p=0.016 ; \delta^{15} \mathrm{~N}, r=0.214, p=$ $0.140 ; n=49$.

Most of these correlations are not statistically significant and the two that are show only moderate strength of association. Still, they merit a few comments due to some interesting regularities. First and regarding the GFS group, the moderate positive correlation between mean HPD cal BP dates and $\delta^{13} \mathrm{C}$ values is statistically significant $(p=0.041)$ and could be accounted for by increased consumption of the Baikal seal, the food resource showing the most negative $\delta^{13} \mathrm{C}$ values among the aquatic foods from the lake potentially consumed by these foragers (around-22\%; Weber et al., 2011: Table 5). Should this be the case, however, one would also expect a negative correlation with $\delta^{15} \mathrm{~N}$ results, for the seal - the top predator in the lakes' ecosystem - measures high on this scale (11.4-15.6\%; Weber et al., 2011: Table 5). The matter, as mentioned above, is complicated by the fact that the GFS group is not homogenous in terms of origin: some people are locals and some are not. Since the fishes of the Upper Lena show even more depleted values (from $-27 \%$ to $-24 \%$ ) than the seals (Weber et al., 2011: Table 5), it is possible that the our data reflect not a dietary trend but increased over time migration of people from the Upper Lena. It is also possible that both trends were taking place at the same time. This argument would still hold even if the place of origin of the non-locals were not the Upper Lena but some other watershed(s), roughly north of Baikal, because $\delta^{13} \mathrm{C}$ values in the fishes there would still be expected to fall into the same very light range, generally characteristic of immature rivers. The matter is further complicated by the fact that the FRE on the Upper Lena appears to be considerably higher than that observed for the individuals with the GF diet in the Little Sea area, making it difficult to see how the former could be the origin of the latter (Schulting et al., 2015). 
Second, the GF group - likely non-local in origin - is the only one that shows negative albeit statistically not significant correlations: both stable isotope values become more positive (higher) as the associated dates become younger (lower). If analysis of additional individuals with GF diet shows this pattern to be significant, it would have to be explained in terms of an increased reliance on shallow water fishes as has been also suggested for the Angara and some of the Shamanka II EN groups.

And lastly, combining the GFS and GF groups into one unit produces another trend- $\mathrm{a}$ moderate positive correlation - that is also statistically significant: $\delta^{13} \mathrm{C}$ values become lower as the mean HPD cal BP dates get younger $(p=0.015)$. Again, this could be explained by increased consumption of the Baikal seal; however, it is unclear whether this represents a dietary trend or a migration of people from some area, such as the Upper Lena, with low $\delta^{13} \mathrm{C}$ values in its freshwater fishes.

Consequently, it is too early to address this matter conclusively but the results underscore three points: (1) the importance of the FRE correction; (2) the equal importance of determining the place of origin of as many Little Sea individuals as possible; and (3) that there is still much to be learned about the composition and source of the GF diet.

Below, we also report the associations between uncorrected ${ }^{14} \mathrm{C}$ dates and stable isotope values (Fig. 7):

- GFS individuals: PCC, $\delta^{13} \mathrm{C}, r=-0.004, p=0.981 ; \delta^{15} \mathrm{~N}, r=-0.184, p=0.277 ; \mathrm{n}=37$;

- GF individuals: PCC, $\delta^{13} \mathrm{C}, r=-0.632, p=0.050 ; \delta^{15} \mathrm{~N}, r=0.530, p=0.115 ; \mathrm{n}=10$; and

- GFS and GF individuals together: PCC, $\delta^{13} \mathrm{C}, r=0.270, p=0.594 ; \delta^{15} \mathrm{~N}, r=0.594, p<$ $0.000 ; \mathrm{n}=47$.

Of note is the strong negative association between ${ }^{14} \mathrm{C}$ and $\delta^{13} \mathrm{C}$ values for the GF diet (all nonlocals) and the strong positive association between ${ }^{14} \mathrm{C}$ and $\delta^{15} \mathrm{~N}$ values for the GFS and GF diet group combined. The first pattern would mean increased consumption of the Baikal seal or fishes with similarly or more negative $\delta^{13} \mathrm{C}$ values and the second would likely mean decreased reliance on aquatic foods with time. While these two trends contradict one another, neither is apparent after FRE correction of the radiocarbon dates.

\subsection{Early Bronze Age Upper Lena South}

Relative to the Angara valley and the Little Sea micro-regions, the Upper Lena has seen much less archaeological fieldwork but much more, at least in terms of the number of excavated cemeteries $(n=41)$ than Southwest Baikal. Since all EN and LN individuals have been excluded from the chronological analysis for the reasons mentioned above, the discussion is limited to the group of $27 \mathrm{EBA}$ individuals (47\% of 58 documented archaeologically) from 8 cemeteries. Unfortunately, the largest cemetery excavated in the area-Verkholensk with $\sim 50 \mathrm{LN}$ and EBA individuals (Okladnikov, 1978) — has yet to be analyzed but a pilot study is underway. Future archaeological work in the area has the potential to increase substantially the number of LN and EBA cemeteries and burials available for analysis. 
At the moment, the corrected EBA ${ }^{14} \mathrm{C}$ dates range from 4138 $\pm 51 \mathrm{BP}\left(\mathrm{OBK} \_1976.003\right)$ to $3475 \pm 50$ BP (BO2_1971.003, Table 1). On average, the entire sequence of corrected dates is 287 ${ }^{14} \mathrm{C}$ years younger than the uncorrected series with the lowest and highest FRE corrections being $39{ }^{14} \mathrm{C}$ years for OBK_1971.003.02 (3911 $\left.\pm 50 \mathrm{BP}\right)$ and $504{ }^{4} \mathrm{C}$ years for MAK_1992.018 (3986 $\pm 51 \mathrm{BP})$, respectively (Table 1).

Even though none of the stable isotope measurements display statistically significant associations with the mean HPD dates (PCC, $\delta^{13} \mathrm{C}, r=-0.133, p=0.509 ; \delta^{15} \mathrm{~N}, r=-0.003, p=$ $0.986 ; \mathrm{n}=27$ ), the matter still merits some discussion because the area featured prominently in the preceding discussion of dietary patterns during the EBA in the neighbouring Little Sea micro-region. Taking into consideration the food resources available on the Upper Lena, the lack of a dietary trend there toward increased reliance on aquatic foods is not particularly surprising. This is because the fishes in the Upper Lena, and in its many but small tributaries, are an order of magnitude less abundant than on the Angara (Kozhov, 1950; Weber and Bettinger, 2010: Table 2) and likely equally less abundant than in the shallows of Lake Baikal.

In other words, the Upper Lena lacks food resources as a viable alternative to the terrestrial game (red deer, moose and roe deer), in the other micro-regions supplied in considerable abundance by the aquatic environment. Thus, facing a shortage of terrestrial game, for whatever reasons - cultural or natural, rather than turning attention to the much poorer than elsewhere local fishery, a more effective strategy could have been migration to other places, such as the Little Sea, where at least the aquatic foods offered better returns than on the Upper Lena. This would account for the fact that in our stable isotope data for the EBA, including the results produced by Dr. M.A. Katzenberg, University of Calgary (Weber et al., 2011: Table 8), we do not see much evidence for permanent relocation of people from the fish-rich micro-regions, i.e. the Angara and the Little Sea, to the fish-poor Upper Lena. None of the Upper Lena EBA individuals examined shows stable isotope signatures characteristic of the Angara EBA and only two display $\delta^{15} \mathrm{~N}$ values that are in the range of the GFS diet group. That is, in the ORAU dataset (Table 1), one result (14.7\%o) comes from an adult female (MAK_1992.018) and the other from a child, probably of an immediately post-weaning age whose $\delta^{15} \mathrm{~N}$ measurement of $15.0 \%$ could still be affected by nursing (MNZ_1974.004.01). However, it is surprising that on the Angara we currently do not seem to see any EBA individuals of possible Upper Lena origin, though the sample size is small (Table 2). The two Angara individuals displaying $\delta^{13} \mathrm{C}$ values in the range characteristic of the Upper Lena are of the LN age (Fig. 2B, Table 1).

Overall then, the Upper Lena EBA groups do not appear to have lived there entirely without experiencing dietary trend but the trend seems to be of a slightly different kind. The emphasis on freshwater foods appears to have been practiced not at home but in a fish-rich micro-region (i.e. Little Sea) and not by all individuals but only by those who decided to relocate there, that is the Little Sea's GF diet group. Combining the Upper Lena EBA set with the Little Sean EBA GF set, while justified, does not, however, reveal statistically significant associations between the relevant variables. More results, not only in terms of the number of examined individuals but 
also in terms of additional geochemical tracers, will be needed from both micro-regions to resolve these complicated interactions.

\section{CONCLUSION}

This is another paper in the series of studies examining the FRE in the Cis-Baikal region and its impact on the chronology of the middle Holocene archaeology there. The first three demonstrated the influence of the FRE on ${ }^{14} \mathrm{C}$-dated human remains in the Cis-Baikal ecosystem and developed equations to correct for it (Bronk Ramsey et al., 2014; Schulting et al., 2014; 2015), while in this study we make use of these new developments (see also Weber et al., n.d.). More specifically, applied to several sets of radiocarbon and carbon and nitrogen stable isotope results from the middle Holocene in Cis-Baikal, the approach allows new findings with regard to culture change over time. First, it identifies a dietary trend toward a greater reliance on aquatic foods during the EN on the Angara and on Southwest Baikal. Prior to the correction of the radiocarbon dates for the FRE these trends are either not as strong or run in the opposite direction that is toward decreased reliance on aquatic foods. Second, it identifies the potential presence of two phases of cemetery use at Shamanka II with people in each displaying roughly similar dietary shifts. And third, it helps correct the trend observed among the EBA groups in the Little Sea micro-region. Rather than an increased over time dietary contribution of the Baikal seal, increased migration of people from a different area, perhaps the Upper Lena, appears to be a more likely explanation. Additional tests on Cis-Baikal human skeletal materials are expected to shed more light on these processes.

While all findings from this analysis are important, the significance of the identification of the EN chronological trends in diet is paramount. As mentioned early in the paper, much bioarchaeological work has been completed on middle Holocene human skeletal remains from Cis-Baikal with a number of interesting and important findings; none, however, have defined any kind of temporal changes within archaeological periods (e.g., EN, LN or EBA), micro-regions (e.g., Angara, Southwest Baikal, Little Sea, and Upper Lena) or specific cemeteries (e.g., Shamanka II, Lokomotiv, Ust'-Ida I, or Khuzhir-Nuge XIV). Simply put, all our findings thus far have revealed patterns resulting from comparison between these large units of analysis rather than their constituent components, i.e., human individuals. Consequently, the discovery of the dietary trend during the EN is an extremely promising result, as it marks the beginning of a major shift in current research on middle Holocene foragers in the Baikal region from the focus on comparison between these large and ahistorical units of analysis to examination of temporal changes within them down to the level of individual cemeteries. Despite the extensive program of radiocarbon dating applied to the middle Holocene foragers in the Baikal region, the chronological dynamic within each of the relevant spatio-temporal units was hitherto missing. It is not only the stable isotope measurements that can be analyzed taking into account the chronological dimension but also the bioarchaeological and mortuary datasets. Such large bodies of information as those provided by the Shamanka II, Lokomotiv, Ust'-Ida I and Khuzhir-Nuge 
XIV cemeteries, which have been documented and studied more comprehensively than the others, are likely to produce many revealing insights.

Another question that comes immediately to mind is to what extent the increased contribution of the aquatic food during the EN on the Angara and Southwest Baikal is related to the local depletion of high-ranked terrestrial game resources (moose, red deer and roe deer) either due to natural causes or to overhunting. In theory, any large concentration of people in one place for any length of time-quite convincingly supported in both micro-regions by the presence of large cemeteries-should relatively quickly lead to cycles of game depletion and recovery (e.g., Belovsky, 1988). Although this matter will be difficult to resolve empirically due to the notoriously low temporal resolution of archaeological layers at the region's campsites, the new tool for FRE correction of dates on human remains may offer assistance in this regard. This is because it is also expected that cycles in game resources should be followed by corresponding changes in distribution of the hunter-gatherer population (Belovsky, 1988). It is reasonable to expect that such demographic fluctuations could also be reflected in shifts in use patterns of the existing cemeteries as well as establishment of new ones and this can now be traced effectively with the FRE regression models. More work on the matter is clearly in order including the paleoecological modelling of the terrestrial and aquatic food resources in the region during the middle Holocene.

The revised ages of the various mortuary traditions may bring them more in line with the dating of assemblages from stratified sites, a discrepancy noted recently for the Little Sea microregion (Goriunova and Novikov, 2010). In this regard, however, it is important to note that perfect correlation between the age of relevant mortuary traditions and associated cemeteries on one side and corresponding strata at habitation sites on the other is not expected. This problem is related to the fact that both kinds of sites are a product of entirely different site formation processes; whereas cemeteries form rather well delineated spatially and temporally units of analysis this is not the case with habitation sites. Ideally, one would want the materials representing LM, EN, LN, and EBA mortuary traditions each to correspond to a separate stratum, which, unfortunately, is rather unrealistic. At campsites natural formation processes can be highly variable from one location to another, and materials can be mixed into strata with any combination of these units. Furthermore, including in the mix the MN component, which is not represented in mortuary sites, will add even more complexity to an already complex situation. In a nutshell, correlation between mortuary and habitation sites, both in terms of chronological and material culture, is a rather difficult matter and one should not expect major breakthroughs any time soon.

Also, even though the entire middle Holocene culture historical sequence is now only a few hundred years younger than previously thought, the FRE correction will help in examination of relationships between the Cis-Baikal archaeological sequence with other chronological models that are unaffected by the FRE. This regards both the archaeological sequences beyond CisBaikal as well as paleoenvironmental reconstructions based either on proxy records or mathematical models. 
Overall, successful FRE correction opens several new and important avenues for future research. Dating of the remaining human skeletal materials from the entire Cis-Baikal region, including the rest of the burials from Lokomotiv and Ust'-Ida I, will be essential in the effort. It is regrettable that many important materials from the earlier excavations appear to be unavailable for research. However, a few other collections are accessible but, for other reasons, have not been examined so far by the Baikal-Hokkaido Archaeology Project. These include the cemeteries of Shumilikha (EBA) on the Angara (Svinin, 1981), Verkholensk (LN and EBA) on the Upper Lena (Okladnikov, 1978), Uliarba (EBA) and Ulan-Khada (mostly EBA) in the Little Sea area (Komarova and Sher, 1991; Goriunova, 2004), and Fofanovo (EN and EBA) in the Selenga delta (Gerasimov and Chernykh, 1975). Work on these materials will drive future refinements to the culture history of middle Holocene hunter-gatherers in the Cis-Baikal region.

\section{ACKNOWLEDGEMENTS}

We owe our thanks to the members of the Baikal Archaeology Project for their enthusiastic involvement including the fieldwork in Russia and implementation of various laboratory analyses over the last 25 years, and to the Social Sciences and Humanities Research Council of Canada for its continuous financial support (Major Collaborative Research Initiative grants Nos. 410-2000-1000, 412-2005-1004, and 412-2011-1001). Additional funding was provided by the Russian Research Foundation (grants No. 14-50-00036 and 33.1637.2014/K) and by the Russian Ministry of Education and Science (grant No. 1433). Our thanks also go to Ms. Erin Jessup for her assistance with the preparation of this paper and particularly for organizing and crosschecking the large body of archaeological, bioarchaeological, and geochemical data used in this paper. 


\section{References}

Ascough, P.L., Cook, G.T., Church, M.J., Dunbar, E., Einarsson, A., McGovern, T.H., Dugmore, A.J., Perdikaris, S., Hastie, H., Frioriksson, A., Gestsdottir, H. 2010. Temporal and spatial variations in freshwater C-14 reservoir effects: Lake Myvatn, Northern Iceland. Radiocarbon 52, 1098-1112.

Bazaliiskii, V.I., Turkin, G.V., Tiutrin, A.A. 2001. Mogil'nik Tal'skii na Iuzhnom Baikale. In: Problemy arkheologii, etnografii, antropologii Sibiri i sopredel'nykh territorii, A.P. Derevianko and V.I. Molodin (Eds.), Vol. 10(1), 33-40. Institut arkheologii i ethnografii SO RN, Novosibirsk. [In Russian]

Bazaliiskii, V.I. 2009. Otchet o provedenii istoriko-kul'turnoi ekspertizy uchastka stroitel'stva ogrady v SV chasti roshchi Zvezdochka vdol' ul. Zvezdinskoi v Sverdlovskom administrativnom okruge g. Irkutska. Archives of the Institute of Archaeology of the Russian Academy of Sciences, Irkutsk. [In Russian]

Bazaliiskii, V.I., 2010. Mesolithic and Neolithic mortuary complexes in the Baikal region of Siberia. In: Weber, A.W., Katzenberg, M.A., Schurr, T. (Eds.), Prehistoric Hunter-Gatherers of the Baikal Region, Siberia: Bioarchaeological Studies of Past Lifeways. University of Pennsylvania Museum of Archaeology and Anthropology, Philadelphia, pp. 51-86.

Bazaliiskii, V.I. 2012. Pogrebal'nye kompleksy Baikal'skoi Sibiri: traditsii pogrebenii, absoliutnyi vozrast. Izvestiia Laboratorii drevnikh tekhnologii (Irkutsk GTU) 9, 91- 93. [In Russian]

Bazaliiskii, V.I., Ineshin, A.V. 1995. Mogil'nik Turuka na verkhnei Lene. In: Obozrenie rezul'tatov polevykh i laboratornykh issledovanii arkheologov, etnografov i antropologov Sibiri i Dal'nego Vostoka v 1993 godu. Izdatel'stvo IAEt SO RAN, Novosibirsk, pp. 171-2. [In Russian]

Bazaliiskii, V.I., Men'shagin, E.V., Lykhin, Iu.P.. 1996. Neoliticheskie zakhoroneniia v skal'nykh nishakh v ust'e ruch'ia Nikol'skii na verkhnei Lene. Arkheologicheskoe nasledie Baikal'skoi Sibiri: Izuchenie, okhrana i ispol'zovanie (Irkutsk) 1, 33-46. [In Russian]

Bazaliiskiy, V.I., Savelyev, N.A. 2003. The wolf of Baikal: the "Lokomotiv" early Neolithic cemetery in Siberia (Russia). Antiquity 77, 20-30.

Belovsky, G. 1988. An optimal foraging-based model of hunter-gatherer population dynamics. Journal of Anthropological Archaeology 7, 329-372.

Berdnikova, N.E. 2001. Geoarkheologicheskii ob"ekt Ust'-Belaia: Kul'turnye kompleksy. In: Kamennyi vek Iuzhnogo Priangar'ia, vol. 2, Bel'skii geoarkheologicheskii raion. Izdatel'stvo Irkutskogo gosudarstvennogo universiteta, Irkutsk, pp. 113-46, 210-40. [In Russian]

Brock F, Higham TFG, Ditchfield P, Bronk Ramsey C. 2010. Current pretreatment methods for AMS radiocarbon dating at the Oxford Radiocarbon Accelerator Unit (ORAU). Radiocarbon 52(1), 102-12.

Bronk Ramsey, C. 2014. OxCal 4.2.4. https://c14.arch.ox.ac.uk/.

Bronk Ramsey, C. 2009. Bayesian analysis of radiocarbon dates. Radiocarbon, 51(1), 337-360. Bronk Ramsey, C., Schulting, R.J., Goriunova, O.I., Bazaliiskii, V.I., Weber A.W. 2014. Analyzing radiocarbon reservoir offsets through stable nitrogen isotopes and Bayesian 
modeling: A case study using paired human and faunal remains from the Cis-Baikal region, Siberia. Radiocarbon 56 (2), 1-11.

Cook, G.T., Bonsall, C., Hedges, R.E.M., McSweeney, K., Boronean, V., Pettitt, P.B. 2001. A freshwater diet-derived $14 \mathrm{C}$ reservoir effect at the stone age sites in the Iron Gate Gorge. Radiocarbon 43, 453-460.

Georgievskaia, G.M. 1989 Kitoiskaia kul'tura Pribaikal'ia [The Kitoi culture of the Baikal region]. Nauka, Novosibirsk. [In Russian]

Gerasimov, M.M., Chernykh, E.N. 1975. Raskopki fofanovskogo mogil'nika v 1959 g. In: Mandel'shtam, A. M. (Ed.), Pervobytnaia arkheologiia Sibiri. Nauka, Leningrad, pp. 2348. [In Russian]

Goriunova, O.I. 1997. Serovskie pogrebeniia Priol'khon'ia (oz. Baikal). Izdatel'stvo IAEt SO RAN, Novosibirsk. [In Russian]

Goriunova, O.I. 2002. Drevnie mogil'niki Pribaikal'ia: Neolit - bronzovyi vek. Izdatel'stvo Irkutskogo gosudarstvennogo universiteta, Irkutsk. [In Russian]

Goriunova, O.I. 2004. Drevnie pogrebeniia mogil'nika Uliarba na Baikale: Neolit-paleometall. Izdatel'stvo Instituta Arkheologii i Etnografii SO RAN, Novosibirsk. [In Russian]

Haverkort, C., Weber, A.W., Katzenberg, M.A., Goriunova, O.I., Simonetti, A., Creaser, R.A. 2008. Hunter-gatherer mobility strategies and resource use based on strontium isotope $\left({ }^{87} \mathrm{Sr} /{ }^{86} \mathrm{Sr}\right)$ analysis: a case study from Middle Holocene Lake Baikal, Siberia. Journal of Archaeological Science 35, 1265-1280.

Higham, T.F.G., Warren, R., Belinskij, A., Härke, H., Wood, R. 2010. Radiocarbon dating, stable isotope analysis and diet-derived offsets in ages from the Klin Yar site, Russian north Caucasus. Radiocarbon 52, 653-670.

Hoaglin, D.C., Iglewicz, B. 1987. Fine-Tuning Some Resistant Rules for Outlier Labeling. Journal of the American Statistical Association 82 (400), 1147-1149.

Hoaglin, D.C., Iglewicz, B., Tukey, J.W. 1986. Performance of Some Resistant Rules for Outlier Labeling. Journal of the American Statistical Association 81 (396), 991-999.

Kharinskii, A.V., Sosnovskaia, N.S. 2000. Mogil'nik bronzovogo veka Khadarta IV. In: Medvedev, G.I. (Ed.), Baikal'skaia Sibir' v drevnosti: Sbornik nauchnykh trudov. Vol. 2, part 2, 66-100. Izdatel'stvo Irkutskogo pedagogicheskogo universiteta, Irkutsk. [In Russian]

Komarova, N.V., Sher, Ia.A. 1991. Mogil'niki bukhty Ulan-Khada. In: Drevnosti Baikala, V.M. Masson (Ed.), Izdatel'stvo Irkutskogo gosudarstvennogo universiteta, Irkutsk, pp. 41-56. [In Russian]

Konopatskii, A.K. 1977. Drevnii mogil'nik u s. Manzurka. Izvestiia SO AN SSSR (Irkutsk). Seria obshchestvennykh nauk. Vol. 1 No. 1 (271), 71-6. [In Russian]

Konopatskii, A. K. 1982. Drevnie kul'tury Baikala (o. Ol'khon), Nauka, Novosibirsk. [In Russian]

Kozhov, M.M. 1950. Presnye vody Vostochnoi Sibiri (bassein Baikala, Angary, Vitima, verkhnego techenia Leny i Nizhnei Tunguski). Irkutskoe oblastnoe gosudarstvennoe izdatel'stvo, Irkutsk. [In Russian]

Lee, S., Bronk Ramsey, C. 2012. Development and application of the trapezoidal model for archaeological chronologies. Radiocarbon, 54(1), 107-122.

Lieverse, A.R., Schulting, R.J., Antonova, A., Bazaliiskii, V.I. and Weber, A.W. 2012. A possible Early Bronze Age massacre in the Baikal region of Siberia. Paper presented at the 45th annual Chacmool conference, War and Peace: Conflict Resolution in 
Achaeology, Calgary, AB, 8-11 November 2012.

Lillie, M., Budd, C., Potekhina, I., Hedges, R.E.M. 2009. The radiocarbon reservoir effect: new evidence from the cemeteries of the middle and lower Dnieper basin, Ukraine. Journal of Archaeological Science 36, 256-264.

Losey, R.J., Nomokonova, T., Goriunova, O.I., 2008. Fishing ancient Lake Baikal, Siberia: inferences from the reconstruction of harvested perch (Perca fluviatilis) size. Journal of Archaeological Science 35, 577-590.

Mamonova, N.N., Sulerzhitskii, L.D. 1989 Opyt datirovaniia po C14 pogrebenii Pribaikal'ia epokhi golotsena. Sovetskaia arkheologiia 1, 19-32. [In Russian]

Masson, V.M. (Ed.).1991. Drevnosti Baikala. Irkutskii gosudarstvennyi universitet, Irkutsk. [In Russian]

Nomokonova, T., Losey, R.J., Goriunova, O.I., Weber, A.W. 2013. A freshwater old carbon offset in Lake Baikal, Siberia and problems with the radiocarbon dating of archaeological sediments: Evidence from the Sagan-Zaba II site. Quaternary International 290-291, 110-125. [In Russian]

Okladnikov, A.P. 1950 Neolit i bronzovyi vek Pribaikal'ia (chast' I i II). Materialy i issledovaniia po arkheologii SSSR, Vol. 18. Izdatel'stvo Akademii nauk SSSR, Moscow. [In Russian]

Okladnikov, A.P. 1955 Neolit i bronzovyi vek Pribaikal'ia (chast' III), Materialy i issledovaniia po arkheologii SSSR, Vol. 43. Izdatel'stvo Akademii nauk SSSR, Moscow. [In Russian]

Okladnikov, A.P. 1971. Arkheologicheskie issledovaniia v verkhov'iakh r. Leny v 1971. LOIA Akademii Nauk SSSR, Leningrad, Field Report No. R-1 4485. [In Russian]

Okladnikov, A.P. 1974. Neoliticheskie pamiatniki Angary (ot Shchukino do Bureti), Nauka, Novosibirsk. [In Russian]

Okladnikov, A.P. 1975 Neoliticheskie pamiatniki Srednei Angary (ot ust'ia r. Beloi do Ust'Udy), Nauka, Novosibirsk. [In Russian]

Okladnikov, A.P. 1976 Neoliticheskie pamiatniki Nizhnei Angary (ot Serovo do Bratska). Nauka, Novosibirsk. [In Russian]

Okladnikov, A.P. 1978 Verkholenskii mogil'nik—pamiatnik drevnei kul'tury narodov Sibiri. Nauka, Novosibirsk. [In Russian]

Okladnikov, A.P., A.K. Konopatskii. 1984. Pogrebeniia epokhi neolita i rannei bronzy na Angare (po materialam raskopok 1977 g.). In: Arkheologiia iuga Sibiri i Dal'nego Vostoka. Nauka, Novosibirsk, pp. 18-35. [In Russian]

Olsen, J., Heinemeier, J., Lübke, H., Lüth, F., Terberger, T. 2010. Dietary habits and freshwater reservoir effects in bones from a Neolithic NE German cemetery. Radiocarbon 52, 635644.

Prokopenko, A.A, Williams, D.F, Karabanov, E.B, Khursevich, G.K. 1999. Response of Lake Baikal ecosystem to climate forcing and $\mathrm{pCO}_{2}$ change over the last glacial/interglacial transition. Earth and Planetary Science Letters 172 (3-4), 239-53.

Raynard, L.M. Turros, N. 2015. The known, the unknown and the unknowable: weaning times from archaeological bones using nitrogen isotope ratios. Journal of Archaeological Science 53, 618-625.

Reimer, P. et al. 2013. Intcal13 and marine13 radiocarbon age calibration curves $0-50,000$ years cal BP. Radiocarbon 55 (4), 1869-1869.

Scharlotta, I., Weber, A.W. 2014. Mobility of middle Holocene foragers in the Cis-Baikal region, Siberia: Individual life history approach, strontium ratios, rare earth and trace elements. 
Quaternary International 348, 37-65.

Schulting, R.J., Bronk Ramsey, C., Goriunova, O.I., Bazaliiskii, V.I., Weber, A.W. 2104.

Analysing radiocarbon reservoir offsets with stable isotope data: a case study using paired human and faunal remains from the Cis-Baikal region, Siberia. Radiocarbon 56 (3), 991-1008.

Schulting, R.J., Bronk Ramsey, C., Bazaliiskii, Weber, A.W. 2015. Highly variable freshwater reservoir offsets found along the Upper Lena watershed, Cis-Baikal, southern Siberia. Radiocarbon 57(4), 1-13.

Svinin, V.V. (Ed.). 1981. Bronzovyi vek Priangar'ia: Mogil'nik Shumilikha. Irkutskii gosudarstvennyi universitet, Irkutsk. [In Russian]

Tiutrin, A.A., Bazaliiskii, V.I. 1996. Mogil'nik v ust'e reki Idy v doline Angary. Akheologiia i etnologiia Sibiri i Dal'nego Vostoka 1, 85-90. [In Russian]

Turkin, G.V., Kharinskii, A.V. 2004. Mogil'niki Shamanka II: K voprosu o khronologii i kul'turnoi prinadlezhnosti pogrebal'nykh kompleksov neolita-bronzovogo veka na Iuzhnom Baikale. Izvestiia Laboratorii drevnikh tekhnologii (Irkutsk GTU) 2, 124-58. [In Russian]

Vitkovskii, N. I. 1882. Otchet o raskopkakh mogil kamennogo veka v Irkutskoi gub., na levom beregu Angary, proizvedennykh letom 1881 g. Izvestia VSORGO XIII (1-2), 1-36. [In Russian]

Vitkovskii, N. I. 1889. Sledy kamennogo veka v doline r. Angary. Izvestia VSORGO XX, 1-42. [In Russian]

Ward, G.K., Wilson, S.R. 1978. Procedures for Comparing and Combining Radiocarbon Age Determinations: A Critique. Archaeometry 20 (1), 19-31.

Waters-Rist, A.L., Bazaliiskii, V.I., Weber, A.W., Katzenberg, M.A. 2011. Infant and child diet in Neolithic hunter-fisher-gatherers from Cis-Baikal, Siberia: intra-long bone stable nitrogen and carbon isotope ratios. American Journal of Physical Anthropology 146, 225-241.

Weber, A.W. 1995. The Neolithic and Early Bronze Age of the Lake Baikal Region, Siberia: A review of recent research. Journal of World Prehistory 9, 99-165.

Weber, A.W. 2012. Patterns of cemetery use at Kurma XI: Bayesian approach to the examination of radiocarbon dates. In: Weber, A.W. McKenzie, H.G., Lieverse, A.R., Goriunova O.I. (Eds.), KURMA XI, a Middle Holocene hunter-gatherer cemeteries on Lake Baikal, Siberia: Archaeological and Osteological Materials. Archaeology in China and East Asia Vol. 3, German Archaeological Institute, Berlin and Northern Hunter-gatherers Research Series, Vol. 6, Canadian Circumpolar Institute Press, University of Alberta, Edmonton, pp. 141-172.

Weber, A.W., Bettinger, R.L. 2010. Middle Holocene hunter-gatherers of Cis-Baikal, Siberia: an overview for the new century. Journal of Anthropological Archaeology 29, 491-506.

Weber, A.W., Goriunova, O.I. 2013. Hunter-gatherer migrations, mobility and social relations: A case study from the Bronze Age Baikal region, Siberia. In: Weber, A.W. an. Zvelebil, M., (Eds.), Human bioarchaeology: group identity and individual life histories, Journal of Anthropological Archaeology, Special Issue 32 (6), 330-346.

Weber, A.W., Beukens, R., Bazaliiskii, V.I., Goriunova, O.I., Savel'ev, N.A. 2006. Radiocarbon dates from Neolithic and Bronze Age hunter-gatherer cemeteries in the Cis-Baikal region of Siberia. Radiocarbon 48 (3), 1-40.

Weber, A.W., Link, D.W., Katzenberg, M.A. 2002. Hunter-gatherer culture change and 
continuity in the Middle Holocene of the Cis-Baikal, Siberia. Journal of Anthropological Archaeology 21, 230-299.

Weber, A.W., Goriunova, O.I., McKenzie, H.G. (Eds.). 2008. KHUZHIR-NUGE XIV, a Middle Holocene Hunter-gatherer Cemetery on Lake Baikal, Siberia: Archaeological Materials. Northern Hunter-gatherers Research Series, Vol. 4. Canadian Circumpolar Institute Press, University of Alberta, Edmonton.

Weber, A.W., McKenzie, H.G., Beukens, R. 2010. Radiocarbon dating of middle Holocene culture history in Cis-Baikal. In: Weber, A.W., Katzenberg, M.A., Schurr, T.G.S. (Eds.), Prehistoric Hunter-gatherers of the Baikal Region, Siberia: Bioarchaeological Studies of Past Lifeways. University of Pennsylvania Museum of Archaeology and Anthropology Press, Philadelphia. pp. 27-50.

Weber, A.W., McKenzie, H.G., Lieverse, A.R., Goriunova, O.I. (Eds.). 2012. KURMA XI, a Middle Holocene hunter-gatherer cemetery on Lake Baikal, Siberia: Archaeological and Osteological Materials. Archaeology in China and East Asia Vol. 3, German Archaeological Institute, Berlin and Northern Hunter-gatherers Research Series Northern Hunter-gatherers Research Series, Vol. 6, Canadian Circumpolar Institute Press, University of Alberta, Edmonton.

Weber, A.W., Schulting, R.J., Bronk Ramsey, C., Bazaliiskii, V.I. n.d. Biogeochemical data from the Shamanka II Early Neolithic cemetery on Southwest Baikal: Chronological and dietary patterns. Submitted to Quaternary International.

Weber, A.W., White, D., Bazaliiskii, V.I., Goriunova, O.I., Savel'ev, N.A., Katzenberg, M.A. 2011. Hunter-gatherer foraging ranges, migrations, and travel in the middle Holocene. Baikal region of Siberia: Insights from carbon and nitrogen stable isotope signatures Journal of Anthropological Archaeology 30, 523-548.

Wood, R.E., Higham, T., Buzilhova, A., Surorov, A., Heinemeier, J., Olsen, J. 2013. Freshwater radiocarbon reservoir effects at the burial ground of Minino, northwest Russia. Radiocarbon 55, 163-177.

Zubkov, V.S. 1978. O pogrebal'nom obriade na mogil'nike Ust'-Iamnyi (Verkhniaia Lena). In: Arkheologiia i etnografiia Vostochnoi Sibiri. Abstracts. Izdatel'stvo Irkutskogo gosudarstvennogo universiteta, Irkutsk, pp. 30-2. [In Russian]

Zubkov, V.S. 2000. Neolit i bronzovyi vek verkhnei Leny: Istoriia issledovaniia i problemy izucheniia. In: Medvedev, G.I. (Ed.), Baikal'skaia Sibir' v drevnosti: Sbornik nauchnykh trudov. Vol. 2, part 2, 15-45. Izdatel'stvo Irkutskogo pedagogicheskogo universiteta, Irkutsk. [In Russian] 


\section{Figures}

Figure 1. Location of the archaeological sites examined in the paper.

$\begin{array}{clrlrl}\text { No. } & \text { Site } & \text { No. } & \text { Site } & \text { No. } & \text { Site } \\ 3 & \text { Ershi } & 82 & \text { Ulus Khal'skii } & 122 & \text { Sarminskii Mys } \\ 7 & \text { Glazkovo } & 84 & \text { Makrushino } & 124 & \text { Kulgana } \\ 8 & \text { Lokomotiv } & 85 & \text { Iushino } & 129 & \text { Shamanskii Mys } \\ 14 & \text { Kitoi } & 89 & \text { Popovskii Lug 2 } & 138 & \text { Kurma XI } \\ 16 & \text { Galashikha } & 91 & \text { Makarovo } & 141 & \text { Khuzhir-Nuge XIV } \\ 18 & \text { Shumilikha } & 95 & \text { Nikol'skii Grot } & 149 & \text { Borki } \\ 19 & \text { Ust'-Belaia } & 98 & \text { Obkhoi } & 142 & \text { Shamanka II } \\ 36 & \text { Ust'-Ida I } & 99 & \text { Ust'-Iamnaia } & 148 & \text { Khadarta IV } \\ 40 & \text { Gorodishche II } & 101 & \text { Zapleskino } & 152 & \text { Kaiskaya Gora } \\ 44 & \text { Pad' Khinskaia } & 108 & \text { Turuka } & 154 & \text { Roshcha Zvezdochka } \\ 72 & \text { Isakovo } & 109 & \text { Zakuta } & 156 & \text { Badai } \\ 81 & \text { Manzurka } & 114 & \text { Khotoruk } & & \end{array}$

Figure 2. Geographic distribution of carbon and nitrogen stable isotope values for Middle Holocene individuals from Cis-Baikal examined in the paper: (A) Late Mesolithic and Early Neolithic; (B) Late Neolithic, Early Bronze Age and Late Bronze Age.

Figure 3. Results of Bayesian modeling of temporal parameters for the middle Holocene culture history in Cis-Baikal using the trapezium distribution: (A) period boundaries; (B) period intervals and spans.

Figure 4. Mean HPD cal BP dates by $\delta^{15} \mathrm{~N}$ for the Late Mesolithic and Early Neolithic in the Angara valley.

Figure 5. Mean HPD cal BP dates by $\delta^{15} \mathrm{~N}$ for the Early Neolithic on Southwest Baikal. Figure 6. Mean HPD cal BP dates by $\delta^{13} \mathrm{C}(\mathrm{A})$ and $\delta^{15} \mathrm{~N}(\mathrm{~B})$ for the Late Neolithic and Early Bronze Age in the Little Sea.

Figure 7. Conventional radiocarbon dates $\mathrm{BP}$ by $\delta^{13} \mathrm{C}(\mathrm{A})$ and $\delta^{15} \mathrm{~N}(\mathrm{~B})$ for the Late Neolithic and Early Bronze Age in the Little Sea. 


\section{Tables and Supplements}

Table 1. Corrected radiocarbon dates for the middle Holocene Cis-Baikal region and results of the Bayesian analysis using the trapezium distribution model. Cases are grouped by "Typological period" and sorted by "Corrected date BP".

Table 2. Geographic and temporal distribution of FRE-corrected radiocarbon dates used in the Bayesian analysis of middle Holocene Cis-Baikal culture history.

Table 3. Summary of Bayesian modeling of corrected ORAU radiocarbon dates for the middle Holocene Cis-Baikal region.

Supplement 1. Archaeological and ORAU geochemical data for the middle Holocene Cis-Baikal region employed in the study. Cases are grouped by micro-region and then sorted by "Site" and "Master_ID".

Supplement 2. OxCal 4.2.4 input file for Bayesian analysis of middle Holocene culture history of Cis-Baikal, Siberia, using the default uniform distribution model. All dates are corrected for the freshwater reservoir effect and grouped by culture historical periods and then sorted by corrected ${ }^{14} \mathrm{C}$ date BP.

Supplement 3. OxCal 4.2.4 input file for Bayesian analysis of middle Holocene culture history of Cis-Baikal, Siberia, using the trapezium distribution model. All dates are corrected for the freshwater reservoir effect and grouped by culture historical periods and then sorted by corrected ${ }^{14} \mathrm{C}$ date $\mathrm{BP}$. 


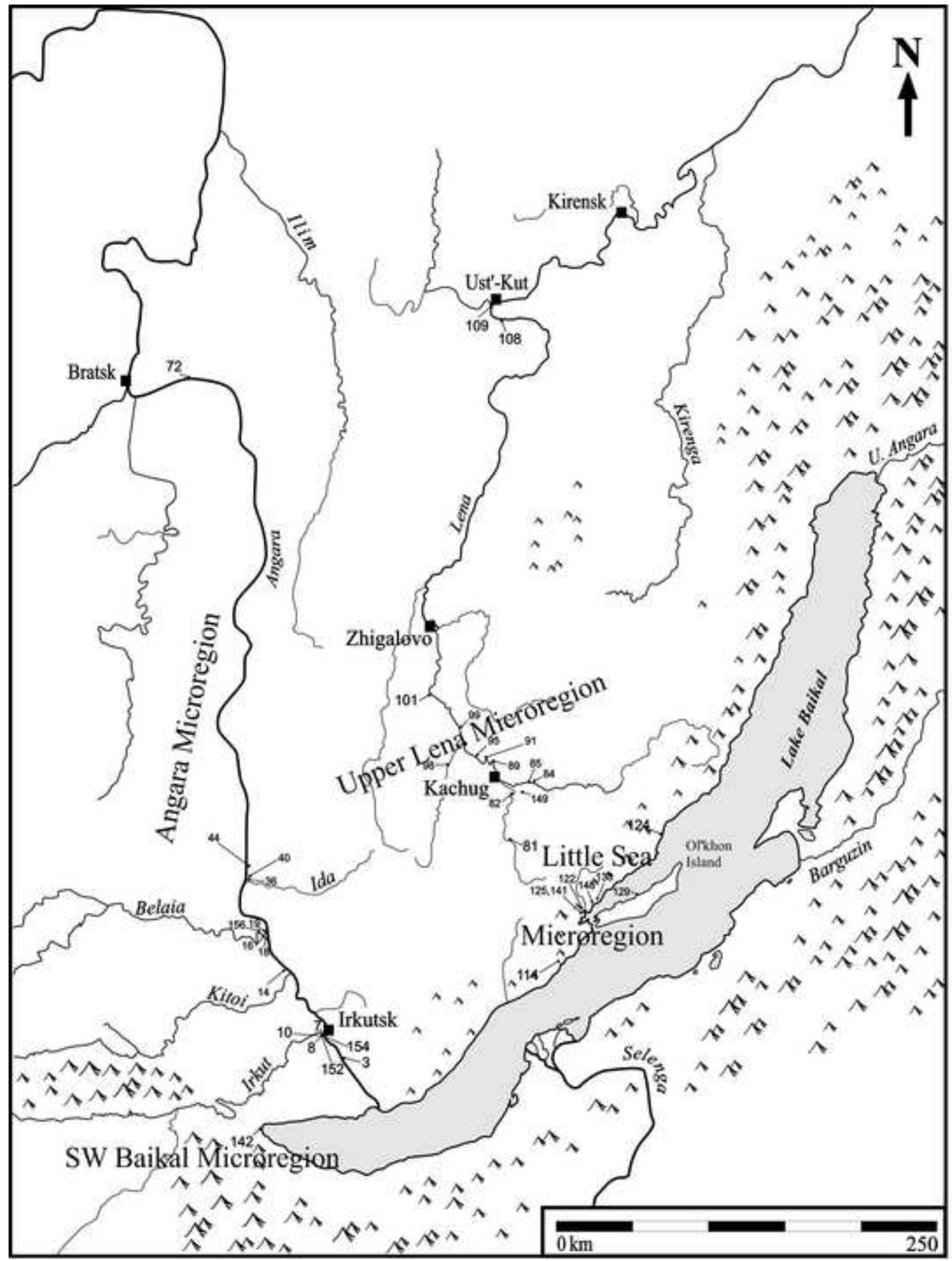


Figure 2A

Click here to download high resolution image

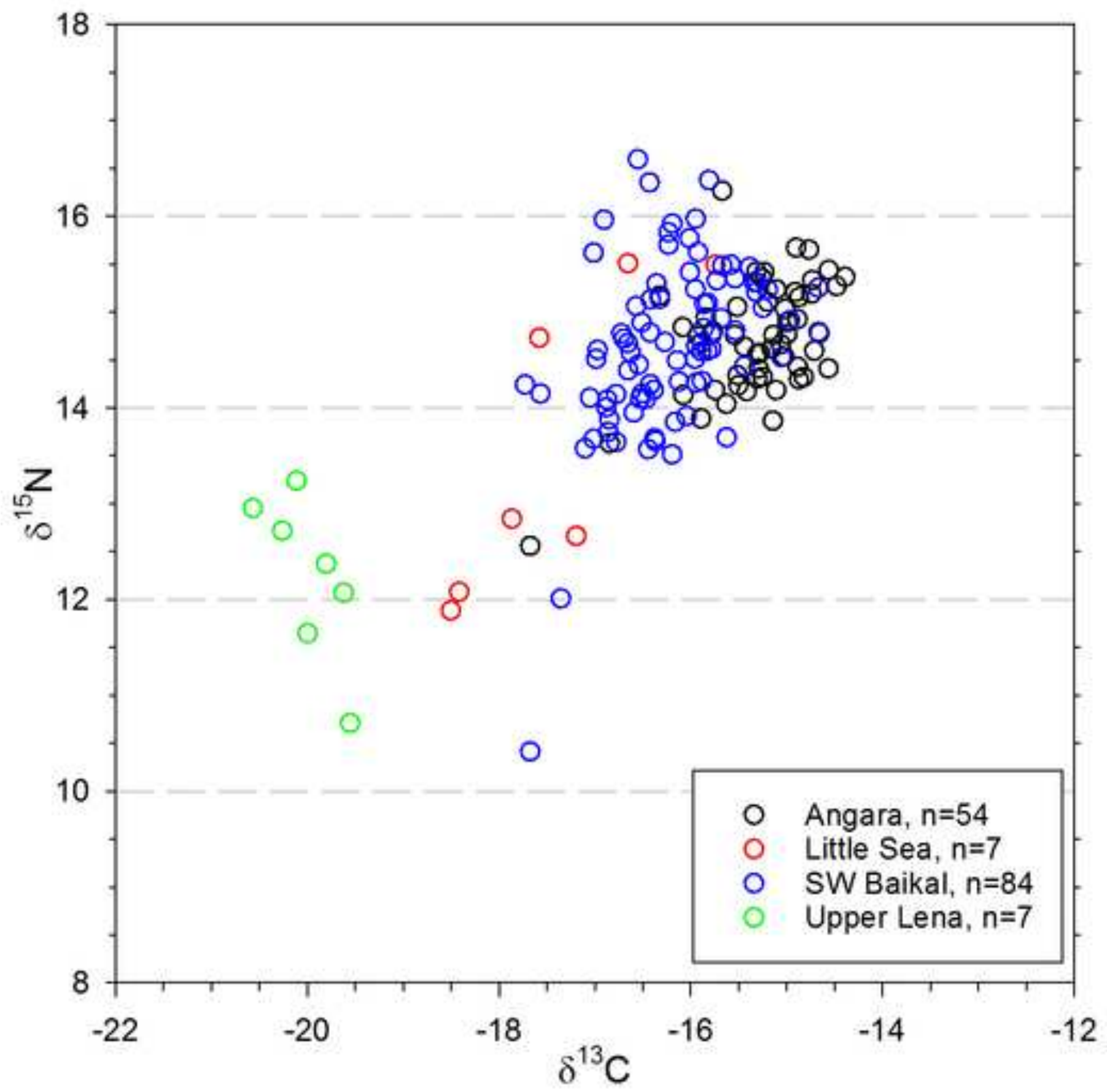




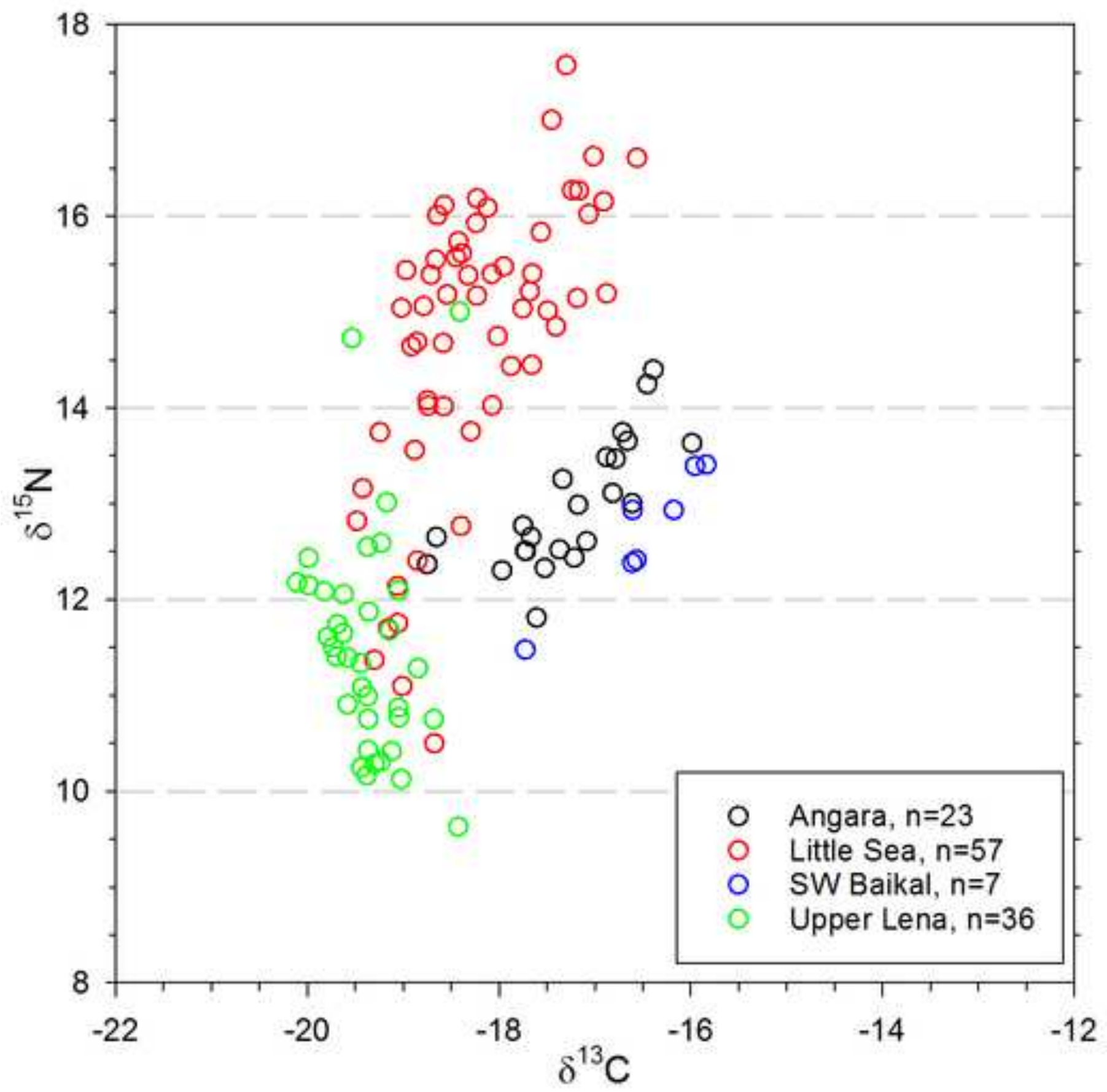


Click here to download high resolution image

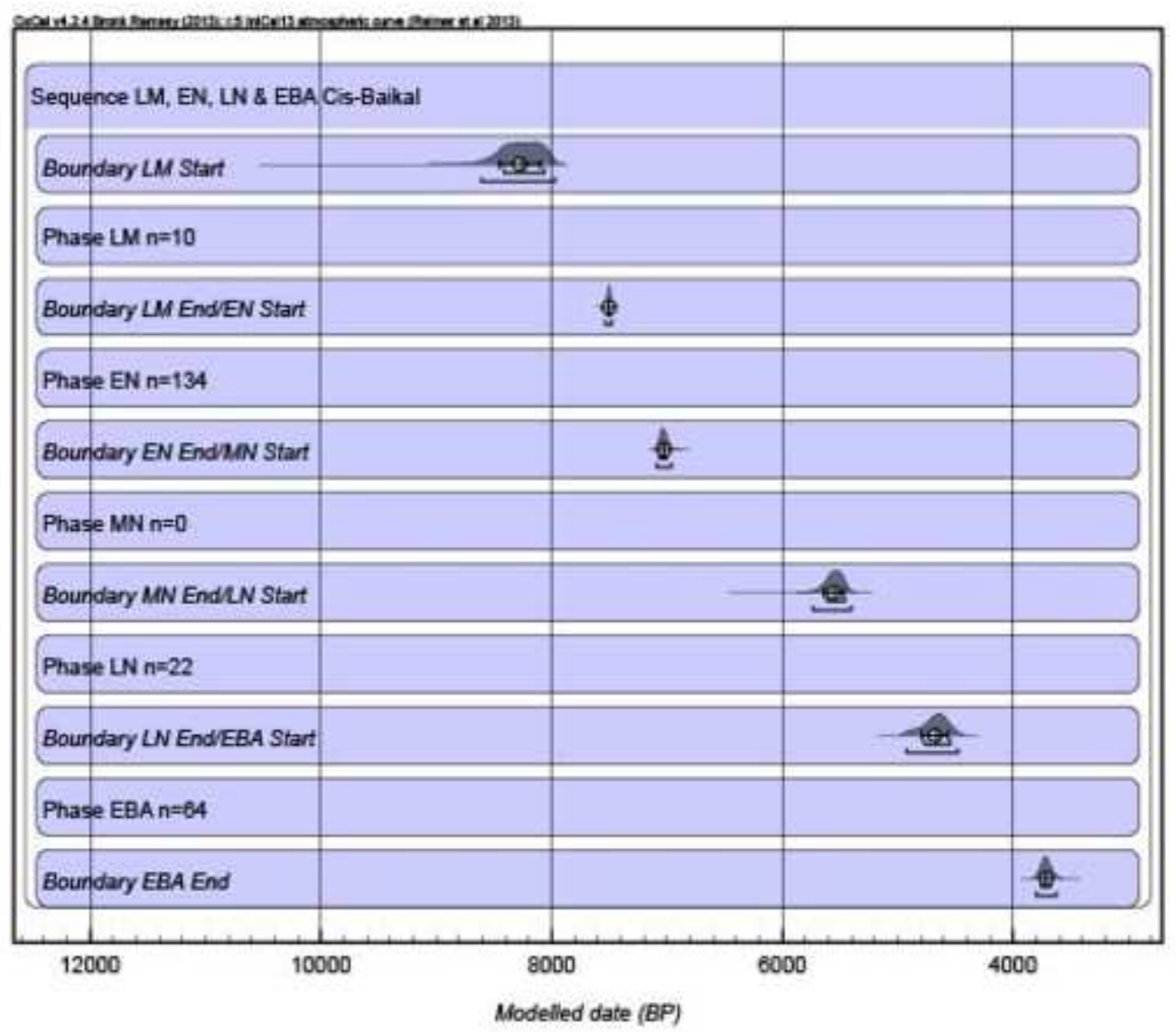




\section{Figure 3B}

Click here to download high resolution image

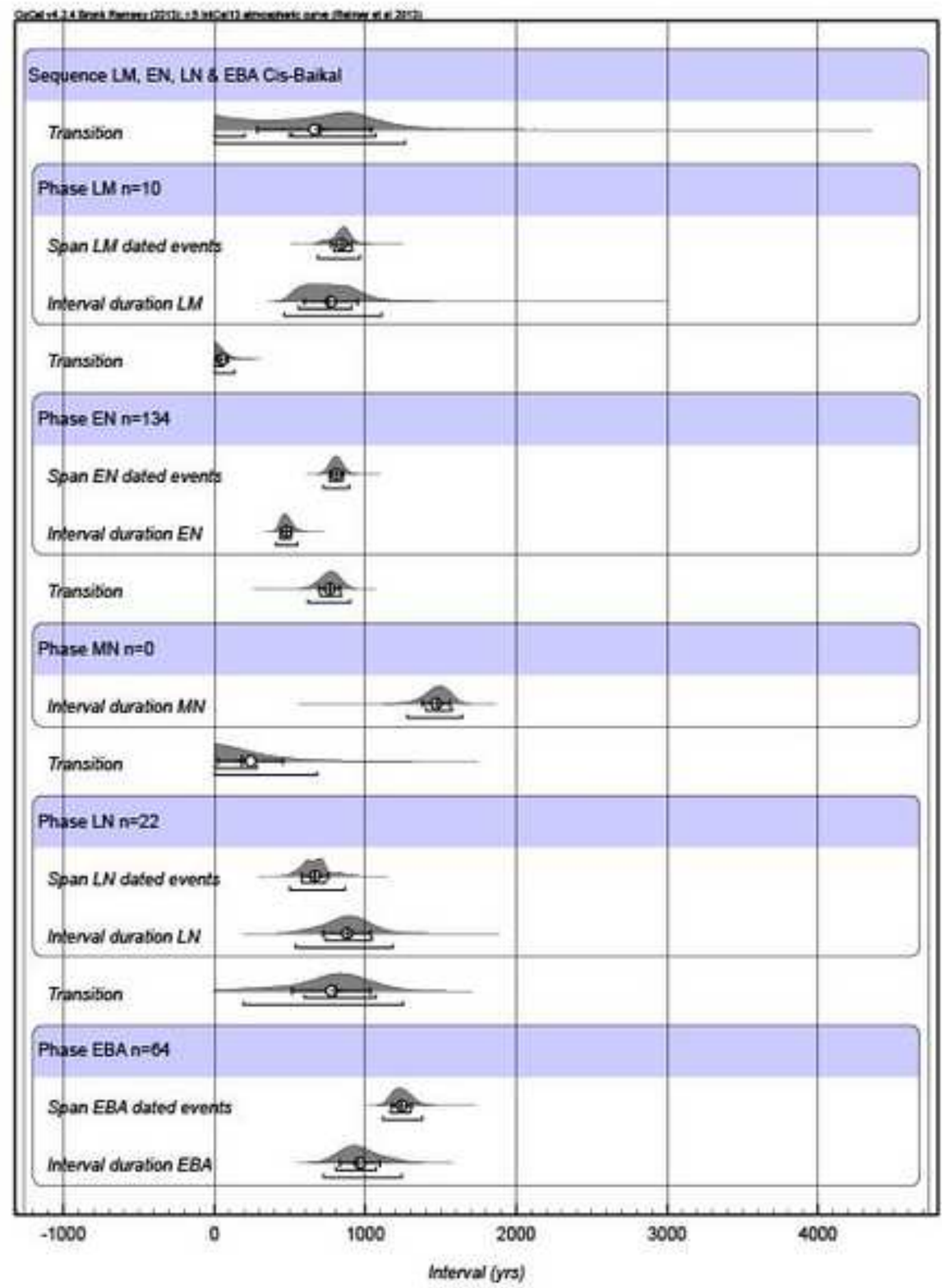


Figure 4
Click here to download high resolution image

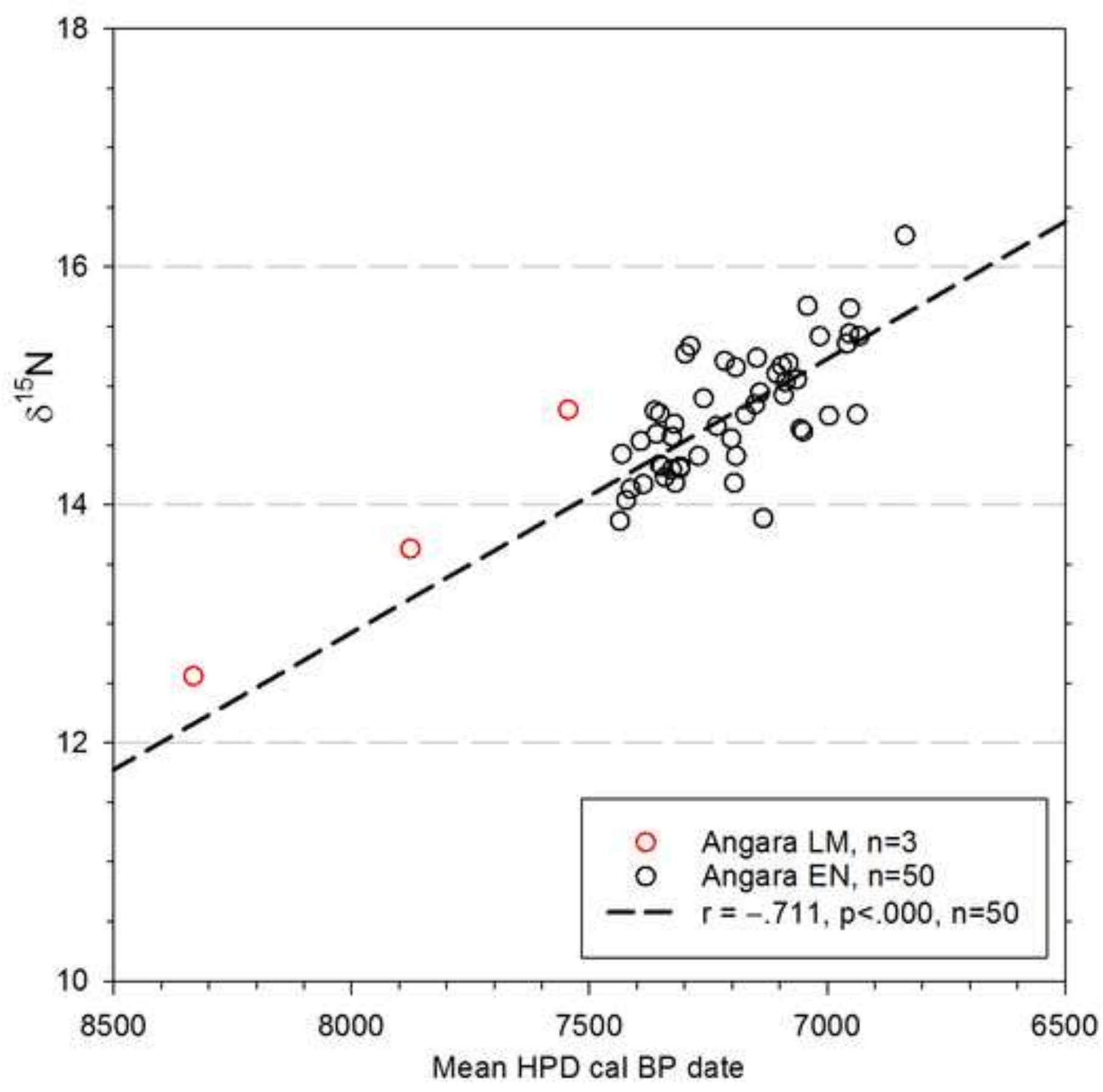




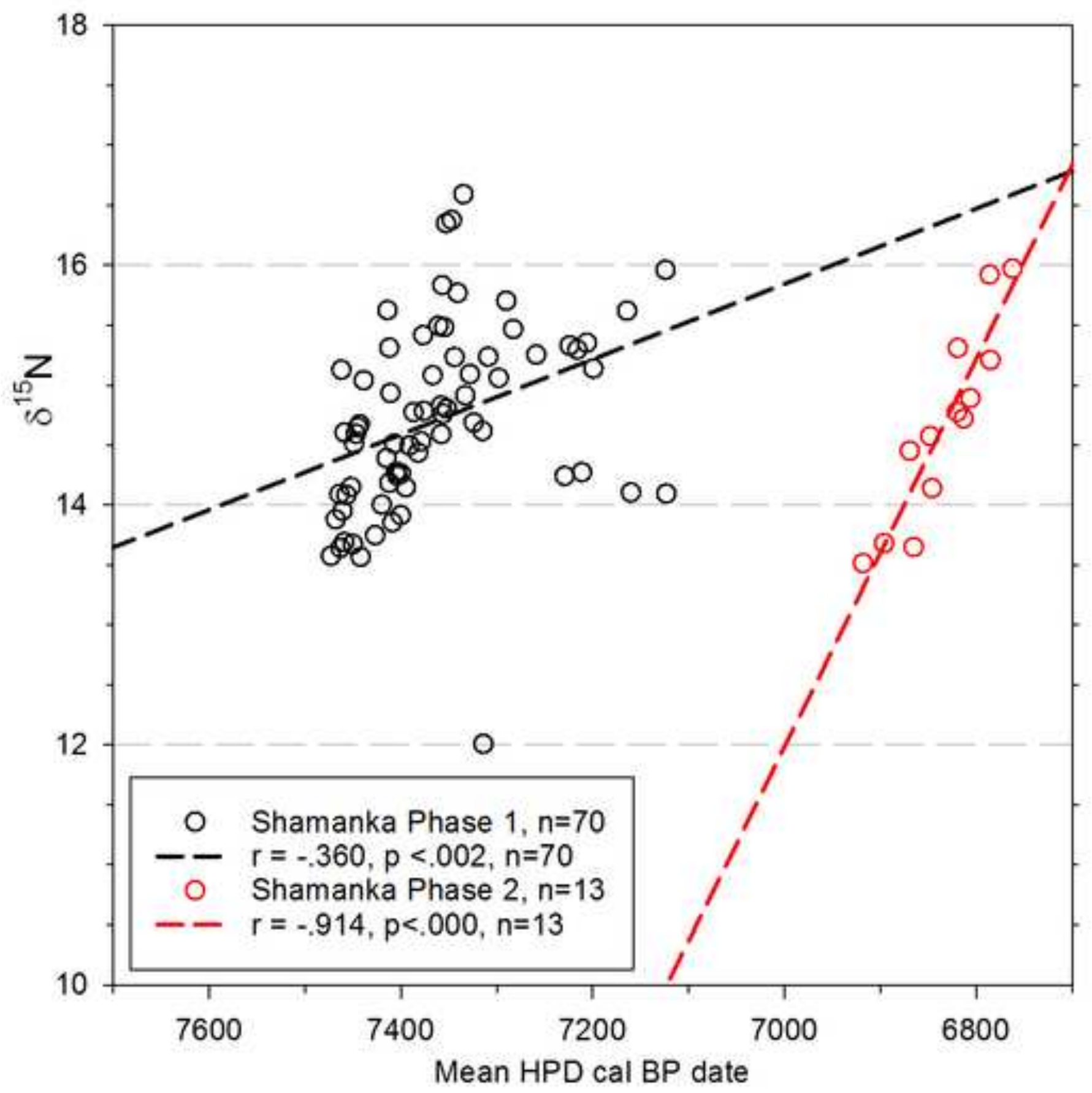




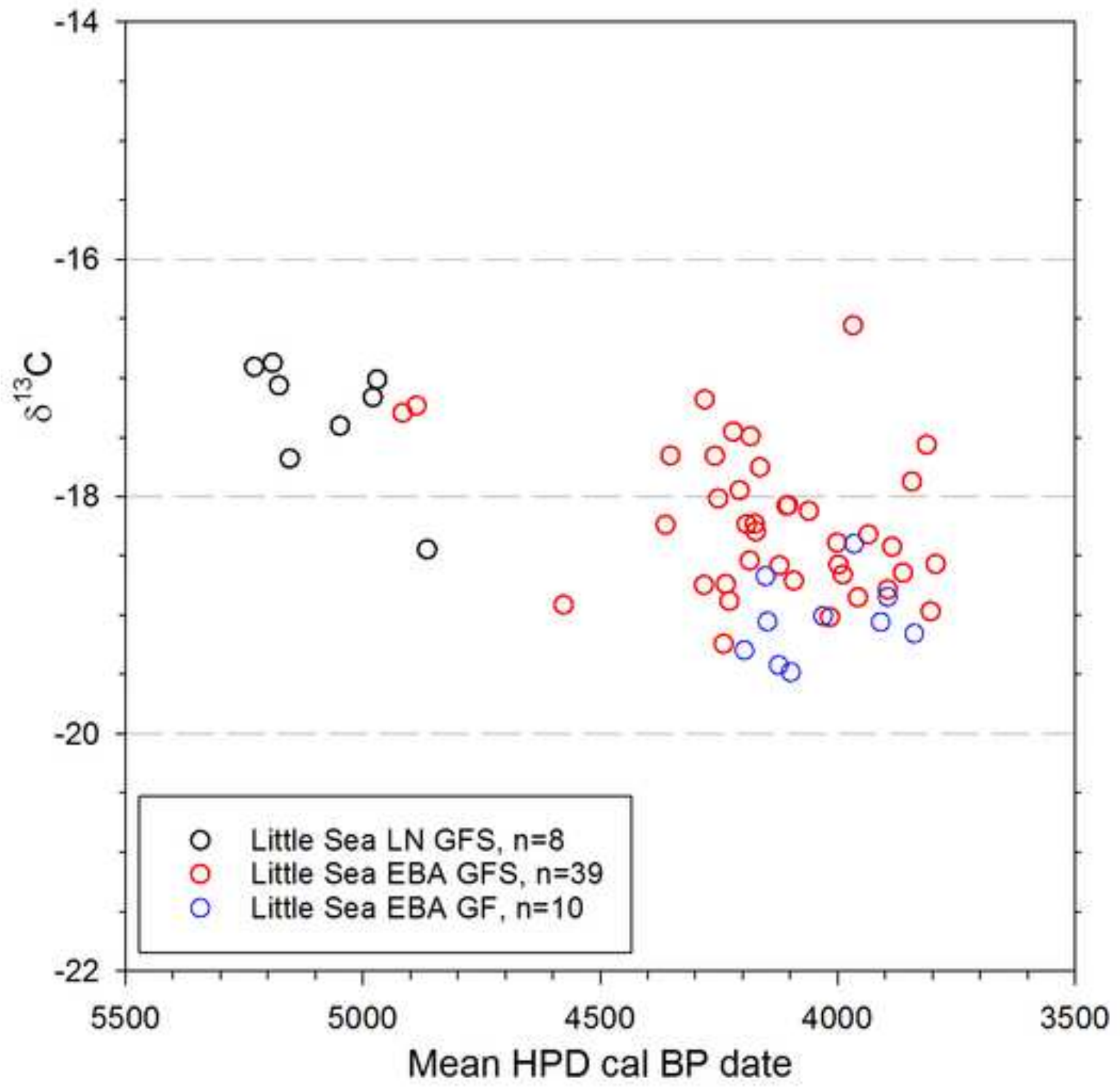




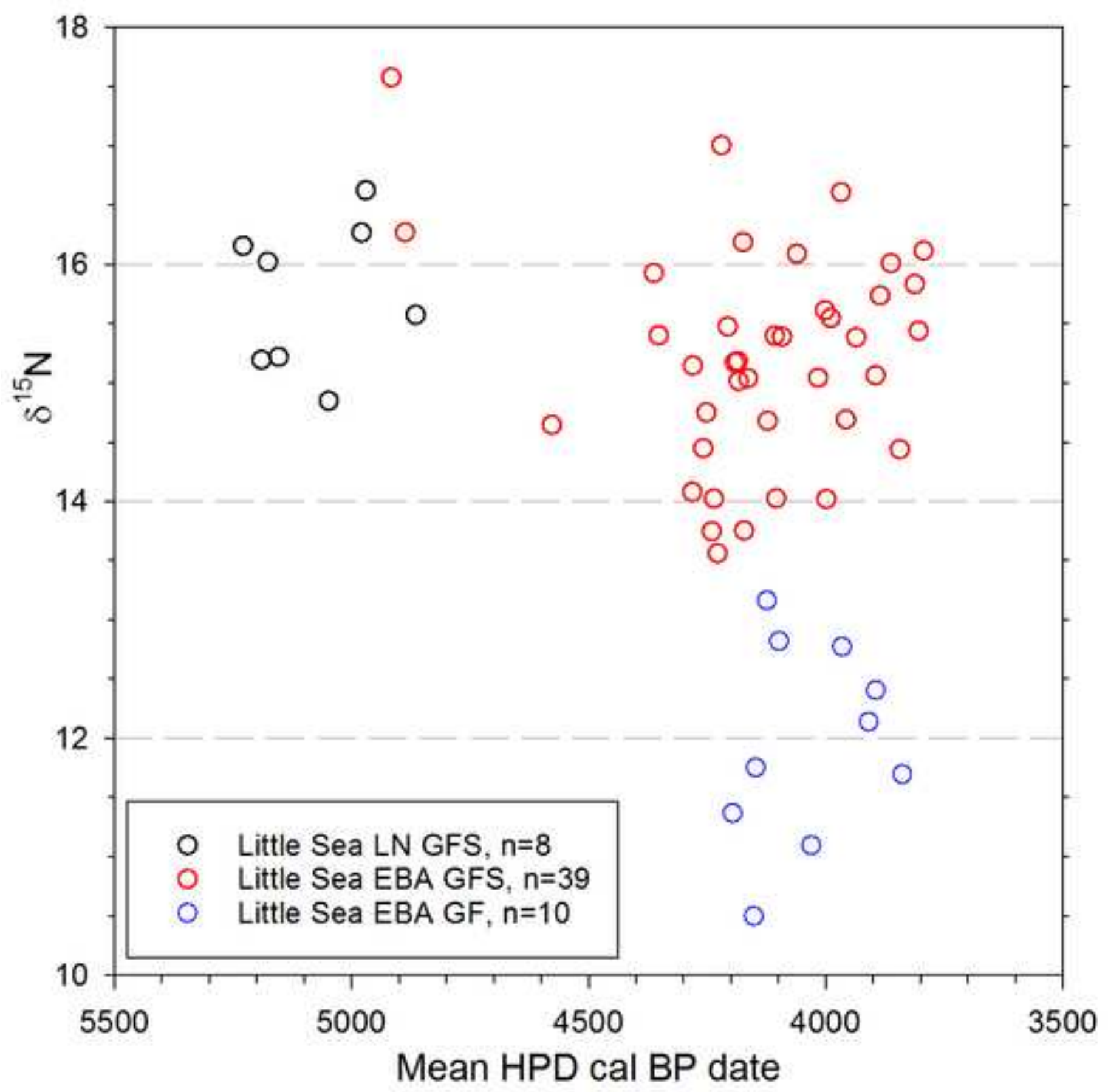




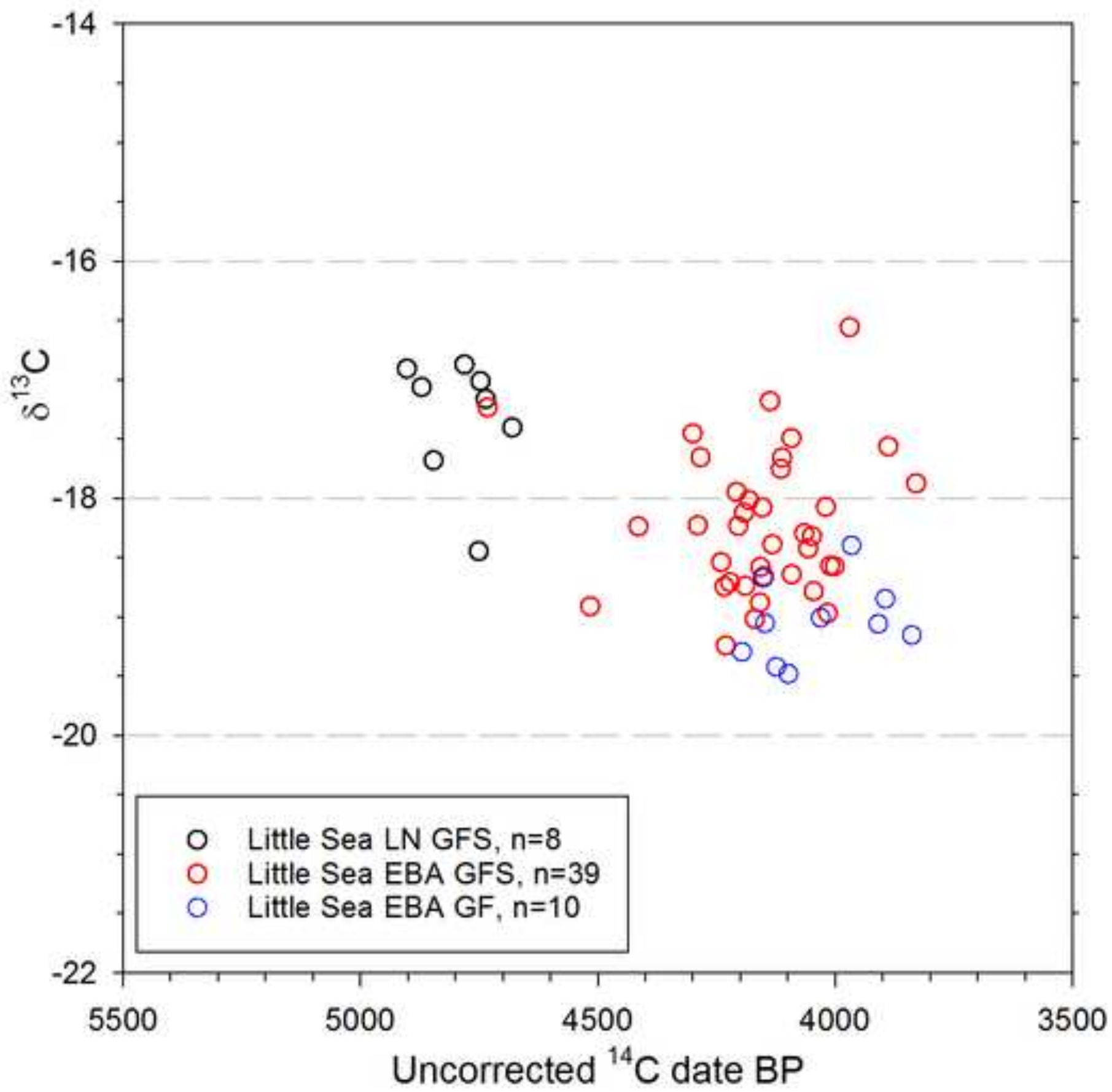




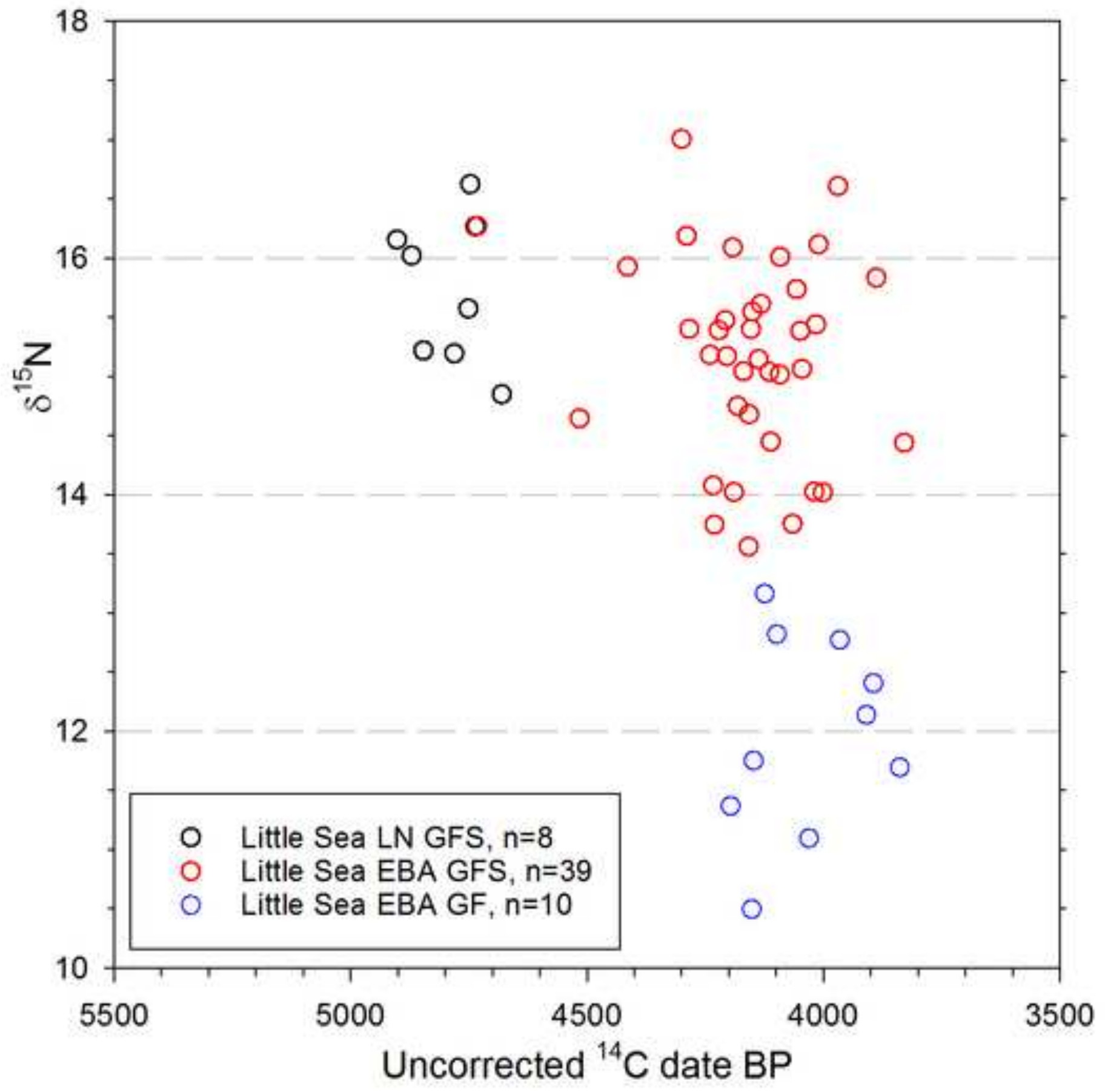


Table 1

\begin{tabular}{|c|c|c|c|c|c|c|c|c|c|c|c|c|c|c|c|}
\hline No. & Site & MASTER_ID & $\begin{array}{c}\text { Date } \\
\text { BP }\end{array}$ & $\sigma$ & $\begin{array}{l}\text { Corrected } \\
\text { date BP }\end{array}$ & $\begin{array}{c}\text { Corrected } \\
\sigma\end{array}$ & $\begin{array}{c}\text { Date } \\
\text { difference }\end{array}$ & $\begin{array}{c}\mu \text { HPD } \\
\text { date BP }\end{array}$ & $\begin{array}{c}\mu H P D \\
\sigma\end{array}$ & $\begin{array}{l}\text { Median } \\
\text { date BP }\end{array}$ & Diet & Micro-region & $\begin{array}{c}\text { Typological } \\
\text { period }\end{array}$ & Phase & Lab comment \\
\hline 1 & Kaiskaya Gora & KGO_2006.001.01 & 7755 & 40 & 7568 & 76 & 187 & 8332 & 80 & 8346 & & Angara & LM & & \\
\hline 2 & Khotoruk & KHO_1978.007 & 7657 & 39 & 7533 & 65 & 124 & 8309 & 69 & 8322 & GF & Little Sea & LM or EN & & \\
\hline 3 & Kurma XI & KUR_2003.024 & 7474 & 37 & 7237 & 64 & 237 & 8060 & 65 & 8054 & GFS & Little Sea & LM or EN & & \\
\hline 4 & Pad' Khinskaia & PKH_1936.001 & 7381 & 37 & 7060 & 74 & 321 & 7876 & 73 & 7881 & & Angara & LM & & \\
\hline 5 & Sarminskii Mys & SMS_1987.022 & 7078 & 38 & 6942 & 64 & 136 & 7778 & 69 & 7773 & GF & Little Sea & LM or EN & & \\
\hline 6 & Kurma XI & KUR_2003.022 & 7019 & 36 & 6887 & 63 & 132 & 7729 & 65 & 7724 & GF & Little Sea & LM or EN & & \\
\hline 7 & Khotoruk & KHO_1977.002.00 & 6722 & 36 & 6688 & 63 & 34 & 7571 & 43 & 7570 & GF & Little Sea & LM or EN & & \\
\hline 8 & Khotoruk & KHO_1978.004.02 & 6790 & 37 & 6669 & 64 & 121 & 7561 & 41 & 7559 & GFS & Little Sea & LM or EN & & \\
\hline 9 & Khotoruk & KHO_1978.005.01 & 6901 & 38 & 6621 & 64 & 280 & 7544 & 33 & 7544 & GFS & Little Sea & LM or EN & & \\
\hline 10 & Ershi & ESH_1987.001 & 7067 & 37 & 6599 & 74 & 468 & 7544 & 34 & 7544 & & Angara & LM or EN & & \\
\hline 11 & Shamanka II & SHA_2005.066.01 & 6967 & 28 & 6653 & 70 & 314 & 7473 & 30 & 7474 & & SW Baikal & EN & 1 & R_Combine, $\chi^{2}$-Test: $d f=1 \mathrm{~T}=1.8(5 \% 3.8)$ \\
\hline 12 & Shamanka II & SHA_2006.073 & 7010 & 45 & 6631 & 78 & 379 & 7464 & 38 & 7468 & & SW Baikal & EN & 1 & \\
\hline 13 & Shamanka II & SHA_2004.058.01 & 6980 & 28 & 6628 & 70 & 352 & 7468 & 33 & 7470 & & SW Baikal & EN & 1 & R_Combine, $\chi^{2}$-Test: $d f=1 \mathrm{~T}=0.7(5 \% 3.8)$ \\
\hline 14 & Shamanka II & SHA_2003.027.01 & 6939 & 33 & 6616 & 72 & 323 & 7463 & 37 & 7466 & & SW Baikal & EN & 1 & \\
\hline 15 & Shamanka II & SHA_2006.076 & 7123 & 37 & 6614 & 74 & 509 & 7462 & 38 & 7465 & & SW Baikal & EN & 1 & \\
\hline 16 & Shamanka II & SHA_2003.034 & 6970 & 35 & 6609 & 73 & 361 & 7461 & 39 & 7464 & & SW Baikal & EN & 1 & \\
\hline 17 & Shamanka II & SHA_2007.085 & 6935 & 39 & 6607 & 75 & 328 & 7459 & 41 & 7463 & & SW Baikal & EN & 1 & \\
\hline 18 & Shamanka II & SHA_2004.043 & 7046 & 35 & 6603 & 73 & 443 & 7459 & 40 & 7463 & & SW Baikal & EN & 1 & \\
\hline 19 & Shamanka II & SHA_2002.021.02 & 6972 & 34 & 6586 & 73 & 386 & 7452 & 44 & 7458 & & SW Baikal & EN & 1 & \\
\hline 20 & Shamanka II & SHA_2007.088 & 6910 & 35 & 6583 & 73 & 327 & 7450 & 45 & 7457 & & SW Baikal & EN & 1 & \\
\hline 21 & Shamanka II & SHA_2007.093.02 & 7012 & 37 & 6581 & 74 & 431 & 7449 & 46 & 7456 & & SW Baikal & EN & 1 & \\
\hline 22 & Shamanka II & SHA_2005.062.03 & 7022 & 39 & 6580 & 75 & 442 & 7447 & 47 & 7455 & & SW Baikal & EN & 1 & \\
\hline 23 & Shamanka II & SHA_2006.077 & 7025 & 40 & 6573 & 76 & 452 & 7443 & 50 & 7452 & & SW Baikal & EN & 1 & \\
\hline 24 & Shamanka II & SHA_2002.023.05 & 7021 & 35 & 6573 & 73 & 448 & 7445 & 48 & 7454 & & SW Baikal & EN & 1 & \\
\hline 25 & Shamanka II & SHA_2004.045 & 6881 & 36 & 6568 & 74 & 313 & 7442 & 50 & 7451 & & SW Baikal & EN & 1 & \\
\hline 26 & Shamanka II & SHA_2004.041 & & & 6567 & 53 & 378 & 7457 & 34 & 7458 & & SW Baikal & EN & 1 & R_Combine, $\chi^{2}$-Test: $d f=1 \mathrm{~T}=0.0(5 \% 3.8)$ \\
\hline 27 & Shamanka II & SHA_2006.079 & 7063 & 39 & 6565 & 75 & 498 & 7439 & 51 & 7450 & & SW Baikal & EN & 1 & \\
\hline 28 & Lokomotiv-Raisovet & LOR_1991.007.01 & 6980 & 50 & 6559 & 81 & 421 & 7431 & 56 & 7444 & & Angara & EN & & \\
\hline 29 & Lokomotiv & LOK_1990.043.02 & 6905 & 35 & 6555 & 73 & 350 & 7435 & 52 & 7446 & & Angara & EN & & \\
\hline 30 & Shamanka II & SHA_2004.050.02 & 6875 & 26 & 6539 & 69 & 336 & 7427 & 54 & 7439 & & SW Baikal & EN & 1 & R_Combine, $\chi^{2}$-Test: $d f=1 \mathrm{~T}=1.0(5 \% 3.8)$ \\
\hline 31 & Lokomotiv & LOK_1990.041.02 & 6908 & 35 & 6535 & 73 & 373 & 7422 & 56 & 7435 & & Angara & EN & & \\
\hline 32 & Shamanka II & SHA_2004.044.02 & 6901 & 35 & 6533 & 73 & 368 & 7420 & 57 & 7433 & & SW Baikal & EN & 1 & \\
\hline 33 & Shamanka II & SHA_2005.065 & 6945 & 45 & 6529 & 78 & 416 & 7415 & 59 & 7428 & & SW Baikal & EN & 1 & \\
\hline 34 & Shamanka II & SHA_2004.057.00 & 7060 & 50 & 6528 & 81 & 532 & 7412 & 61 & 7426 & & SW Baikal & EN & 1 & \\
\hline 35 & Ust' Ida & UID_1993.043 & 6910 & 45 & 6526 & 78 & 384 & 7413 & 60 & 7426 & & Angara & EN & & \\
\hline 36 & Shamanka II & SHA_2003.033 & 6913 & 34 & 6522 & 73 & 391 & 7412 & 58 & 7426 & & SW Baikal & EN & 1 & \\
\hline 37 & Shamanka II & SHA_2005.062.04 & 7005 & 38 & 6521 & 75 & 484 & 7411 & 59 & 7424 & & SW Baikal & EN & 1 & \\
\hline 38 & Shamanka II & SHA_2007.092 & 6867 & 35 & 6518 & 73 & 349 & 7409 & 59 & 7422 & & SW Baikal & EN & 1 & \\
\hline 39 & Shamanka II & SHA_2006.074 & 6948 & 39 & 6516 & 75 & 432 & 7407 & 59 & 7419 & & SW Baikal & EN & 1 & \\
\hline 40 & Shamanka II & SHA_2005.061.02 & 6915 & 38 & 6513 & 75 & 402 & 7405 & 60 & 7417 & & SW Baikal & EN & 1 & \\
\hline 41 & Shamanka II & SHA_2002.022 & & & 6512 & 52 & 571 & 7414 & 50 & 7426 & & SW Baikal & EN & 1 & R_Combine, $\chi^{2}$-Test: $d f=1 \mathrm{~T}=0.3(5 \% 3.8)$ \\
\hline 42 & Shamanka II & SHA_1998.004 & 6906 & 38 & 6506 & 75 & 400 & 7400 & 60 & 7408 & & SW Baikal & EN & 1 & \\
\hline 43 & Shamanka II & SHA_2005.062.01 & 6862 & 37 & 6505 & 74 & 357 & 7400 & 60 & 7407 & & SW Baikal & EN & 1 & \\
\hline 44 & Shamanka II & SHA_2004.039 & & & 6500 & 42 & 399 & 7404 & 46 & 7418 & & SW Baikal & EN & 1 & R_Combine, $\chi^{2}$-Test: $d f=1 \mathrm{~T}=0.1$ (5\% 3.8) \\
\hline
\end{tabular}




\begin{tabular}{|c|c|c|c|c|c|c|c|c|c|c|c|c|c|c|}
\hline 45 & Shamanka II & SHA_2005.067 & 6885 & 40 & 6499 & 76 & 386 & 7395 & 61 & 7399 & SW Baikal & EN & 1 & \\
\hline 46 & Lokomotiv & LOK_1990.044.01 & 6929 & 35 & 6494 & 73 & 435 & 7392 & 59 & 7395 & Angara & EN & & \\
\hline 47 & Shamanka II & SHA_2003.032 & 6921 & 35 & 6492 & 73 & 429 & 7391 & 59 & 7393 & SW Baikal & EN & 1 & \\
\hline 48 & Shamanka II & SHA_2006.069.02 & 6953 & 39 & 6488 & 75 & 465 & 7387 & 60 & 7389 & SW Baikal & EN & 1 & \\
\hline 49 & Lokomotiv & LOK_1990.042 & 6873 & 27 & 6484 & 70 & 389 & 7386 & 58 & 7387 & Angara & EN & & R_Combine, $\chi^{2}$-Test: $d f=1 \mathrm{~T}=0.1(5 \% 3.8)$ \\
\hline 50 & Shamanka II & SHA_2002.024.02 & 6901 & 34 & 6479 & 73 & 422 & 7382 & 59 & 7383 & SW Baikal & EN & 1 & \\
\hline 51 & Shamanka II & SHA_2005.063.02 & 6908 & 32 & 6474 & 72 & 434 & 7379 & 59 & 7380 & SW Baikal & EN & 1 & \\
\hline 52 & Shamanka II & SHA_2004.055.02 & 7017 & 39 & 6472 & 75 & 545 & 7377 & 60 & 7379 & SW Baikal & EN & 1 & \\
\hline 53 & Shamanka II & SHA_2004.048.01 & & & 6469 & 51 & 459 & 7376 & 46 & 7377 & SW Baikal & EN & 1 & R_Combine, $\chi^{2}$-Test: $d f=1 \mathrm{~T}=1.5(5 \% 3.8)$ \\
\hline 54 & Shamanka II & SHA_2005.060.02 & 6959 & 39 & 6456 & 75 & 503 & 7367 & 60 & 7370 & SW Baikal & EN & 1 & \\
\hline 55 & Lokomotiv-Raisovet & LOR_1998.014 & 6915 & 40 & 6448 & 76 & 467 & 7362 & 61 & 7365 & Angara & EN & & \\
\hline 56 & Shamanka II & SHA_2007.090 & 7000 & 40 & 6445 & 76 & 555 & 7361 & 62 & 7364 & SW Baikal & EN & 1 & \\
\hline 57 & Shamanka II & SHA_2004.055.01 & 6881 & 38 & 6440 & 75 & 441 & 7358 & 61 & 7362 & SW Baikal & EN & 1 & \\
\hline 58 & Shamanka II & SHA_2004.050.03 & 6911 & 26 & 6439 & 69 & 472 & 7358 & 57 & 7361 & SW Baikal & EN & 1 & R_Combine, $\chi^{2}$-Test: $d f=1 \mathrm{~T}=5.8(5 \% 3.8)$ \\
\hline 59 & Shamanka II & SHA_2006.069.01 & 6899 & 35 & 6436 & 73 & 463 & 7356 & 60 & 7360 & SW Baikal & EN & 1 & \\
\hline 60 & Lokomotiv & LOK_1980.022.03 & & & 6435 & 54 & 442 & 7358 & 47 & 7361 & Angara & EN & & R_Combine, $\chi^{2}$-Test: $d f=1 \mathrm{~T}=0.1(5 \% 3.8)$ \\
\hline 61 & Shamanka II & SHA_2004.056.02 & 6986 & 27 & 6433 & 70 & 553 & 7355 & 58 & 7359 & SW Baikal & EN & 1 & R_Combine, $\chi^{2}$-Test: $d f=1 \mathrm{~T}=3.5(5 \% 3.8)$ \\
\hline 62 & Shamanka II & SHA_2004.047 & & & 6432 & 51 & 595 & 7357 & 46 & 7360 & SW Baikal & EN & 1 & R_Combine, $\chi^{2}$-Test: $d f=1 \mathrm{~T}=1.1(5 \% 3.8)$ \\
\hline 63 & Shamanka II & SHA_2006.075 & 7093 & 37 & 6431 & 74 & 662 & 7353 & 61 & 7357 & SW Baikal & EN & 1 & \\
\hline 64 & Lokomotiv & LOK_1984.029 & 6894 & 36 & 6430 & 74 & 464 & 7352 & 61 & 7357 & Angara & EN & & \\
\hline 65 & Shamanka II & SHA_2002.025.01 & 6897 & 35 & 6429 & 73 & 468 & 7352 & 61 & 7356 & SW Baikal & EN & 1 & \\
\hline 66 & Lokomotiv & LOK_1980.002.02 & 6838 & 36 & 6428 & 74 & 410 & 7351 & 62 & 7356 & Angara & EN & & \\
\hline 67 & Lokomotiv & LOK_1980.002.03 & 6829 & 34 & 6421 & 73 & 408 & 7347 & 62 & 7352 & Angara & EN & & \\
\hline 68 & Shamanka II & SHA_2004.054.01 & 6939 & 38 & 6417 & 75 & 522 & 7344 & 64 & 7349 & SW Baikal & EN & 1 & \\
\hline 69 & Shamanka II & SHA_2004.053.02 & 7001 & 38 & 6412 & 75 & 589 & 7341 & 65 & 7347 & SW Baikal & EN & 1 & \\
\hline 70 & Lokomotiv-Raisovet & LOR_1980.003.01 & 6808 & 37 & 6411 & 74 & 397 & 7341 & 64 & 7346 & Angara & EN & & \\
\hline 71 & Shamanka II & SHA_2004.046 & & & 6411 & 53 & 666 & 7347 & 50 & 7350 & SW Baikal & EN & 1 & R_Combine, $\chi^{2}$-Test: $d f=1 \mathrm{~T}=0.0(5 \% 3.8)$ \\
\hline 72 & Shamanka II & SHA_2006.083.02 & 7095 & 36 & 6402 & 74 & 693 & 7335 & 66 & 7340 & SW Baikal & EN & 1 & \\
\hline 73 & Shamanka II & SHA_2005.061.01 & 6881 & 40 & 6399 & 76 & 482 & 7333 & 68 & 7337 & SW Baikal & EN & 1 & \\
\hline 74 & Shamanka II & SHA_2005.062.02 & 6895 & 37 & 6391 & 74 & 504 & 7328 & 69 & 7331 & SW Baikal & EN & 1 & \\
\hline 75 & Lokomotiv & LOK_1981.024.01 & 6793 & 36 & 6388 & 74 & 405 & 7326 & 70 & 7329 & Angara & EN & & \\
\hline 76 & Lokomotiv & LOK_1985.033 & 6827 & 34 & 6388 & 73 & 439 & 7326 & 69 & 7329 & Angara & EN & & \\
\hline 77 & Shamanka II & SHA_2006.071 & 6838 & 27 & 6384 & 70 & 454 & 7324 & 68 & 7326 & SW Baikal & EN & 1 & R_Combine, $\chi^{2}$-Test: $d f=1 \mathrm{~T}=0.7(5 \% 3.8)$ \\
\hline 78 & Lokomotiv & LOK_1988.038.02 & 6836 & 38 & 6383 & 75 & 453 & 7321 & 72 & 7325 & Angara & EN & & \\
\hline 79 & Lokomotiv-Raisovet & LOR_1998.013.01 & 6770 & 40 & 6380 & 76 & 390 & 7319 & 74 & 7322 & Angara & EN & & \\
\hline 80 & Shamanka II & SHA_2006.070 & 6819 & 37 & 6374 & 74 & 445 & 7315 & 74 & 7317 & SW Baikal & EN & 1 & \\
\hline 81 & Shamanka II & SHA_2003.026.02 & 6490 & 34 & 6373 & 73 & 117 & 7314 & 73 & 7316 & SW Baikal & EN & 1 & \\
\hline 82 & Lokomotiv & LOK_1981.025.05 & 6775 & 45 & 6369 & 78 & 406 & 7309 & 78 & 7312 & Angara & EN & & \\
\hline 83 & Lokomotiv & LOK_1981.024.04 & 6775 & 40 & 6367 & 76 & 408 & 7308 & 77 & 7311 & Angara & EN & & \\
\hline 84 & Shamanka II & SHA_2005.068 & 6889 & 37 & 6367 & 74 & 522 & 7309 & 76 & 7311 & SW Baikal & EN & 1 & \\
\hline 85 & Shamanka II & SHA_2004.051 & 6856 & 40 & 6356 & 76 & 500 & 7298 & 81 & 7301 & SW Baikal & EN & 1 & \\
\hline 86 & Lokomotiv & LOK_1988.038.01 & 6882 & 37 & 6355 & 74 & 527 & 7298 & 79 & 7300 & Angara & EN & & \\
\hline 87 & Shamanka II & SHA_2004.053.01 & 6928 & 37 & 6347 & 74 & 581 & 7290 & 82 & 7292 & SW Baikal & EN & 1 & \\
\hline 88 & Kitoi & KIT_surface & 6879 & 37 & 6344 & 74 & 535 & 7287 & 83 & 7289 & Angara & EN & & \\
\hline 89 & Shamanka II & SHA_2004.052.02 & 6892 & 37 & 6341 & 74 & 551 & 7283 & 83 & 7285 & SW Baikal & EN & 1 & \\
\hline 90 & Lokomotiv & LOK_1981.025.01 & 6748 & 35 & 6329 & 73 & 419 & 7270 & 86 & 7271 & Angara & EN & & \\
\hline 91 & Lokomotiv-Raisovet & LOR_1980.001 & 6800 & 40 & 6320 & 76 & 480 & 7259 & 91 & 7261 & Angara & EN & & \\
\hline
\end{tabular}




\begin{tabular}{|c|c|c|c|c|c|c|c|c|c|c|c|c|c|c|}
\hline 92 & Shamanka II & SHA_2004.052.01 & 6845 & 40 & 6320 & 76 & 525 & 7259 & 91 & 7261 & SW Baikal & EN & 1 & \\
\hline 93 & Lokomotiv & LOK_1985.034 & 6748 & 36 & 6298 & 74 & 450 & 7232 & 93 & 7236 & Angara & EN & & \\
\hline 94 & Shamanka II & SHA_2005.059.02 & 6694 & 39 & 6296 & 75 & 398 & 7229 & 94 & 7234 & SW Baikal & EN & 1 & \\
\hline 95 & Shamanka II & SHA_2001.016 & 6826 & 25 & 6292 & 69 & 534 & 7224 & 88 & 7228 & SW Baikal & EN & 1 & R_Combine, $\chi^{2}$-Test: $d f=1 \mathrm{~T}=0.4(5 \% 3.8)$ \\
\hline 96 & Shamanka II & SHA_2008.108.02 & 6816 & 32 & 6286 & 72 & 530 & 7216 & 92 & 7222 & SW Baikal & EN & 1 & \\
\hline 97 & Lokomotiv & LOK_1980.022.02 & 6804 & 28 & 6285 & 70 & 519 & 7215 & 90 & 7221 & Angara & EN & & R_Combine, $\chi^{2}$-Test: $d f=1 \mathrm{~T}=0.0(5 \% 3.8)$ \\
\hline 98 & Shamanka II & SHA_2007.096.02 & 6684 & 26 & 6282 & 69 & 402 & 7211 & 89 & 7218 & SW Baikal & EN & 1 & R_Combine, $\chi^{2}$-Test: $d f=1 \mathrm{~T}=0.0(5 \% 3.8)$ \\
\hline 99 & Shamanka II & SHA_2005.063.01 & 6815 & 38 & 6278 & 75 & 537 & 7206 & 95 & 7215 & SW Baikal & EN & 1 & \\
\hline 100 & Lokomotiv & LOK_1980.007 & 6711 & 35 & 6274 & 73 & 437 & 7201 & 94 & 7211 & Angara & EN & & \\
\hline 101 & Shamanka II & SHA_2008.112 & 6782 & 38 & 6272 & 75 & 510 & 7199 & 96 & 7209 & SW Baikal & EN & 1 & \\
\hline 102 & Kitoi & KIT_1880.004 & 6660 & 35 & 6269 & 73 & 391 & 7195 & 94 & 7205 & Angara & EN & & \\
\hline 103 & Lokomotiv & LOK_1981.025.03 & 6779 & 34 & 6267 & 73 & 512 & 7192 & 94 & 7203 & Angara & EN & & \\
\hline 104 & Galashikha & GAL_Grave17-2 & 6685 & 36 & 6266 & 74 & 419 & 7191 & 95 & 7202 & Angara & EN & & \\
\hline 105 & Lokomotiv & LOK_1988.039 & 6713 & 35 & 6250 & 73 & 463 & 7171 & 94 & 7185 & Angara & EN & & \\
\hline 106 & Shamanka II & SHA_2007.086.02 & 6815 & 35 & 6244 & 73 & 571 & 7164 & 94 & 7177 & SW Baikal & EN & 1 & \\
\hline 107 & Shamanka II & SHA_2006.083.01 & 6620 & 40 & 6240 & 76 & 380 & 7160 & 96 & 7173 & SW Baikal & EN & 1 & \\
\hline 108 & Kitoi & KIT_1880.011 & 6706 & 35 & 6233 & 73 & 473 & 7151 & 93 & 7164 & Angara & EN & & \\
\hline 109 & Lokomotiv & LOK_1980.006 & 6751 & 35 & 6229 & 73 & 522 & 7147 & 93 & 7159 & Angara & EN & & \\
\hline 110 & Ust' Belaia & UBE_1962.005 & 6710 & 33 & 6224 & 72 & 486 & 7141 & 92 & 7152 & Angara & EN & & \\
\hline 111 & Lokomotiv & LOK_1985.030.01 & 6570 & 34 & 6217 & 73 & 353 & 7134 & 92 & 7141 & Angara & EN & & \\
\hline 112 & Shamanka II & SHA_2005.060.01 & 6819 & 38 & 6206 & 75 & 613 & 7124 & 94 & 7125 & SW Baikal & EN & 1 & \\
\hline 113 & Shamanka II & SHA_2007.086.01 & 6584 & 39 & 6205 & 75 & 379 & 7123 & 94 & 7124 & SW Baikal & EN & 1 & \\
\hline 114 & Ust' Belaia & UBE_1962.008 & 6694 & 34 & 6188 & 73 & 506 & 7106 & 91 & 7108 & Angara & EN & & \\
\hline 115 & Galashikha & GAL_Grave18 & 6690 & 36 & 6176 & 74 & 514 & 7095 & 92 & 7098 & Angara & EN & & \\
\hline 116 & Galashikha & GAL_Grave17-1 & 6655 & 35 & 6172 & 73 & 483 & 7091 & 92 & 7095 & Angara & EN & & \\
\hline 117 & Shumilikha & SHU_1972.002.01 & 6664 & 37 & 6167 & 74 & 497 & 7087 & 93 & 7092 & Angara & EN & & \\
\hline 118 & Lokomotiv & LOK_1981.025.02 & 6678 & 35 & 6161 & 73 & 517 & 7081 & 93 & 7086 & Angara & EN & & \\
\hline 119 & Ust' Belaia & UBE_1962.009.00 & 6640 & 32 & 6141 & 72 & 499 & 7063 & 94 & 7070 & Angara & EN & & \\
\hline 120 & Lokomotiv & LOK_1981.024.05 & 6580 & 36 & 6133 & 74 & 447 & 7055 & 97 & 7063 & Angara & EN & & \\
\hline 121 & Lokomotiv & LOK_1980.009 & 6573 & 34 & 6128 & 73 & 445 & 7050 & 97 & 7057 & Angara & EN & & \\
\hline 122 & Lokomotiv & LOK_1981.023 & 6695 & 40 & 6118 & 76 & 577 & 7041 & 101 & 7047 & Angara & EN & & \\
\hline 123 & Galashikha & GAL_Grave05-1 & 6640 & 35 & 6095 & 73 & 545 & 7015 & 104 & 7010 & Angara & EN & & \\
\hline 124 & Galashikha & GAL_Grave16 & 6540 & 35 & 6079 & 73 & 461 & 6996 & 106 & 6987 & Angara & EN & & \\
\hline 125 & Galashikha & GAL_Grave04(1978) & 6586 & 34 & 6049 & 73 & 537 & 6958 & 108 & 6945 & Angara & EN & & \\
\hline 126 & Galashikha & GAL_Grave05-2 & 6592 & 36 & 6044 & 74 & 548 & 6953 & 108 & 6940 & Angara & EN & & \\
\hline 127 & Shamanka II & SHA_2004.049.01 & & & 6041 & 52 & 306 & 6918 & 83 & 6912 & SW Baikal & EN & 2 & R_Combine, $\chi^{2}$-Test: $d f=1 \mathrm{~T}=0.4(5 \% 3.8)$ \\
\hline 128 & Lokomotiv & LOK_1985.035 & 6615 & 40 & 6041 & 76 & 574 & 6952 & 109 & 6939 & Angara & EN & & \\
\hline 129 & Galashikha & GAL_Grave03 & 6496 & 35 & 6033 & 73 & 463 & 6937 & 106 & 6926 & Angara & EN & & \\
\hline 130 & Galashikha & GAL_Grave07 & 6573 & 36 & 6028 & 74 & 545 & 6932 & 106 & 6921 & Angara & EN & & \\
\hline 131 & Shamanka II & SHA_1999.007 & 6329 & 33 & 6001 & 72 & 328 & 6896 & 98 & 6886 & SW Baikal & EN & 2 & \\
\hline 132 & Shamanka II & SHA_2004.050.01 & 6405 & 25 & 5981 & 69 & 424 & 6869 & 88 & 6863 & SW Baikal & EN & 2 & R_Combine, $\chi^{2}$-Test: $d f=1 \mathrm{~T}=0.3(5 \% 3.8)$ \\
\hline 133 & Shamanka II & SHA_2008.104 & 6312 & 25 & 5977 & 69 & 335 & 6865 & 87 & 6859 & SW Baikal & EN & 2 & R_Combine, $\chi^{2}$-Test: $d f=1 \mathrm{~T}=5.0(5 \% 3.8)$ \\
\hline 134 & Shamanka II & SHA_2008.108.01 & 6395 & 32 & 5955 & 72 & 440 & 6848 & 86 & 6844 & SW Baikal & EN & 2 & \\
\hline 135 & Shamanka II & SHA_2003.030 & 6338 & 33 & 5953 & 72 & 385 & 6846 & 85 & 6842 & SW Baikal & EN & 2 & \\
\hline 136 & Shamanka II & SHA_2004.044.01 & & & 5952 & 52 & 532 & 6819 & 62 & 6821 & SW Baikal & EN & 2 & R_Combine, $\chi^{2}$-Test: $d f=1 \mathrm{~T}=0.2(5 \% 3.8)$ \\
\hline 137 & Roshcha Zvezdochka & ROZ_2008.003 & 6590 & 36 & 5939 & 74 & 651 & 6836 & 85 & 6834 & Angara & EN & & \\
\hline 138 & Shamanka II & SHA_2004.042.01 & 6386 & 34 & 5921 & 73 & 465 & 6820 & 80 & 6819 & SW Baikal & EN & 2 & \\
\hline 139 & Shamanka II & SHA_2008.108.03 & 6373 & 32 & 5915 & 72 & 458 & 6813 & 78 & 6811 & SW Baikal & EN & 2 & \\
\hline
\end{tabular}




\begin{tabular}{|c|c|c|c|c|c|c|c|c|c|c|c|c|c|c|c|}
\hline 140 & Shamanka II & SHA_2005.064.01 & 6381 & 37 & 5902 & 74 & 479 & 6806 & 78 & 6800 & & SW Baikal & EN & 2 & \\
\hline 141 & Shamanka II & SHA_2003.035.01 & 6396 & 33 & 5877 & 72 & 519 & 6785 & 73 & 6777 & & SW Baikal & EN & 2 & \\
\hline 142 & Shamanka II & SHA_1998.006 & 6483 & 37 & 5875 & 74 & 608 & 6786 & 74 & 6778 & & SW Baikal & EN & 2 & \\
\hline 143 & Shamanka II & SHA_2005.059.01 & 6450 & 38 & 5835 & 75 & 615 & 6762 & 70 & 6754 & & SW Baikal & EN & 2 & \\
\hline 144 & Isakovo & ISA_1932.002 & 4913 & 31 & 4715 & 71 & 198 & 5424 & 84 & 5413 & & Angara & $\mathrm{LN}$ & & \\
\hline 145 & Ust' Ida & UID_1989.025.03 & 4903 & 31 & 4710 & 71 & 193 & 5421 & 84 & 5411 & & Angara & $\mathrm{LN}$ & & \\
\hline 146 & Ust' Ida & UID_1988.018 & 4890 & 30 & 4710 & 71 & 180 & 5421 & 84 & 5411 & & Angara & $\mathrm{LN}$ & & \\
\hline 147 & Ust' Ida & UID_1991.038 & 4833 & 39 & 4670 & 75 & 163 & 5386 & 104 & 5392 & & Angara & $\mathrm{LN}$ & & \\
\hline 148 & Ust' Ida & UID_1987.008 & 4824 & 32 & 4666 & 72 & 158 & 5386 & 102 & 5392 & & Angara & $\mathrm{LN}$ & & \\
\hline 149 & Ust' Ida & UID_1991.041 & 4876 & 33 & 4663 & 72 & 213 & 5382 & 104 & 5391 & & Angara & $\mathrm{LN}$ & & \\
\hline 150 & Ust' Ida & UID_1989.020.02 & 4854 & 39 & 4655 & 75 & 199 & 5369 & 114 & 5384 & & Angara & $\mathrm{LN}$ & & \\
\hline 151 & Ust' Ida & UID_1994.052 & 4965 & 30 & 4644 & 71 & 321 & 5359 & 115 & 5379 & & Angara & $\mathrm{LN}$ & & \\
\hline 152 & Ust' Ida & UID_1994.054 & 4857 & 37 & 4617 & 74 & 240 & 5310 & 133 & 5330 & & Angara & $\mathrm{LN}$ & & \\
\hline 153 & Ust' Ida & UID_1989.021.02 & 4921 & 29 & 4597 & 70 & 324 & 5275 & 135 & 5299 & & Angara & $\mathrm{LN}$ & & \\
\hline 154 & Ust' Ida & UID_1987.005 & 4852 & 35 & 4596 & 73 & 256 & 5271 & 137 & 5294 & & Angara & $\mathrm{LN}$ & & \\
\hline 155 & Ust' Ida & UID_1989.020.01 & 4885 & 30 & 4584 & 71 & 301 & 5250 & 134 & 5262 & & Angara & $\mathrm{LN}$ & & \\
\hline 156 & Ust' Ida & UID_1989.026.05 & 4749 & 36 & 4578 & 74 & 171 & 5238 & 135 & 5240 & & Angara & $\mathrm{LN}$ & & \\
\hline 157 & Shamanski Mys & SHM_1976.001.01 & 4902 & 33 & 4572 & 61 & 330 & 5229 & 123 & 5226 & GFS & Little Sea & $\mathrm{LN}$ & & \\
\hline 158 & Ust' Ida & UID_1994.053.01 & 4791 & 30 & 4548 & 71 & 243 & 5194 & 122 & 5181 & & Angara & $\mathrm{LN}$ & & \\
\hline 159 & Sarminskii Mys & SMS_1986.019.05 & 4781 & 33 & 4546 & 61 & 235 & 5190 & 110 & 5176 & GFS & Little Sea & $\mathrm{LN}$ & & \\
\hline 160 & Sarminskii Mys & SMS_1987.029.02 & 4871 & 31 & 4534 & 60 & 337 & 5177 & 105 & 5168 & GFS & Little Sea & $\mathrm{LN}$ & & \\
\hline 161 & Sarminskii Mys & SMS_1986.019.01 & 4846 & 33 & 4507 & 61 & 339 & 5154 & 103 & 5156 & GFS & Little Sea & $\mathrm{LN}$ & & \\
\hline 162 & Sarminskii Mys & SMS_1986.017 & 4680 & 32 & 4412 & 61 & 268 & 5048 & 123 & 5021 & GFS & Little Sea & $\mathrm{LN}$ & & \\
\hline 163 & Sarminskii Mys & SMS_1986.011.01 & 4736 & 33 & 4363 & 61 & 373 & 4979 & 107 & 4954 & GFS & Little Sea & $\mathrm{LN}$ & & \\
\hline 164 & Sarminskii Mys & SMS_1986.011.04 & 4747 & 29 & 4359 & 59 & 388 & 4970 & 101 & 4948 & GFS & Little Sea & $\mathrm{LN}$ & & \\
\hline 165 & Sarminskii Mys & SMS_1986.019.02 & 4751 & 32 & 4283 & 61 & 468 & 4865 & 95 & 4861 & GFS & Little Sea & $\mathrm{LN}$ & & \\
\hline 166 & Shamanski Mys & SHM_1975.001 & & & 4410 & 43 & 514 & 4916 & 42 & 4906 & GFS & Little Sea & EBA & & R_Combine, $\chi^{2}$-Test: $d f=1 \mathrm{~T}=0.5(5 \% 3.8)$ \\
\hline 167 & Sarminskii Mys & SMS_1986.009 & 4732 & 32 & 4350 & 61 & 382 & 4887 & 57 & 4884 & GFS & Little Sea & EBA & & \\
\hline 168 & Ust' Ida & UID_1991.042 & 4551 & 31 & 4248 & 71 & 303 & 4726 & 97 & 4721 & & Angara & EBA & & \\
\hline 169 & Gorodishche II & GO2_1996.003 & 4556 & 32 & 4221 & 72 & 335 & 4699 & 93 & 4699 & & Angara & EBA & & \\
\hline 170 & Gorodishche II & GO2_1996.004 & 4445 & 31 & 4171 & 71 & 274 & 4663 & 95 & 4662 & & Angara & EBA & & \\
\hline 171 & Gorodishche II & GO2_1995.002 & 4543 & 31 & 4145 & 71 & 398 & 4643 & 99 & 4640 & & Angara & EBA & & \\
\hline 172 & Obkhoi & OBK_1976.003 & 4391 & 32 & 4138 & 51 & 253 & 4654 & 88 & 4648 & & Upper Lena & EBA & & \\
\hline 173 & Kurma XI & KUR_2002.009 & 4515 & 21 & 4076 & 56 & 439 & 4577 & 101 & 4562 & GFS & Little Sea & EBA & & R_Combine, $\chi^{2}$-Test: $d f=1 \mathrm{~T}=1.3(5 \% 3.8)$ \\
\hline 174 & Obkhoi & OBK_1971.013 & 4352 & 31 & 4021 & 51 & 331 & 4496 & 79 & 4486 & & Upper Lena & EBA & & \\
\hline 175 & Makrushino & MAK_1992.018 & 4490 & 31 & 3986 & 51 & 504 & 4447 & 78 & 4452 & & Upper Lena & EBA & & \\
\hline 176 & Kurma XI & KUR_2003.025 & 4414 & 30 & 3938 & 60 & 476 & 4362 & 91 & 4361 & GFS & Little Sea & EBA & & \\
\hline 177 & Kurma XI & KUR_2003.026 & 4283 & 27 & 3930 & 58 & 353 & 4352 & 87 & 4352 & GFS & Little Sea & EBA & & \\
\hline 178 & Makrushino & MAK_1992.019 & 4199 & 30 & 3917 & 50 & 282 & 4338 & 75 & 4339 & & Upper Lena & EBA & & \\
\hline 179 & Obkhoi & OBK_1971.003.02 & 3950 & 30 & 3911 & 50 & 39 & 4332 & 75 & 4333 & & Upper Lena & EBA & & \\
\hline 180 & Badai & BAD_1920.000 & 4052 & 29 & 3898 & 70 & 154 & 4308 & 99 & 4311 & & Angara & EBA & & \\
\hline 181 & Ust' Belaia & UBE_1957.002 & 4073 & 21 & 3893 & 67 & 180 & 4304 & 95 & 4308 & & Angara & EBA & & R_Combine, $\chi^{2}$-Test: $d f=1 \mathrm{~T}=1.9(5 \% 3.8)$ \\
\hline 182 & Obkhoi & OBK_1971.001.02 & & & 3892 & 35 & 222 & 4323 & 59 & 4326 & & Upper Lena & EBA & & R_Combine, $\chi^{2}$-Test: $d f=1 \mathrm{~T}=1.3(5 \% 3.8)$ \\
\hline 183 & Makrushino & MAK_1992.013.00 & 4242 & 30 & 3892 & 50 & 350 & 4312 & 76 & 4316 & & Upper Lena & EBA & & \\
\hline 184 & Kurma XI & KUR_2003.018 & 4233 & 31 & 3869 & 60 & 364 & 4281 & 90 & 4284 & GFS & Little Sea & EBA & & \\
\hline 185 & Khadarta IV & KHA_2010.011 & 4137 & 31 & 3868 & 60 & 269 & 4280 & 90 & 4283 & GFS & Little Sea & EBA & & \\
\hline
\end{tabular}




\begin{tabular}{|c|c|c|c|c|c|c|c|c|c|c|c|c|c|c|}
\hline 186 & Obkhoi & OBK_1971.001.03 & 3999 & 30 & 3856 & 50 & 143 & 4272 & 82 & 4272 & & Upper Lena & EBA & \\
\hline 187 & Makarovo & MKV_1973.001 & 4215 & 32 & 3853 & 51 & 362 & 4267 & 84 & 4267 & & Upper Lena & EBA & \\
\hline 188 & Obkhoi & OBK_1971.007 & 4073 & 30 & 3852 & 50 & 221 & 4267 & 83 & 4266 & & Upper Lena & EBA & \\
\hline 189 & Khadarta IV & KHA_2010.015 & 4111 & 31 & 3849 & 60 & 262 & 4258 & 93 & 4258 & GFS & Little Sea & EBA & \\
\hline 190 & Kurma XI & KUR_2002.007.01 & 4181 & 36 & 3845 & 63 & 336 & 4251 & 97 & 4251 & GFS & Little Sea & EBA & \\
\hline 191 & Kulgana & KUL_1977.000 & 4230 & 31 & 3835 & 60 & 395 & 4240 & 96 & 4238 & GFS & Little Sea & EBA & \\
\hline 192 & Kurma XI & KUR_2002.013 & 4189 & 31 & 3831 & 60 & 358 & 4235 & 96 & 4232 & GFS & Little Sea & EBA & \\
\hline 193 & Kurma XI & KUR_2002.014 & 4158 & 28 & 3826 & 59 & 332 & 4228 & 96 & 4225 & GFS & Little Sea & EBA & \\
\hline 194 & Obkhoi & OBK_1971.001.01 & 4121 & 18 & 3821 & 44 & 300 & 4223 & 80 & 4215 & & Upper Lena & EBA & R_Combine, $\chi^{2}$-Test: $d f=2 T=1.1(5 \% 6.0)$ \\
\hline 195 & Kurma XI & KUR_2002.010 & 4300 & 26 & 3820 & 58 & 480 & 4220 & 96 & 4215 & GFS & Little Sea & EBA & \\
\hline 196 & Kurma XI & KUR_2002.003 & 4207 & 33 & 3811 & 61 & 396 & 4206 & 100 & 4203 & GFS & Little Sea & EBA & \\
\hline 197 & Kurma XI & KUR_2002.012 & 3979 & 33 & 3804 & 61 & 175 & 4196 & 101 & 4193 & GF & Little Sea & EBA & \\
\hline 198 & Kurma XI & KUR_2002.005 & 4204 & 31 & 3801 & 60 & 403 & 4191 & 100 & 4189 & GFS & Little Sea & EBA & \\
\hline 199 & Obkhoi & OBK_1971.004.01 & 4089 & 29 & 3800 & 50 & 289 & 4189 & 88 & 4187 & & Upper Lena & EBA & \\
\hline 200 & Ust' Ida & UID_1991.039 & 3890 & 33 & 3798 & 72 & 92 & 4185 & 113 & 4183 & & Angara & EBA & \\
\hline 201 & Kurma XI & KUR_2002.007.02 & 4240 & 34 & 3797 & 62 & 443 & 4185 & 102 & 4182 & GFS & Little Sea & EBA & \\
\hline 202 & Sarminskii Mys & SMS_1986.012 & 4092 & 30 & 3796 & 60 & 296 & 4183 & 100 & 4181 & GFS & Little Sea & EBA & \\
\hline 203 & Obkhoi & OBK_1971.003.01 & 4070 & 31 & 3796 & 51 & 274 & 4183 & 89 & 4181 & & Upper Lena & EBA & \\
\hline 204 & Kurma XI & KUR_2003.017 & 4289 & 25 & 3790 & 58 & 499 & 4174 & 98 & 4172 & GFS & Little Sea & EBA & \\
\hline 205 & Sarminskii Mys & SMS_1987.033 & 4065 & 27 & 3789 & 58 & 276 & 4172 & 98 & 4170 & GFS & Little Sea & EBA & \\
\hline 206 & Khadarta IV & KHA_2010.005 & 4114 & 31 & 3783 & 60 & 331 & 4163 & 100 & 4160 & GFS & Little Sea & EBA & \\
\hline 207 & Khuzhir-Nuge XIV & K14_2000.077 & 3790 & 21 & 3776 & 56 & 14 & 4151 & 94 & 4148 & GF & Little Sea & EBA & R_Combine, $\chi^{2}$-Test: $d f=1 \mathrm{~T}=0.3(5 \% 3.8)$ \\
\hline 208 & Kurma XI & KUR_2002.001 & 3954 & 31 & 3773 & 60 & 181 & 4147 & 99 & 4144 & GF & Little Sea & EBA & \\
\hline 209 & Obkhoi & OBK_1971.004.02 & 4000 & 29 & 3773 & 50 & 227 & 4144 & 86 & 4143 & & Upper Lena & EBA & \\
\hline 210 & Kurma XI & KUR_2003.019 & 4121 & 25 & 3759 & 58 & 362 & 4124 & 95 & 4122 & GF & Little Sea & EBA & \\
\hline 211 & Kurma XI & KUR_2002.006 & 4157 & 32 & 3757 & 61 & 400 & 4122 & 98 & 4120 & GFS & Little Sea & EBA & \\
\hline 212 & Shamanski Mys & SHM_1973.001 & 4153 & 32 & 3747 & 61 & 406 & 4107 & 96 & 4105 & GFS & Little Sea & EBA & \\
\hline 213 & Khadarta IV & KHA_2010.009 & 4019 & 31 & 3745 & 60 & 274 & 4104 & 95 & 4102 & GFS & Little Sea & EBA & \\
\hline 214 & Obkhoi & OBK_1971.014.02 & 3929 & 29 & 3742 & 50 & 187 & 4095 & 80 & 4097 & & Upper Lena & EBA & \\
\hline 215 & Kurma XI & KUR_2002.015 & 4078 & 30 & 3741 & 60 & 337 & 4098 & 94 & 4096 & GF & Little Sea & EBA & \\
\hline 216 & Sarminskii Mys & SMS 1986.013 & 4221 & 31 & 3737 & 60 & 484 & 4092 & 93 & 4090 & GFS & Little Sea & EBA & \\
\hline 217 & Obkhoi & OBK_1971.014.01 & 3977 & 30 & 3736 & 50 & 241 & 4087 & 79 & 4088 & & Upper Lena & EBA & \\
\hline 218 & Khadarta IV & KHA_2010.008 & 4191 & 30 & 3714 & 60 & 477 & 4060 & 88 & 4055 & GFS & Little Sea & EBA & \\
\hline 219 & Manzurka & MNZ_1974.004.01 & 3985 & 29 & 3706 & 50 & 279 & 4047 & 74 & 4044 & & Upper Lena & EBA & \\
\hline 220 & Ust' Iamnaia & UIA_1977.005 & 4137 & 30 & 3691 & 50 & 446 & 4029 & 73 & 4030 & & Upper Lena & EBA & \\
\hline 221 & Khuzhir-Nuge XIV & K14_1998.037.01 & 3803 & 31 & 3690 & 60 & 113 & 4030 & 85 & 4029 & GF & Little Sea & EBA & \\
\hline 222 & Kurma XI & KUR_2002.016 & 4169 & 27 & 3679 & 58 & 490 & 4016 & 82 & 4015 & GFS & Little Sea & EBA & \\
\hline 223 & Kurma XI & KUR_2002.004 & 4132 & 22 & 3667 & 56 & 465 & 4001 & 79 & 3998 & GFS & Little Sea & EBA & R_Combine, $\chi^{2}$-Test: $d f=1 \mathrm{~T}=0.3(5 \% 3.8)$ \\
\hline 224 & Khadarta IV & KHA_2010.012 & 4001 & 29 & 3664 & 59 & 337 & 3998 & 82 & 3994 & GFS & Little Sea & EBA & \\
\hline 225 & Shamanski Mys & SHM_1973.002 & 4150 & 30 & 3657 & 60 & 493 & 3989 & 83 & 3984 & GFS & Little Sea & EBA & \\
\hline 226 & Ust' lamnaia & UIA_surface & 3957 & 29 & 3641 & 50 & 316 & 3968 & 72 & 3961 & & Upper Lena & EBA & \\
\hline 227 & Khuzhir-Nuge XIV & K14_1999.057.02 & 3969 & 29 & 3639 & 59 & 330 & 3967 & 82 & 3961 & GFS & Little Sea & EBA & \\
\hline 228 & Khuzhir-Nuge XIV & K14_2001.087 & 3833 & 30 & 3637 & 60 & 196 & 3965 & 83 & 3958 & GF & Little Sea & EBA & \\
\hline 229 & Shamanski Mys & SHM_1972.002 & & & 3634 & 43 & 436 & 3957 & 65 & 3950 & GFS & Little Sea & EBA & R_Combine, $\chi^{2}$-Test: $d f=1 \mathrm{~T}=0.4(5 \% 3.8)$ \\
\hline 230 & Ulus Khalskii & UKH_1930.000 & 3991 & 30 & 3619 & 50 & 372 & 3940 & 72 & 3934 & & Upper Lena & EBA & \\
\hline 231 & Khadarta IV & KHA_2003.003 & 4048 & 22 & 3614 & 56 & 434 & 3935 & 79 & 3930 & GFS & Little Sea & EBA & R_Combine, $\chi^{2}$-Test: $d f=1 \mathrm{~T}=1.4(5 \% 3.8)$ \\
\hline 232 & Obkhoi & OBK_1971.005 & 3888 & 31 & 3608 & 51 & 280 & 3926 & 73 & 3921 & & Upper Lena & EBA & \\
\hline 233 & Manzurka & MNZ_1974.001 & 3938 & 29 & 3595 & 50 & 343 & 3908 & 71 & 3905 & & Upper Lena & EBA & \\
\hline
\end{tabular}




\begin{tabular}{|c|c|c|c|c|c|c|c|c|c|c|c|c|}
\hline 234 & Sarminskii Mys & SMS_1987.021 & 3813 & 27 & 3594 & 58 & 219 & 3909 & 81 & 3906 & GF & Little Sea \\
\hline 235 & Shamanka II & SHA_2000.009 & 3886 & 21 & 3593 & 67 & 293 & 3911 & 90 & 3907 & & SW Baikal \\
\hline 236 & Shamanski Mys & SHM_1972.001.01 & 4045 & 31 & 3582 & 60 & 463 & 3894 & 83 & 3892 & GFS & Little Sea \\
\hline 237 & Khuzhir-Nuge XIV & K14_1998.036.01 & 3800 & 30 & 3582 & 60 & 218 & 3894 & 83 & 3892 & GF & Little Sea \\
\hline 238 & Shamanka II & SHA_2008.103.02 & 3746 & 28 & 3578 & 70 & 168 & 3894 & 92 & 3890 & & SW Baikal \\
\hline 239 & Shamanski Mys & SHM_1973.004 & 4056 & 30 & 3575 & 60 & 481 & 3885 & 82 & 3883 & GFS & Little Sea \\
\hline 240 & Khadarta IV & KHA_2010.007 & 4091 & 31 & 3556 & 60 & 535 & 3862 & 79 & 3861 & GFS & Little Sea \\
\hline 241 & Khuzhir-Nuge XIV & K14_1999.045 & 3829 & 29 & 3540 & 59 & 289 & 3843 & 75 & 3842 & GFS & Little Sea \\
\hline 242 & Borki & BO1_1971.002 & 3742 & 30 & 3539 & 50 & 203 & 3834 & 67 & 3838 & & Upper Lena \\
\hline 243 & Khuzhir-Nuge XIV & K14_1998.037.02 & 3727 & 22 & 3538 & 56 & 189 & 3838 & 71 & 3839 & GF & Little Sea \\
\hline 244 & Obkhoi & OBK_1971.010 & 3922 & 28 & 3535 & 49 & 387 & 3829 & 65 & 3833 & & Upper Lena \\
\hline 245 & Shamanka II & SHA_2008.107 & 3764 & 20 & 3531 & 67 & 233 & 3841 & 79 & 3837 & & SW Baikal \\
\hline 246 & Borki & BO2_1971.002 & & & 3506 & 36 & 283 & 3792 & 46 & 3792 & & Upper Lena \\
\hline 247 & Khuzhir-Nuge XIV & K14_1999.049 & 3888 & 30 & 3506 & 60 & 382 & 3812 & 66 & 3810 & GFS & Little Sea \\
\hline 248 & Borki & BO1_1971.001 & 3844 & 29 & 3503 & 50 & 341 & 3801 & 56 & 3800 & & Upper Lena \\
\hline 249 & Glazkovo & GLZ_1887.006 & 3684 & 29 & 3502 & 70 & 182 & 3819 & 74 & 3815 & & Angara \\
\hline 250 & Khadarta IV & KHA_2010.006 & 4015 & 30 & 3494 & 60 & 521 & 3804 & 63 & 3802 & GFS & Little Sea \\
\hline 251 & Shamanka II & SHA_2008.109 & 3724 & 33 & 3490 & 72 & 234 & 3813 & 72 & 3809 & & SW Baikal \\
\hline 252 & Shamanka II & SHA_2008.103.01 & 3650 & 28 & 3486 & 70 & 164 & 3809 & 69 & 3806 & & SW Baikal \\
\hline 253 & Borki & BO2_1971.003 & 3740 & 29 & 3475 & 50 & 265 & 3785 & 51 & 3790 & & Upper Lena \\
\hline 254 & Shamanski Mys & SHM_1973.003.01 & 4010 & 30 & 3474 & 60 & 536 & 3793 & 58 & 3795 & GFS & Little Sea \\
\hline 255 & Ust' Ida & UID_1994.048 & 3854 & 30 & 3437 & 71 & 417 & 3786 & 61 & 3791 & & Angara \\
\hline 256 & Shamanka II & SHA_2008.111 & 3700 & 33 & 3409 & 72 & 291 & 3777 & 60 & 3785 & & SW Baikal \\
\hline
\end{tabular}

Note: records are grouped by "Typological period" and sorted by "Corrected date BP".

\section{Records removed from chronological analysis.}

\begin{tabular}{|c|c|c|c|c|c|c|}
\hline 257 & Lokomotiv-Raisovet & LOR_1997.011 & 6923 & 27 & 6384 & 70 \\
\hline 258 & Shamanka II & SHA_2004.042.02 & & & 6890 & 52 \\
\hline 259 & Shamanka II & SHA_2008.106 & 2633 & 27 & 2583 & 70 \\
\hline 260 & lushino I & IUSH_0000.000 & 5165 & 32 & 4567 & 186 \\
\hline 261 & lushino & IUSH_2007.000.00 & 6897 & 28 & 6366 & 186 \\
\hline 262 & Manzurka & MNZ_1974.002 & 5189 & 32 & 4632 & 186 \\
\hline 263 & Nikolskii Grot & NGT_1982.001.01 & 8070 & 45 & 7465 & 189 \\
\hline 264 & Nikolskii Grot & NGT_1982.001.02 & 6983 & 38 & 6194 & 188 \\
\hline 265 & Nikolskii Grot & NGT_1982.002.01 & 6980 & 40 & 6067 & 188 \\
\hline 266 & Nikolskii Grot & NGT_surface & 7136 & 35 & 6406 & 187 \\
\hline 267 & Popovskii Lug 2 & POP2_2010.001 & 6618 & 35 & 5935 & 187 \\
\hline 268 & Turuka & TUR_1992.002 & 6795 & 36 & 6290 & 187 \\
\hline 269 & Turuka & TUR_1992.004 & 5289 & 33 & 4611 & 187 \\
\hline 270 & Turuka & TUR_1993.005 & 5214 & 33 & 4637 & 187 \\
\hline 271 & Zakuta & ZAK_1993.001 & 5121 & 30 & 4694 & 186 \\
\hline 272 & Zakuta & ZAK_1994.002 & 5189 & 30 & 4657 & 186 \\
\hline 273 & Zakuta & ZAK_1994.003 & 5136 & 32 & 4408 & 186 \\
\hline 274 & Zakuta & ZAK_1994.005 & 4926 & 33 & 4247 & 187 \\
\hline 275 & Zapleskino & ZAP 0000.003 & 5138 & 31 & 4604 & 186 \\
\hline
\end{tabular}

$\begin{array}{cc}\text { Angara } & \text { EN } \\ \text { SW Baikal } & \text { EN } \\ \text { SW Baikal } & \text { LBA } \\ \text { Upper Lena } & \text { LM or EN } \\ \text { Upper Lena } & \text { LM or EN } \\ \text { Upper Lena } & \text { LM or EN } \\ \text { Upper Lena } & \text { LN } \\ \text { Upper Lena } & \text { LN } \\ \text { Upper Lena } & \text { LN } \\ \text { Upper Lena } & \text { LN } \\ \text { Upper Lena } & \text { LM or EN } \\ \text { Upper Lena } & \text { EN } \\ \text { Upper Lena } & \text { EN } \\ \text { Upper Lena } & \text { EN } \\ \text { Upper Lena } & \text { LN } \\ \text { Upper Lena } & \text { LN } \\ \text { Upper Lena } & \text { LN } \\ \text { Upper Lena } & \text { LN } \\ \text { Upper Lena } & \text { LN }\end{array}$

R_Combine, $\chi^{2}$-Test: $d f=1 \mathrm{~T}=3.4(5 \% 3.8)$

R_Combine, $\chi^{2}$-Test: $d f=1 \mathrm{~T}=0.0(5 \% 3.8)$

R_Combine, $\chi^{2}$-Test: $d f=1 \mathrm{~T}=3.2(5 \% 3.8)$ 
Table 2

Table 2

Micro-region

Angara

LM LM or EN

Little Sea

1
7

SW Baikal

7

Upper Lena

Column totals

2

8

EN

LN

EBA Row totals

$\begin{array}{ccc}14 & 9 & 76 \\ 8 & 49 & 64\end{array}$

83

$6 \quad 89$

\begin{tabular}{cccc} 
& & 27 & 27 \\
\hline 133 & 22 & 91 & 256
\end{tabular}

$8 \quad 133$

91 
Table 3

TRAPEZIUM DISTRIBUTION MODEL

Cis-Baikal

LM Start

LM End

LM Span

LM Interval

EN Start

EN Span

EN Interval

MN Start

MN End

MN Span

MN Interval

LN Start

LN End

LN Span

LN Interval

EBA Start

EBA End

EBA Span

EBA Interval $68.2 \% \mathrm{cal}$ y $B P$

$\begin{array}{ccc}8418-8069 & 8609-7967 & 8277 \pm 176 \\ 7516-7488 & 7532-7475 & 7503 \pm 14 \\ 793-913 & 687-965 & 842 \pm 67 \\ 564-913 & 465-1109 & 774 \pm 176\end{array}$

$\begin{array}{ccc}7516-7488 & 7532-7475 & 7503 \pm 14 \\ 7065-6999 & 7090-6958 & 7027 \pm 33 \\ 764-850 & 722-897 & 809 \pm 43 \\ 433-508 & 407-552 & 476 \pm 37\end{array}$

7065-6999

5626-5471

n/a

1389-1562

7090-6958

$7027 \pm 33$

5759-5413

$5571 \pm 88$

$\mathrm{n} / \mathrm{a}$

$\mathrm{n} / \mathrm{a}$

1258-1630

$1456 \pm 94$

5626-5471

4674-4524

5759-5413

$5571 \pm 88$

588-738

4747-4438

$4597 \pm 76$

839-1078

513-873

$679 \pm 87$

728-1238

$973 \pm 126$

4674-4524

3760-3694

4747-4438

$4597 \pm 76$

3795-3657

1115-1336

$3726 \pm 34$

1153-1263

683-1048

$1218 \pm 56$

$871 \pm 91$
UNIFORM DISTRIBUTION MODEL

\begin{tabular}{ccc}
$68.2 \%$ cal y BP & $95.4 \%$ cal y BP & $\mu \pm \sigma$ \\
\hline $8510-8282$ & $8672-8217$ & $8428 \pm 124$ \\
$7529-7499$ & $7553-7486$ & $7516 \pm 16$ \\
$702-892$ & $663-926$ & $811 \pm 70$ \\
$781-994$ & $695-1158$ & $912 \pm 125$ \\
& & \\
$7529-7499$ & $7553-7486$ & $7516 \pm 16$ \\
$6842-6780$ & $6861-6740$ & $6805 \pm 31$ \\
$660-731$ & $637-776$ & $701 \pm 35$ \\
$669-743$ & $644-788$ & $711 \pm 36$ \\
& & \\
$6842-6780$ & $6861-6740$ & $6805 \pm 31$ \\
$5547-5436$ & $5629-5402$ & $5506 \pm 59$ \\
$\mathrm{n} / \mathrm{a}$ & $\mathrm{n} / \mathrm{a}$ & $\mathrm{n} / \mathrm{a}$ \\
$1245-1377$ & $1163-1422$ & $1300 \pm 66$ \\
& & \\
$5547-5436$ & $5629-5402$ & $5506 \pm 59$ \\
$4918-4873$ & $4950-4860$ & $4901 \pm 24$ \\
$482-597$ & $443-674$ & $549 \pm 58$ \\
$529-658$ & $484-741$ & $604 \pm 66$ \\
& & \\
$4918-4873$ & $4950-4860$ & $4901 \pm 24$ \\
$3733-3672$ & $3760-3629$ & $3698 \pm 32$ \\
$1138-1207$ & $1108-1253$ & $1177 \pm 35$ \\
$1159-1239$ & $1125-1289$ & $1204 \pm 41$
\end{tabular}




\begin{tabular}{|c|}
\hline No. \\
\hline Angara \\
\hline 1 \\
\hline 2 \\
\hline 3 \\
\hline 4 \\
\hline 5 \\
\hline 6 \\
\hline 7 \\
\hline 8 \\
\hline 9 \\
\hline 10 \\
\hline 11 \\
\hline 12 \\
\hline 13 \\
\hline 14 \\
\hline 15 \\
\hline 16 \\
\hline 17 \\
\hline 18 \\
\hline 19 \\
\hline 20 \\
\hline 21 \\
\hline 22 \\
\hline 23 \\
\hline 24 \\
\hline 25 \\
\hline 26 \\
\hline 27 \\
\hline 28 \\
\hline 29 \\
\hline 30 \\
\hline 31 \\
\hline 32 \\
\hline 33 \\
\hline 34 \\
\hline 35 \\
\hline 36 \\
\hline 37 \\
\hline 38 \\
\hline 39 \\
\hline 40 \\
\hline 41 \\
\hline 42 \\
\hline 43 \\
\hline 44 \\
\hline 45 \\
\hline 46 \\
\hline 47 \\
\hline 48 \\
\hline 49 \\
\hline 50 \\
\hline 51 \\
\hline 52 \\
\hline 53 \\
\hline 54 \\
\hline 55 \\
\hline 56 \\
\hline 57 \\
\hline 58 \\
\hline 59 \\
\hline 60 \\
\hline 61 \\
\hline 62 \\
\hline 63 \\
\hline 64 \\
\hline 65 \\
\hline 66 \\
\hline 67 \\
\hline 68 \\
\hline 69 \\
\hline 70 \\
\hline 71 \\
\hline 72 \\
\hline 73 \\
\hline 74 \\
\hline 75 \\
\hline 76 \\
\hline 77 \\
\hline 78 \\
\hline 79 \\
\hline 80 \\
\hline 81 \\
\hline 82 \\
\hline Little Se \\
\hline 83 \\
\hline 84 \\
\hline 85 \\
\hline 86 \\
\hline 87 \\
\hline 8 \\
\hline 89 \\
\hline 90 \\
\hline 91 \\
\hline 92 \\
\hline 93 \\
\hline 94 \\
\hline 95 \\
\hline
\end{tabular}




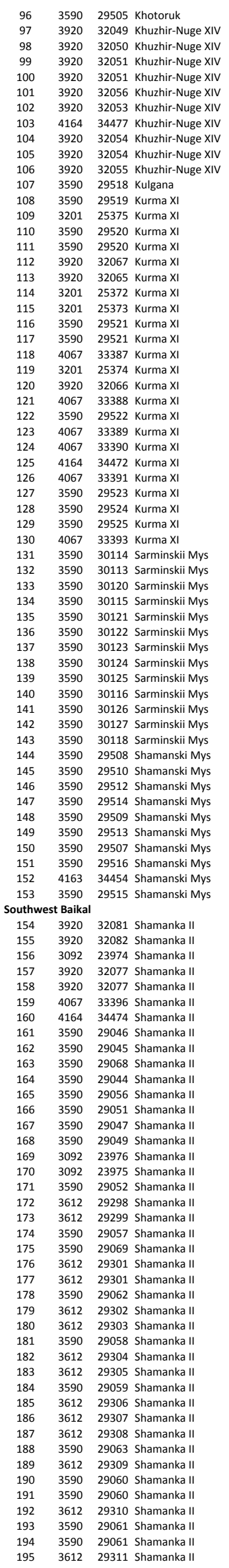

KHO_1978.007 K14_1998.036.01 K14_1998.037.01 K14_1998.037.02 K14_1998.037.02 K14_1998.037.02 K14_1999.045 K14_1999.057.02 K14_2000.077 K14_2000.077 K14 2001.087 KUL_1977.000 KUR_2002.001 KUR 2002.003 KUR 2002.004 KUR_2002.004 KUR 2002.005 KUR_2002.006 KUR_2002.007.01 (U) (UR_2002.009 KUR_2002.009 KUR_2002.010 KUR_2002.012 KUR_2002.013 KUR_2002.014 KUR_2002.015 KUR_2002.016 KUR 2003.017 KUR 2003.018 KUR_2003.018 KUR_2003.019 KUR_2003.024 KUR_2003.025 KUR_2003.026 SMS_1986.00 SMS_1986.011.01 SMS_1986.011.04 SMS_1986.012 SMS_1986.013 SMS_1986.017 SMS_1986.019.01 SMS_1986.019.02 SMS_1986.019.05 SMS_1987.02 SMS 1987.022 SMS_1987.029.00 SMS_1987.033 SHM_1972.001.01 SHM_1972.002 SHM_1972.002 SHM_1973.001 SHM_1973.002 SHM_1973.003.01 SHM_1973.004

SHM_1975.001 SHM 1975.001 SHM_1976.001.01

SHA_1998.004 SHA_1998.00 SHA_1999.007 SHA_2000.009 SHA_2000.009 SHA_2001.016 SHA_2001.016 SHA_2002.021.02 SHA_2002.022 SHA_2002.022 SHA_2002.023.05 SHA_2002.024.02 SHA_2002.025.01 SHA_2002.025.01 SHA_2003.026.02 SHA_2003.027.01 SHA_2003.030 SHA_2003.032 SHA_2003.033 SHA_2003.034 SHA_2004.039 SHA_2004.039

SHA_2004.039

SHA_2004.039

SHA_2004.041

SHA_2004.041

SHA_2004.042.01

SHA_2004.042.02

SHA_2004.042.02

SHA_2004.043

SHA_2004.044.01

SHA_2004.044.01

SHA_2004.045

SHA_2004.046

SHA_2004.046

SHA_2004.047

SHA_2004.047

SHA_2004.048.01

SHA_2004.048.01

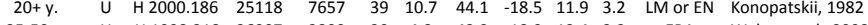
$\begin{array}{llllllllllll}35-50 \mathrm{y} . & \mathrm{U} & \mathrm{H} 1998.318 & 26907 & 3800 & 30 & 4.8 & 42.2 & -18.9 & 12.4 & 3.2\end{array}$

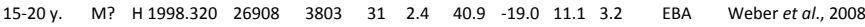
$\begin{array}{llllllllllll}15-20 y . & \text { M? } & \text { H } 1998.393 & 26909 & 3688 & 30 & 3.7 & 41.5 & -19.2 & 11.7 & 3.2 & \text { EBA } \quad \text { Weber et al., } 2008\end{array}$ $\begin{array}{lllllllllllll}15-20 y & \text { M? } & \text { H } 1998.393 & 27554 & 3768 & 31 & 3.7 & 42.0 & -19.1 & 11.7 & 3.2 & \text { EBA } & \text { Weber et al, } 2008\end{array}$

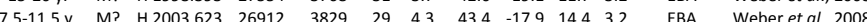

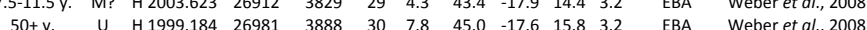

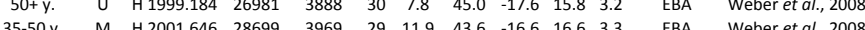

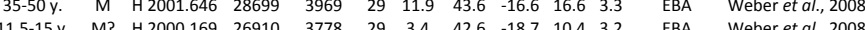

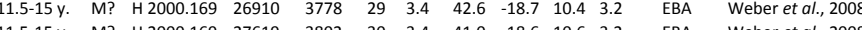

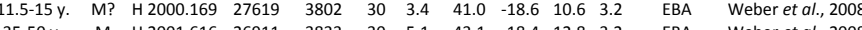

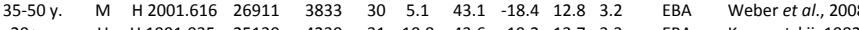

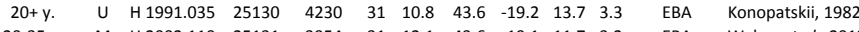

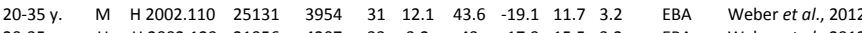

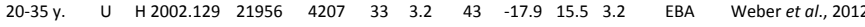

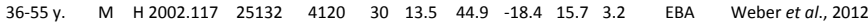

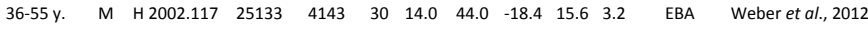

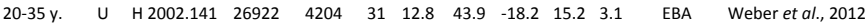
$\begin{array}{lllllllllllll}20-35 y & F & H & 2002.113 & 26920 & 4157 & 32 & 15.2 & 44.3 & -18.6 & 14.7 & 3.1 & \text { EBA Weber etal, } 2012\end{array}$

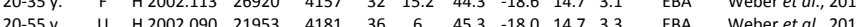

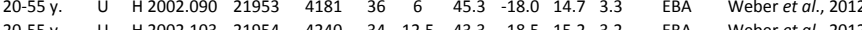

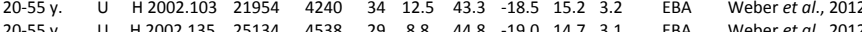

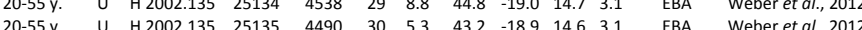

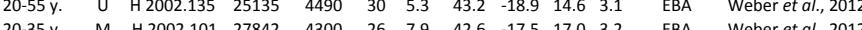

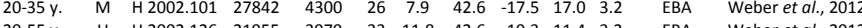

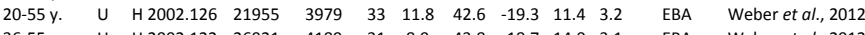

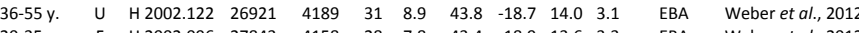

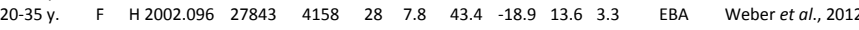

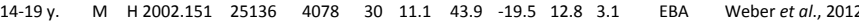

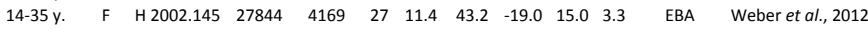

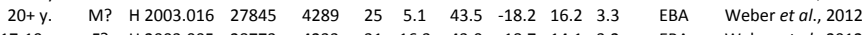

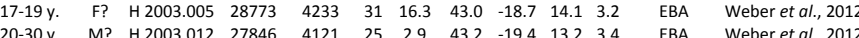

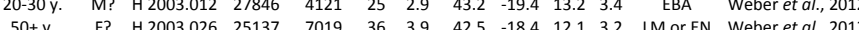

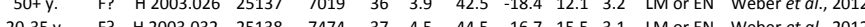

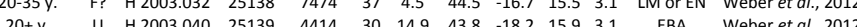
$\begin{array}{lllllllllll}20+y . & H & 2003.040 & 25139 & 4414 & 30 & 14.9 & 43.8 & -18.2 & 15.9 & 3.1\end{array}$ EBA Weber et al., 2012

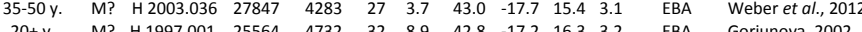

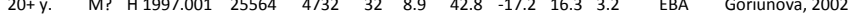

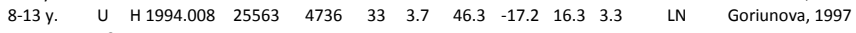

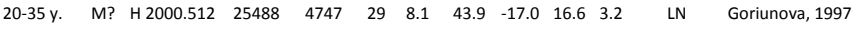

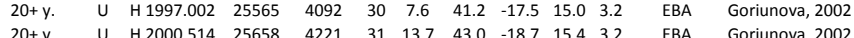
$\begin{array}{lllllllllllll}20-35 \mathrm{y} . & \mathrm{M} & \mathrm{H} 2000.515 & 25566 & 4680 & 32 & 12.7 & 46.7 & -17.4 & 14.8 & 3.2 & \text { LN } & \text { Goriunova, } 1997\end{array}$ $\begin{array}{lllllllllllll}14-19 y . & \text { M } & \text { H } 2000.516 & 25567 & 4846 & 33 & 2.9 & 35.0 & -17.7 & 15.2 & 3.3 & \text { LN } & \text { Goriunova, } 1997\end{array}$ $\begin{array}{lllllllllllll}56+\mathrm{y} . & \mathrm{M} & \mathrm{H} 2000.517 & 25568 & 4751 & 32 & 6.7 & 44.7 & -18.4 & 15.6 & 3.3 & \text { LN } & \text { Goriunova, } 1997\end{array}$

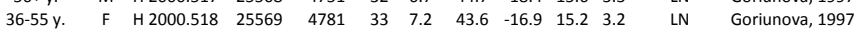

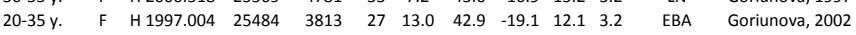
$\begin{array}{llllllllllll}20-35 \mathrm{y} & \text { F? } & \mathrm{H} 2000.520 & 25570 & 7078 & 38 & 2.8 & 44.0 & -17.9 & 12.8 & 3.3 & \text { LM or EN Goriunova, } 1997\end{array}$ $\begin{array}{llllllllllll}8-13 y . & \text { U } & \text { H } 2000.521 & 25571 & 4871 & 31 & 11.6 & 42.6 & -17.1 & 16.0 & 3.2 & \text { LN Goriunova, } 1997\end{array}$ $\begin{array}{lllllllllllll}36-55 \mathrm{y} & \mathrm{F} & \mathrm{H} 1997.006 & 25486 & 4065 & 27 & 8.2 & 43.5 & -18.3 & 13.8 & 3.2 & \text { EBA } & \text { Goriunova, } 2002\end{array}$

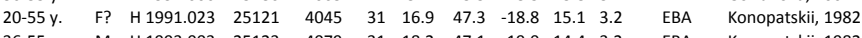

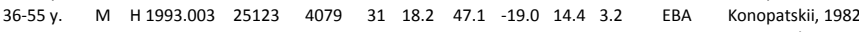

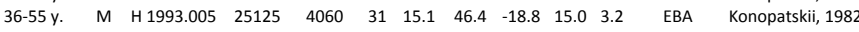

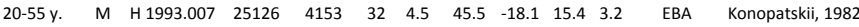

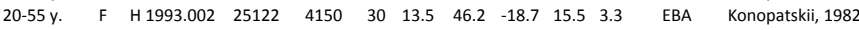

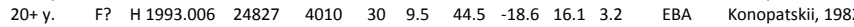
$\begin{array}{llllllllllllll}20+y & U & H & 1991.021 & 25120 & 4056 & 30 & 11.1 & 45.1 & -18.4 & 15.7 & 3.2 & \text { EBA } & \text { Konopatskii, } 1982\end{array}$ $\begin{array}{lllllllllllll}20-35 y & M & H & 2000.204 & 25128 & 4887 & 33 & 11.2 & 45.3 & -17.3 & 17.5 & 3.2 & \text { EBA Konopatskii, } 1982\end{array}$

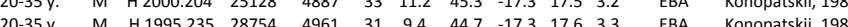
$\begin{array}{ccccccccccccc}20-35 \mathrm{y} . & \mathrm{M} & \mathrm{H} 1995.235 & 28754 & 4961 & 31 & 9.4 & 44.7 & -17.3 & 17.6 & 3.3 & \text { EBA } & \text { Konopatskii, } 1982 \\ 20+\mathrm{y} . & \mathrm{U} & \mathrm{H} 1993.008 & 25127 & 4902 & 33 & 4.0 & 45.8 & -16.9 & 16.2 & 3.3 & \text { LN } & \text { Konopatskii, } 1982\end{array}$

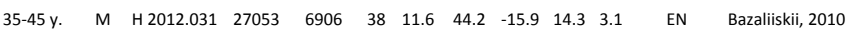

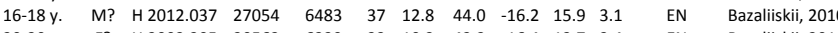

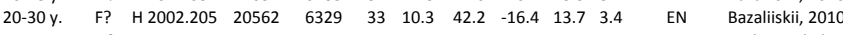

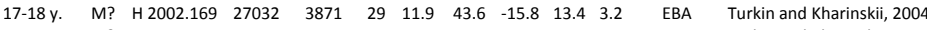
$\begin{array}{llllllllllll}17-18 y . & \text { M? } & \text { H } 2002.169 & 27033 & 3900 & 29 & 11.7 & 43.8 & -15.9 & 13.5 & 3.2 & \text { EBA }\end{array}$

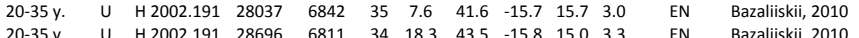

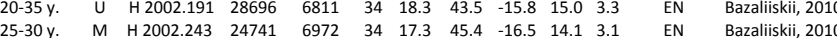

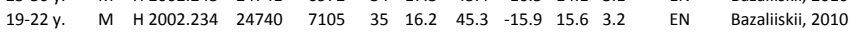
$\begin{array}{llllllllllllll}19-22 y . & M & H & 2009.133 & 24797 & 7059 & 37 & 14.6 & 44.3 & -16.0 & 15.7 & 3.2 & \text { EN } & \text { Bazaliiskii, } 2010\end{array}$

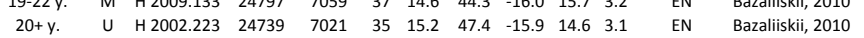

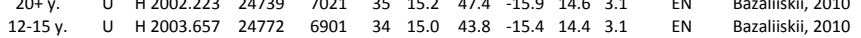
$\begin{array}{lllllllllllll}20-22 \text { y. } & \text { F } & \text { H } 2003.562 & 24746 & 6897 & 35 & 13.1 & 44.5 & -15.5 & 14.8 & 3.0 & \text { EN } & \text { Bazaliiskii, } 2010\end{array}$ $\begin{array}{llllllllllll}20+y . & M\end{array}$

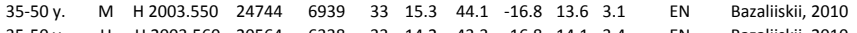

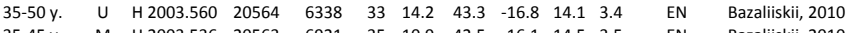

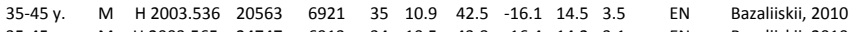
$\begin{array}{lllllllllllll}35-45 \text { y. } & \text { M } & \text { H } 2003.565 & 24747 & 6913 & 34 & 10.5 & 43.8 & -16.4 & 14.2 & 3.1 & \text { EN } & \text { Bazaliiskii, } 2010\end{array}$

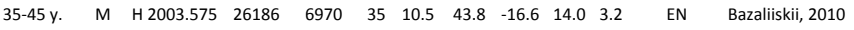

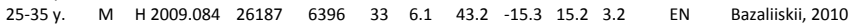

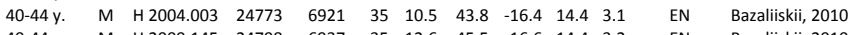
$\begin{array}{lllllllllllll}40-44 y . & \text { M } & \text { H } 2009.145 & 24798 & 6937 & 35 & 12.6 & 45.5 & -16.6 & 14.4 & 3.2 & \text { EN } & \text { Bazaliiskii, } 2010\end{array}$

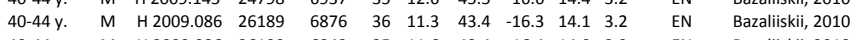
$\begin{array}{lllllllllllll}40-44 \text { y. } & \text { M } & \text { H } 2009.086 & 26190 & 6842 & 35 & 11.6 & 43.4 & -16.4 & 14.0 & 3.2 & \text { EN } & \text { Bazaliiskii, } 2010\end{array}$

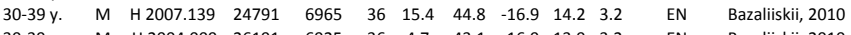
$\begin{array}{lcccccccccccc}30-39 y . & \text { M } & H 22004.009 & 26191 & 6925 & 36 & 4.7 & 43.1 & -16.9 & 13.9 & 3.2 & \text { EN } & \text { Bazaliiskii, } 2010 \\ 40-45 \text { y. } & \text { F } & \text { H } 2004.015 & 26192 & 6386 & 34 & 13.2 & 43.6 & -16.7 & 14.8 & 3.2 & \text { EN } & \text { Bazaliiskii, } 2010\end{array}$ $\begin{array}{ccccccccccccc}40-45 \mathrm{y} . & \mathrm{F} & \mathrm{H} 2004.015 & 26192 & 6386 & 34 & 13.2 & 43.6 & -16.7 & 14.8 & 3.2 & \mathrm{EN} & \text { Bazaliiskii, } 2010 \\ 50+y . & \mathrm{F} & \mathrm{H} 2004.021 & 24774 & 6792 & 35 & 16.3 & 44.9 & -17.6 & 10.5 & 3.0 & \text { EN } & \text { Bazaliiskii, } 2010\end{array}$ $\begin{array}{lllllllllllll}50+\mathrm{y} . & \mathrm{F} & \mathrm{H} 2004.021 & 24774 & 6792 & 35 & 16.3 & 44.9 & -17.6 & 10.5 & 3.0 & \mathrm{EN} & \text { Bazalitiskil, 2010 } \\ 50+\mathrm{y} . & \mathrm{F} & \mathrm{H} 2009.147 & 26193 & 6821 & 35 & 14.4 & 43.4 & -17.8 & 10.3 & 3.2 & \text { EN } & \text { Bazaliiskii, } 2010\end{array}$

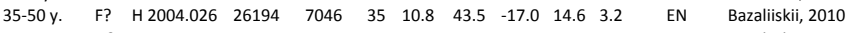

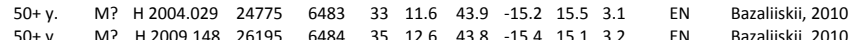

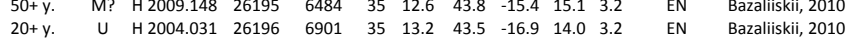

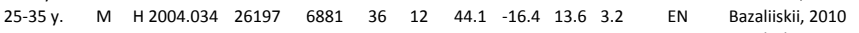

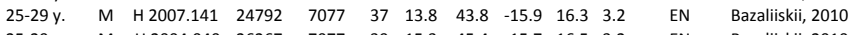

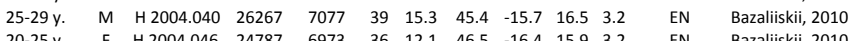

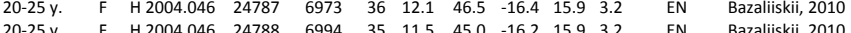

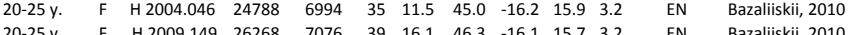

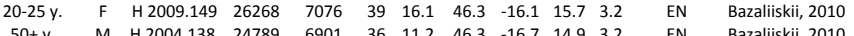

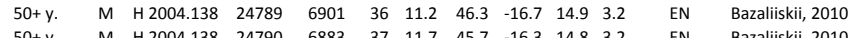
$\begin{array}{lllllllllllll}50+\mathrm{y} . & \mathrm{M} & \mathrm{H} 2004.138 & 24790 & 6883 & 37 & 11.7 & 45.7 & -16.3 & 14.8 & 3.2 & \text { EN } & \text { Bazaliiskii, } 2010 \\ 50+\mathrm{y} & \mathrm{M} & \mathrm{H} 2009.150 & 26269 & 6973 & 39 & 15.0 & 44.6 & -16.3 & 14.6 & 3.2 & \text { EN } & \text { Bazaliiskii, } 2010\end{array}$ 


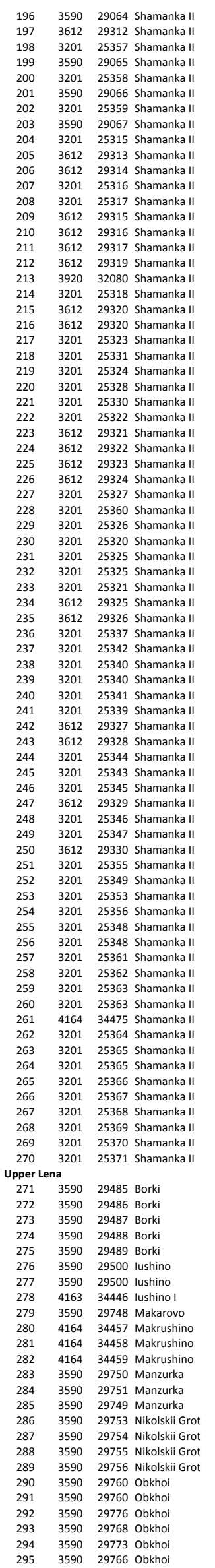

SHA_2004.049.01 SHA_2004.049.01 SHA_2004.050.01 SHA_2004.050.01 SHA_2004.050.02 SHA_2004.050.02 SHA_2004.050.03 SHA_2004.050.03 SHA 2004.051 SHA_2004.051 SHA_2004.052.01 SHA_2004.052.02 SHA_2004.053.01 SHA_2004.053.02 SHA_2004.054.01 SHA_2004.055.01 SHA_2004.055.02 SHA_2004.056.02 SHA_2004.056.02 SHA_2004.057.00 SHA_2004.058.01 SHA_2004.058.01 SHA_2005.059.01 SHA_2005.059.02 SHA_2005.060.01 SHA_2005.060.02 SHA_2005.061.01 SHA_2005.061.02 SHA_2005.062.01 SHA_2005.062.02 SHA_2005.062.03 SHA_2005.062.04 SHA_2005.063.01 SHA_2005.063.01 SHA_2005.063.02 SHA_2005.064. SHA_2005.065 SHA_2005.066.01 SHA_2005.066.01 SHA_2005.067 SHA_2005.068 SHA_2006.069.01 SHA_2006.069.02 SHA_2006.070 SHA_2006.071 SHA_2006.071 SHA_2006.071 SHA_2006.073 SHA_2006.075 SHA_2006.075 SHA_2006.076 SHA_2006.077 SHA_2006.083.01 SHA_2006.083.02 SHA_2007.085

SHA_2007.086.01 SHA_2007.086.02 SHA_2007.088

SHA_2007.090

SHA_2007.090

SHA_2007.093.02 SHA_2007.096.02 SHA_2007.096.02 SHA_2008.103.01 SHA_2008.104 SHA_2008.104 SHA_2008.104 SHA_2008.106 SHA_2008.107 SHA_2008.107 SHA_2008.108.01 SHA_2008.108.01 SHA_2008.108.02 SHA_2008.109 SHA_2008.109 SHA_2008.111

BO1_1971.001 BO1_1971.002 BO2_1971.002 BO2_1971.002 BO2_1971.003 IUSH_2007.000.00 IUSH_2007.000.00 IUSH_0000.000 IUSH_0000.000 MKV_1973.001 MAK_1992.013.00 MAK_1992.018 MAK_1992.019 MNZ_1974.001 MNZ_1974.002 NGT 1982.001 .01 NGT_1982.001.02 NGT_1982.002.01 NGT_surface

OBK_1971.001.01 OBK_1971.001.01 OBK_1971.001.01 OBK_1971.001.01 OBK_1971.001.02 OBK_1971.001.03 $\begin{array}{lllllllllll}17-20 y . & \text { M? } & \text { H } 2007.143 & 24793 & 6319 & 33 & 13.8 & 45.2 & -16.3 & 13.5 & 3.2\end{array}$ $\begin{array}{llllllllllll}17-20 y . & \text { M? } & \text { H } 2004.052 & 26270 & 6378 & 37 & 16.1 & 46.3 & -16.1 & 13.5 & 3.2\end{array}$ $\begin{array}{lllllllllll}25-35 y . & \text { M } & \text { H 2007.146 } & 24794 & 6418 & 35 & 15.9 & 45.3 & -16.6 & 14.8 & 3.2\end{array}$ $\begin{array}{llllllllllll}25-29 y . & \text { M } & \text { H } 2007.148 & 21492 & 6851 & 35 & 21.0 & 41.8 & -16.9 & 13.7 & 3.1\end{array}$ $\begin{array}{lllllllllll}25-29 y & \text { M } & \text { H } 2007.148 & 24795 & 6902 & 37 & 13.6 & 45.5 & -16.8 & 13.7 & 3.2\end{array}$

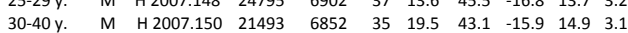
$\begin{array}{lllllllllll}30-40 \mathrm{y} . & \mathrm{M} & \mathrm{H} 2007.150 & 21493 & 6852 & 35 & 19.5 & 43.1 & -15.9 & 14.9 & 3.1 \\ 30-40 \mathrm{y} & \mathrm{M} & \mathrm{H} 2007.150 & 24796 & 6975 & 37 & 13.7 & 44.8 & -15.8 & 14.7 & 3.2\end{array}$

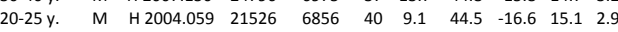

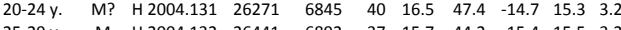

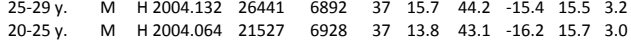
$\begin{array}{llllllllllll}50+\mathrm{y} . & \mathrm{M} & \mathrm{H} 2004.070 & 21528 & 7001 & 38 & 12.3 & 43 & -16.0 & 15.8 & 3.0\end{array}$ $\begin{array}{lllllllllll}17-21 \text { y. } & \text { F } & \text { H } 2004.073 & 26442 & 6939 & 38 & 14.7 & 44.7 & -15.2 & 15.2 & 3.2\end{array}$ $\begin{array}{llllllllllll}35-39 y . & \text { M } & \text { H } 2004.095 & 26443 & 6881 & 38 & 15.6 & 45.1 & -15.9 & 14.6 & 3.2\end{array}$

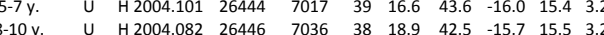

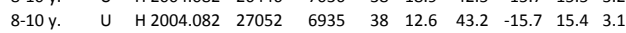

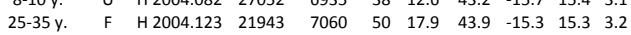
$\begin{array}{lllllllllll}25-35 \mathrm{y} . & \mathrm{F} & \mathrm{H} 2004.123 & 21943 & 7060 & 50 & 17.9 & 43.9 & -15.3 & 15.3 & 3.2 \\ 35-45 \mathrm{y} . & \mathrm{M} & \mathrm{H} 2004.085 & 26447 & 6957 & 39 & 16.4 & 42.2 & -16.8 & 13.9 & 3.2\end{array}$ $\begin{array}{lllllllllll}35-45 y . & \text { M } & \text { H } 2004.085 & 26448 & 7002 & 38 & 18.0 & 42.3 & -16.9 & 13.8 & 3.2\end{array}$

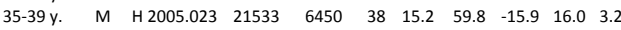

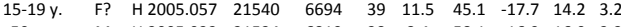
$\begin{array}{llllllllllll}50+\mathrm{y} . & \mathrm{M} & \mathrm{H} & 2005.032 & 21534 & 6819 & 38 & 8.4 & 58.1 & -16.9 & 16.0 & 3.3\end{array}$ $\begin{array}{lllllllllll}40-44 \mathrm{y} . & \mathrm{F} & \mathrm{H} 2005.040 & 21538 & 6959 & 39 & 13.4 & 42.6 & -15.9 & 15.1 & 3.2\end{array}$

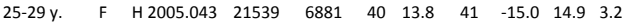
$\begin{array}{lllllllllll}35-45 y . & \mathrm{M} & \mathrm{H} 2005.020 & 21944 & 6915 & 38 & 15.9 & 42.1 & -15.9 & 14.3 & 3.2\end{array}$

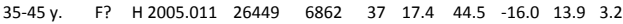
$\begin{array}{lllllllllll}35-45 y . & \text { M } & \text { H } 2005.033 & 26450 & 6895 & 37 & 19.1 & 42.6 & -15.8 & 15.1 & 3.2\end{array}$

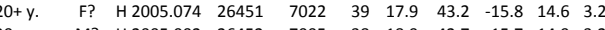
$\begin{array}{lllllllllll}20+y . & \text { M? } & \text { H } 2005.002 & 26452 & 7005 & 38 & 18.9 & 42.7 & -15.7 & 14.9 & 3.2\end{array}$ $\begin{array}{lllllllllll}25-29 y . & \text { M } & \text { H } 2005.039 & 21537 & 6815 & 38 & 10.4 & 42.6 & -15.5 & 15.4 & 3.3\end{array}$ $\begin{array}{lllllllllll}25-35 y . & \text { M } & \text { H } 2007.164 & 21494 & 6908 & 32 & 17.1 & 42.7 & -15.0 & 14.5 & 3.1\end{array}$ $\begin{array}{llllllllllll}30-39 & \text { y. } & \text { M } & \text { H } 2005.037 & 21536 & 6381 & 37 & 15.8 & 42 & -16.5 & 14.9 & 3.2\end{array}$ $\begin{array}{ccccccccccc}50+\mathrm{y} . & \mathrm{M} & \mathrm{H} 2005.005 & 21530 & 6945 & 45 & 13 & 44 & -16.6 & 14.4 & 3.2 \\ 25-35 \mathrm{y} . & \mathrm{F} & \mathrm{H} 2005.034 & 21535 & 7005 & 40 & 13.4 & 59.9 & -17.1 & 13.6 & 3.2\end{array}$ $\begin{array}{llllllllllll}25-35 y . & F & H & 2005.034 & 21945 & 6931 & 39 & 13.4 & 45.2 & -17.1 & 13.6 & 3.2\end{array}$

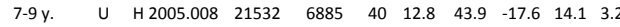

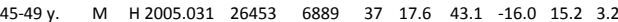

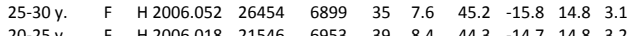

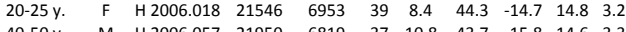

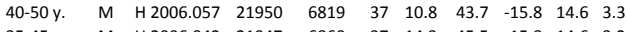
$\begin{array}{llllllllllll}35-45 y . & M & H & 2006.042 & 21947 & 6860 & 37 & 14.3 & 45.5 & -15.8 & 14.6 & 3.2\end{array}$ $\begin{array}{llllllllllll}35-45 y . & M & H & 2006.042 & 21948 & 6814 & 39 & 12.0 & 45.5 & -16.7 & 14.8 & 3.1\end{array}$ $\begin{array}{llllllllllll} & \end{array}$

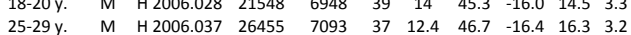
$\begin{array}{llllllllllll}25-29 y . & M & H 2006.037 & 26455 & 7093 & 37 & 12.4 & 46.7 & -16.4 & 16.3 & 3.2 \\ 40-50 y . & M & H 2006.033 & 26456 & 7123 & 37 & 7.2 & 45.1 & -16.4 & 15.1 & 3.2\end{array}$

$\begin{array}{llllllllllll}30-39 y . & F & \text { H } 2006.062 & 21549 & 7025 & 40 & 15 & 43.2 & -16.7 & 14.7 & 3.2\end{array}$

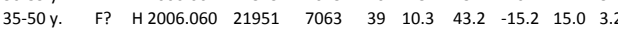

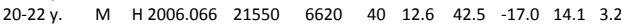

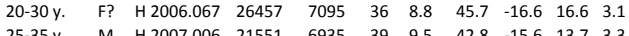

$\begin{array}{lllllllllll}25-35 y . & M & H 2007.006 & 21551 & 6935 & 39 & 9.5 & 42.8 & -15.6 & 13.7 & 3.3 \\ 18-20 y & M & H 2007.008 & 21552 & 6584 & 39 & 12.9 & 41.4 & -16.5 & 14.1 & 3.3\end{array}$

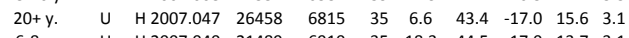

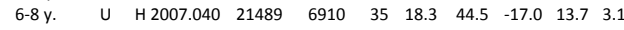

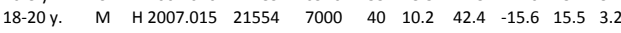

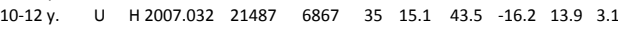

$\begin{array}{lllllllllll}35-40 \mathrm{y} . & \mathrm{F} & \mathrm{H} 2007.045 & 21490 & 7012 & 37 & 17 & 43.7 & -17.0 & 14.5 & 3.1\end{array}$

$\begin{array}{lllllllllll}30-35 \mathrm{y} . & \mathrm{F} & \mathrm{H} 2007.013 & 21553 & 6690 & 40 & 7.1 & 43.1 & -16.5 & 14.2 & 3.2 \\ 30-35 \mathrm{y} . & \mathrm{F} & \mathrm{H} 2007.013 & 27392 & 6679 & 34 & 14.9 & 44.1 & -15.7 & 14.3 & 3.2\end{array}$

$\begin{array}{lllllllllll}30-35 \mathrm{y} . & \mathrm{F} & \mathrm{H} 2007.013 & 27392 & 6679 & 34 & 14.9 & 44.1 & -15.7 & 14.3 & 3.2 \\ 14-16 \mathrm{y} & \mathrm{U} & \mathrm{H} 2008.002 & 21495 & 3650 & 28 & 17.9 & 44.6 & -16.6 & 12.4 & 3.1\end{array}$

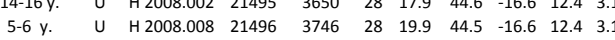

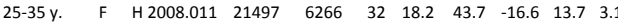

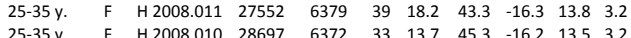

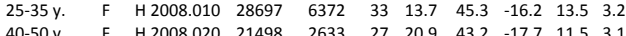

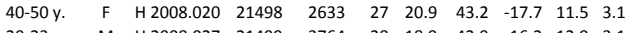
$\begin{array}{lllllllllll}20-23 y . & \text { M } & \text { H } 2008.027 & 21499 & 3764 & 28 & 18.9 & 42.9 & -16.2 & 12.9 & 3.1\end{array}$ $\begin{array}{lllllllllll}20-23 y . & \text { M } & \text { H } 2008.027 & 21500 & 3764 & 28 & 18.7 & 43.0 & -16.2 & 13.0 & 3.1\end{array}$ $\begin{array}{lllllllllll}20-23 \mathrm{y} . & \mathrm{M} & \mathrm{H} 2008.027 & 21500 & 3764 & 28 & 18.7 & 43.0 & -16.2 & 13.0 & 3.1 \\ 35-50 \mathrm{y} & \mathrm{M} & \mathrm{H} 2008.034 & 21501 & 6395 & 32 & 14.4 & 43.9 & -16.6 & 14.6 & 3.2\end{array}$

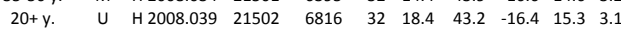
$\begin{array}{llllllllllll}25-35 y . & \text { M } & \text { H } 2008.042 & 21503 & 6373 & 32 & 15.4 & 42.9 & -16.7 & 14.7 & 3.1\end{array}$ $\begin{array}{llllllllllll}40-50 y . & F & H & 2008.049 & 22029 & 3724 & 33 & 11 & 45.5 & -16.6 & 12.9 & 3.3\end{array}$ $\begin{array}{lllllllllll}18-20 \text { y. } & \text { M } & \text { H } 2008.057 & 22030 & 3700 & 33 & 10.3 & 45.2 & -16.0 & 13.4 & 3.2 \\ 25-35 \text { y. } & \text { M } & \text { H } 2008.064 & 21952 & 6782 & 38 & 11.6 & 45.4 & -16.3 & 15.1 & 3.3\end{array}$

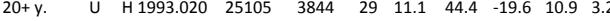

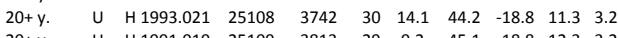

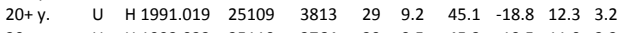

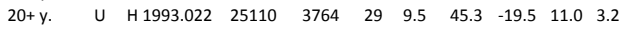

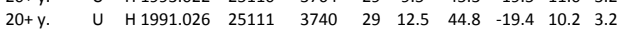

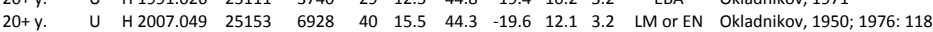

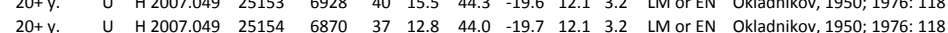

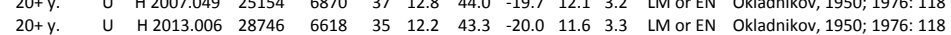
$\begin{array}{lllllllllllll}20+y . & U & H 2013.006 & 28746 & 6618 & 35 & 12.2 & 43.3 & -20.0 & 11.6 & 3.3 & \text { LM or EN Okladnikov, 1950; } 1976: 11 \\ 20+y . & U & H & \text { H } 1991.001 & 25221 & 4215 & 32 & 15.4 & 43.0 & -19.6 & 11.4 & 3.2 & \text { EBA Okladnikov, 1955: } 14\end{array}$ $\begin{array}{lllllllllllll}20+y . & U & H 2013.021 & 28757 & 4242 & 30 & 14.9 & 43.5 & -19.2 & 13.0 & 3.3 & \text { EBA } & \text { V.M. Vetrov pers. comm. }\end{array}$

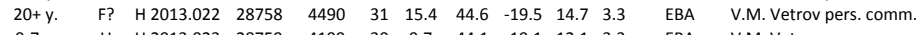
$\begin{array}{lllllllllllll}0-7 \mathrm{y} . & \mathrm{U} & \mathrm{H} 2013.023 & 28759 & 4199 & 30 & 9.7 & 44.1 & -19.1 & 12.1 & 3.3 & \text { EBA } & \text { V.M. Vetrov pers. comm. } \\ 20+\mathrm{y} & \mathrm{U} & \mathrm{H} 1993.018 & 25223 & 3938 & 29 & 15.4 & 46.1 & -19.2 & 12.6 & 3.2 & \text { EBA } & \text { Konopatskii, 1977 }\end{array}$

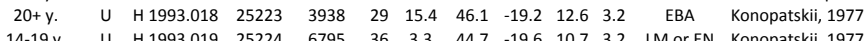

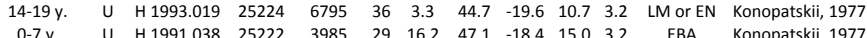
$\begin{array}{llllllllllll}14-19 y . & \text { M } & H & 1992.129 & 25225 & 5289 & 33 & 17.3 & 46.1 & -20.0 & 12.1 & 3.2\end{array}$ LN $\quad$ Bazaliiskii et al., 1996: 33

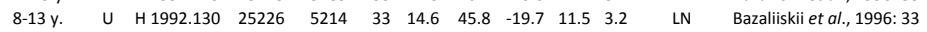
$\begin{array}{lllllllllllll}56+y & \text { F } & \text { H } 1992.131 & 25227 & 5165 & 32 & 15.1 & 45.6 & -19.8 & 11.6 & 3.2 & \text { LN } & \text { Bazaliiskii et al., 1996: } 33\end{array}$ $\begin{array}{lllllllllllll}56+\mathrm{y} . & \mathrm{F} & \mathrm{H} 1992.131 & 25227 & 5165 & 32 & 15.1 & 45.6 & -19.8 & 11.6 & 3.2 & \mathrm{LN} & \text { Bazaliiskii et al., 1996: } 33 \\ 20+\mathrm{y} . & \mathrm{U} & \mathrm{H} 1992.133 & 25228 & 5189 & 32 & 18.0 & 45.6 & -19.7 & 11.7 & 3.2 & \text { LN } & \text { Bazaliiskii et al., 1996: } 33\end{array}$

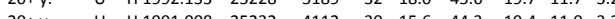

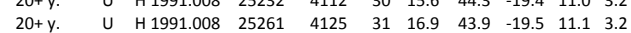
$\begin{array}{lllllllllll}20+\mathrm{y} . & U & \mathrm{H} 1991.008 & 25261 & 4125 & 31 & 16.9 & 43.9 & -19.5 & 11.1 & 3.2 \\ 20+\mathrm{y} . & U & H 1997.263 & 25276 & 4126 & 29 & 15.9 & 46.3 & -19.2 & 10.9 & 3.2\end{array}$

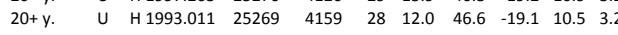
$\begin{array}{lllllllllll}20+\mathrm{y} . & U & \mathrm{H} 1997.254 & 25273 & 4065 & 29 & 14.0 & 45.6 & -19.1 & 10.3 & 3.2 \\ 20+\mathrm{y} & \text { U } & \text { H } 1991.032 & 25267 & 3999 & 30 & 12.0 & 42.9 & -18.7 & 10.7 & 3.2\end{array}$ Bazaliiskii, 2010 Bazaliiskii, 2010 Bazaliiskii, 2010 Bazaliiskii, 2010 Bazaliiskii, 2010 Bazaliiskii, 2010 Bazaliiskii, 2010 Bazaliiskii, 2010 Bazaliiskii, 2010 Bazaliiskii, 2010 Bazaliiskii, 2010 Bazaliiskii, 2010 Bazaliiskii, 2010 Bazaliiskii, 2010 Bazaliiskii, 2010 Bazaliiskii, 2010 Bazaliiskii, 2010 Bazaliiskii, 2010 Bazaliiskii, 2010 Bazaliiskii, 2010 Bazaliiskii, 2010 Bazaliiskii, 2010 Bazaliiskii, 2010 Bazaliiskii, 2010 Bazaliiskii, 2010 Bazaliiskii, 2010 Bazaliiskii, 2010 Bazaliiskii, 2010 Bazaliiskii, 2010 Bazaliiskii, 2010 Bazaliiskii, 2010 Bazaliiskii, 2010 Bazaliiskii, 2010 Bazaliiskii, 2010 V.I. Bazaliiskii pers. comm. Bazaliiskii, 2010 Bazaliiskii, 2010

V.I. Bazaliiskii pers. comm. V.I. Bazaliiskii pers. comm. Bazaliiskii, 2010 Bazaliiskii, 2010 V.I. Bazaliiskii pers. comm V.I. Bazaliiskii pers. comm.
Bazaliiskii, 2010

Okladnikov, 1971 Okladnikov, 1971 Okladnikov, 1971 Okladnikov, 1971 Okladnikov, 1971
Okladnikov, 1971 Okladnikov, 1971
Okladnikov, 1971 Okladnikov, 1971 Okladnikov, 1971 


\begin{tabular}{|c|c|c|c|c|c|c|c|c|c|c|c|c|c|c|c|c|c|}
\hline 296 & 3590 & 29759 & Obkhoi & OBK_1971.003.01 & $20+y$ & $u$ & H 1991.006 & 25231 & 4070 & 31 & 15.4 & 44.7 & -19.4 & 10.4 & 3.2 & EBA & Okladnikov, 1971 \\
\hline 297 & 3590 & 29757 & Obkhoi & OBK_1971.003.02 & Subadult & $u$ & H 1991.004 & 25229 & 3950 & 30 & 15.8 & 45.1 & -18.4 & 9.6 & 3.2 & EBA & Okladnikov, 1971 \\
\hline 298 & 3590 & 29761 & Obkhoi & OBK_1971.004.01 & $20+y$ & u & H 1991.009 & 25262 & 4089 & 29 & 18.0 & 43.5 & -19.4 & 10.8 & 3.2 & EBA & Okladnikov, 1971 \\
\hline 299 & 3590 & 29762 & Obkhoi & OBK_1971.004.02 & Subadult & $u$ & H 1991.010 & 25263 & 4000 & 29 & 19.8 & 39.1 & -19.1 & 10.9 & 3.2 & EBA & Okladnikov, 1971 \\
\hline 300 & 3590 & 29767 & Obkhoi & OBK_1971.005 & $20+y$ & u & H 1993.010 & 25268 & 3888 & 31 & 14.1 & 45.2 & -19.4 & 10.2 & 3.2 & EBA & Okladnikov, 1971 \\
\hline 301 & 3590 & 29763 & Obkhoi & OBK_1971.007 & $20+y$ & u & H 1991.015 & 25264 & 4073 & 30 & 14.6 & 42.2 & -19.0 & 10.8 & 3.2 & EBA & Okladnikov, 1971 \\
\hline 302 & 3590 & 29769 & Obkhoi & OBK_1971.010 & $20+y$ & $u$ & H 1993.013 & 25270 & 3922 & 28 & 1.7 & 43.8 & -19.7 & 11.4 & 3.2 & EBA & Okladnikov, 1971 \\
\hline 303 & 3590 & 29770 & Obkhoi & OBK_1971.013 & $20+y$ & u & H 1993.014 & 25307 & 4352 & 31 & 15.7 & 46.6 & -19.4 & 11.3 & 3.3 & EBA & Okladnikov, 1971 \\
\hline 304 & 3590 & 29764 & Obkhoi & OBK_1971.014.01 & $20+y$ & u & H 1991.029 & 25265 & 3977 & 30 & 16.3 & 48.3 & -19.2 & 10.3 & 3.2 & EBA & Okladnikov, 1971 \\
\hline 305 & 3590 & 29765 & Obkhoi & OBK_1971.014.02 & $20+y$ & u & H 1991.030 & 25266 & 3929 & 29 & 14.5 & 47.4 & -19.0 & 10.1 & 3.2 & EBA & Okladnikov, 1971 \\
\hline 306 & 3590 & 29758 & Obkhoi & OBK_1976.003 & Subadult & u & H 1991.005 & 25230 & 4391 & 32 & 17.1 & 44.8 & -19.3 & 10.3 & 3.2 & EBA & Okladnikov, 1971 \\
\hline 307 & 3934 & 32202 & Popovskii Lug 2 & POP2_2010.001 & $20+y$. & u & H 2011.001 & 27119 & 8070 & 45 & 14.9 & 41.3 & -19.8 & 12.4 & 3.2 & LM or EN & Zubkov, 2000: 15 \\
\hline 308 & 3590 & 30131 & Turuka & TUR__1992.002 & $20+y$ & u & H 1993.073 & 25574 & 6983 & 38 & 4.0 & 43.9 & -20.3 & 12.7 & 3.2 & EN & Bazaliiskii and Ineshin, 1995 \\
\hline 309 & 3590 & 30129 & Turuka & TUR_1992.004 & $20+y$. & u & H 1992.128 & 25573 & 6980 & 40 & 1.9 & 43.3 & -20.6 & 13.0 & 3.3 & EN & Bazaliiskii and Ineshin, 1995 \\
\hline 310 & 3590 & 30132 & Turuka & TUR_1993.005 & $20+y$ & u & H 1993.074 & 25489 & 7136 & 35 & 5.8 & 43.0 & -20.1 & 13.2 & 3.3 & EN & Bazaliiskii and Ineshin, 1995 \\
\hline 311 & 4163 & 34445 & Ulus Khalskii & UKH_1930.000 & $20+y$ & $u$ & H 2013.005 & 28745 & 3991 & 30 & 17.1 & 43.7 & -19.4 & 12.6 & 3.3 & EBA & Okladnikov, 1955: 14 \\
\hline 312 & 4164 & 34466 & Ust' lamnaia & UIA_1977.005 & $20+y$ & $\mathrm{~F}$ & H 2013.026 & 28767 & 4137 & 30 & 10.6 & 44.8 & -19.8 & 12.1 & 3.3 & EBA & Zubkov, 1978: 30 \\
\hline 313 & 3590 & 30141 & Ust' lamnaia & UIA_surface & $20+y$ & u & H 1997.273 & 25496 & 3957 & 29 & 17.4 & 46.1 & -19.4 & 11.1 & 3.3 & EBA & Zubkov, 1978: 30 \\
\hline 314 & 3590 & 30143 & Zakuta & ZAK_1993.001 & $20+y$ & $u$ & H 1994.001 & 25498 & 5121 & 30 & 7.8 & 44.9 & -19.4 & 11.9 & 3.2 & LN & Bazaliiskii, 2012 \\
\hline 315 & 3590 & 30144 & Zakuta & ZAK_1994.002 & $20+y$ & u & H 1994.002 & 25499 & 5189 & 30 & 16.2 & 44.5 & -19.6 & 12.1 & 3.2 & $\mathrm{LN}$ & Bazaliiskii, 2012 \\
\hline 316 & 3590 & 30145 & Zakuta & ZAK_1994.003 & $20+y$ & u & H 1994.003 & 25575 & 5136 & 32 & 10.1 & 42.9 & -20.1 & 12.2 & 3.2 & $\mathrm{LN}$ & Bazaliiskii, 2012 \\
\hline 317 & 3590 & 30146 & Zakuta & ZAK_1994.005 & $20+y$ & u & H 1995.001 & 25576 & 4926 & 33 & 16.7 & 43.6 & -20.0 & 12.4 & 3.2 & LN & Bazaliiskii, 2012 \\
\hline 318 & 4163 & 34444 & Zapleskino & ZAP 0000.003 & $20+y$. & u & H 2013.004 & 28744 & 5138 & 31 & 13.9 & 44.7 & -19.6 & 11.6 & 3.3 & LN & Okladnikov, 1955: 14 \\
\hline
\end{tabular}

Note: Records are groupded by micro-region and then sorted by "Site" and "Master ID". 
Supplement 2. OxCal 4.2.4 input file for Bayesian analysis of middle Holocene culture history of Cis-Baikal, Siberia, using the default uniform distribution model. All dates are corrected for the freshwater reservoir effect and grouped by culture historical periods and then sorted by corrected ${ }^{14} \mathrm{C}$ date $\mathrm{BP}$.

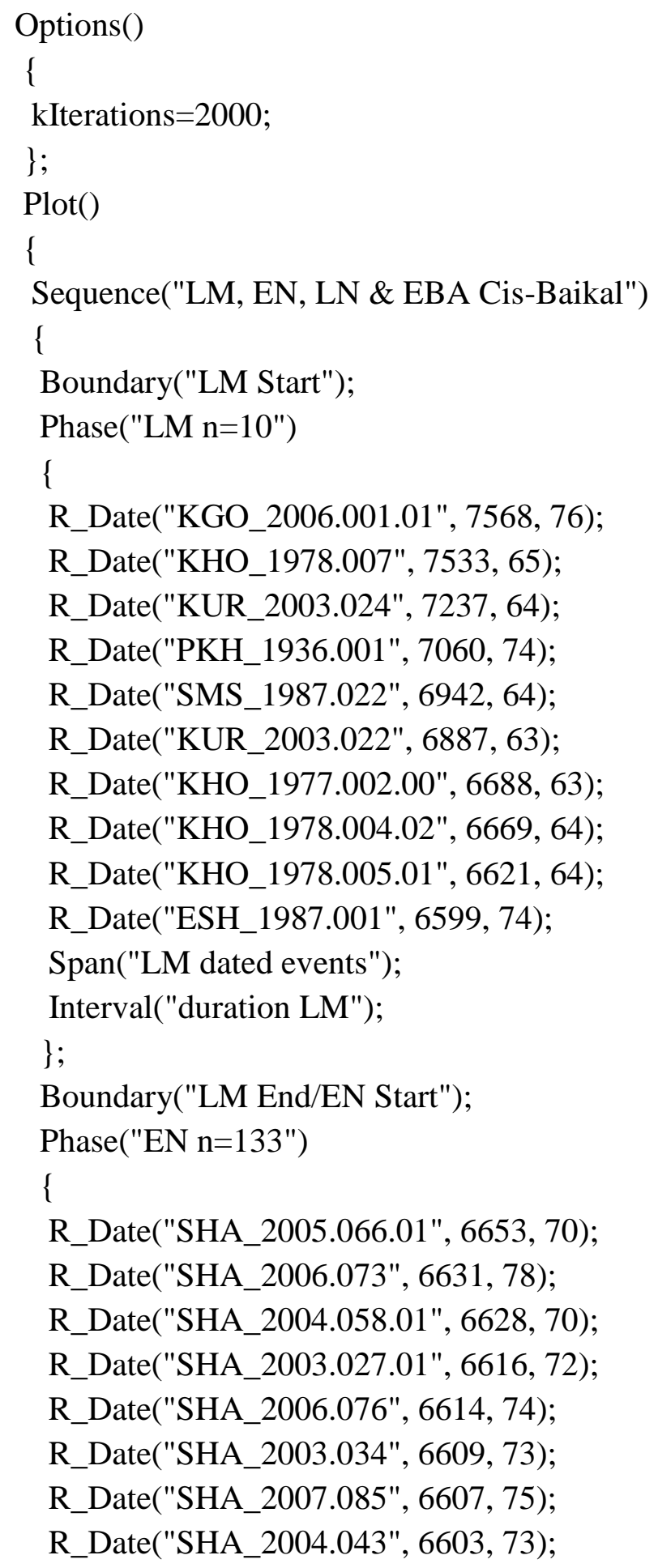


R_Date("SHA_2002.021.02", 6586, 73);

R_Date("SHA_2007.088", 6583, 73);

R_Date("SHA_2007.093.02", 6581, 74);

R_Date("SHA_2005.062.03", 6580, 75);

R_Date("SHA_2006.077", 6573, 76);

R_Date("SHA_2002.023.05", 6573, 73);

R_Date("SHA_2004.045", 6568, 74);

R_Date("SHA_2004.041", 6567, 53);

R_Date("SHA_2006.079", 6565, 75);

R_Date("LOR_1991.007.01", 6559, 81);

R_Date("LOK_1990.043.02", 6555, 73);

R_Date("SHA_2004.050.02", 6539, 69);

R_Date("LOK_1990.041.02", 6535, 73);

R_Date("SHA_2004.044.02", 6533, 73);

R_Date("SHA_2005.065", 6529, 78);

R_Date("SHA_2004.057.00", 6528, 81);

R_Date("UID_1993.043", 6526, 78);

R_Date("SHA_2003.033", 6522, 73);

R_Date("SHA_2005.062.04", 6521, 75);

R_Date("SHA_2007.092", 6518, 73);

R_Date("SHA_2006.074", 6516, 75);

R_Date("SHA_2005.061.02", 6513, 75);

R_Date("SHA_2002.022", 6512, 52);

R_Date("SHA_1998.004", 6506, 75);

R_Date("SHA_2005.062.01", 6505, 74);

R_Date("SHA_2004.039", 6500, 42);

R_Date("SHA_2005.067", 6499, 76);

R_Date("LOK_1990.044.01", 6494, 73);

R_Date("SHA_2003.032", 6492, 73);

R_Date("SHA_2006.069.02", 6488, 75);

R_Date("LOK_1990.042", 6484, 70);

R_Date("SHA_2002.024.02", 6479, 73);

R_Date("SHA_2005.063.02", 6474, 72);

R_Date("SHA_2004.055.02", 6472, 75);

R_Date("SHA_2004.048.01", 6469, 51);

R_Date("SHA_2005.060.02", 6456, 75);

R_Date("LOR_1998.014", 6448, 76);

R_Date("SHA_2007.090", 6445, 76);

R_Date("SHA_2004.055.01", 6440, 75);

R_Date("SHA_2004.050.03", 6439, 69); 
R_Date("SHA_2006.069.01", 6436, 73);

R_Date("LOK_1980.022.03", 6435, 54);

R_Date("SHA_2004.056.02", 6433, 70);

R_Date("SHA_2004.047", 6432, 51);

R_Date("SHA_2006.075", 6431, 74);

R_Date("LOK_1984.029", 6430, 74);

R_Date("SHA_2002.025.01", 6429, 73);

R_Date("LOK_1980.002.02", 6428, 74);

R_Date("LOK_1980.002.03", 6421, 73);

R_Date("SHA_2004.054.01", 6417, 75);

R_Date("SHA_2004.053.02", 6412, 75);

R_Date("LOR_1980.003.01", 6411, 74);

R_Date("SHA_2004.046", 6411, 53);

R_Date("SHA_2006.083.02", 6402, 74);

R_Date("SHA_2005.061.01", 6399, 76);

R_Date("SHA_2005.062.02", 6391, 74);

R_Date("LOK_1981.024.01", 6388, 74);

R_Date("LOK_1985.033", 6388, 73);

R_Date("SHA_2006.071", 6384, 70);

R_Date("LOK_1988.038.02", 6383, 75);

R_Date("LOR_1998.013.01", 6380, 76);

R_Date("SHA_2006.070", 6374, 74);

R_Date("SHA_2003.026.02", 6373, 73);

R_Date("LOK_1981.025.05", 6369, 78);

R_Date("LOK_1981.024.04", 6367, 76);

R_Date("SHA_2005.068", 6367, 74);

R_Date("SHA_2004.051", 6356, 76);

R_Date("LOK_1988.038.01", 6355, 74);

R_Date("SHA_2004.053.01", 6347, 74);

R_Date("KIT_surface", 6344, 74);

R_Date("SHA_2004.052.02", 6341, 74);

R_Date("LOK_1981.025.01", 6329, 73);

R_Date("LOR_1980.001", 6320, 76);

R_Date("SHA_2004.052.01", 6320, 76);

R_Date("LOK_1985.034", 6298, 74);

R_Date("SHA_2005.059.02", 6296, 75);

R_Date("SHA_2001.016", 6292, 69);

R_Date("SHA_2008.108.02", 6286, 72);

R_Date("LOK_1980.022.02", 6285, 70);

R_Date("SHA_2007.096.02", 6282, 69); 
R_Date("SHA_2005.063.01", 6278, 75);

R_Date("LOK_1980.007", 6274, 73);

R_Date("SHA_2008.112", 6272, 75);

R_Date("KIT_1880.004", 6269, 73);

R_Date("LOK_1981.025.03", 6267, 73);

R_Date("GAL_Grave17-2", 6266, 74);

R_Date("LOK_1988.039", 6250, 73);

R_Date("SHA_2007.086.02", 6244, 73);

R_Date("SHA_2006.083.01", 6240, 76);

R_Date("KIT_1880.011", 6233, 73);

R_Date("LOK_1980.006", 6229, 73);

R_Date("UBE_1962.005", 6224, 72);

R_Date("LOK_1985.030.01", 6217, 73);

R_Date("SHA_2005.060.01", 6206, 75);

R_Date("SHA_2007.086.01", 6205, 75);

R_Date("UBE_1962.008", 6188, 73);

R_Date("GAL_Grave18", 6176, 74);

R_Date("GAL_Grave17-1", 6172, 73);

R_Date("SHU_1972.002.01", 6167, 74);

R_Date("LOK_1981.025.02", 6161,73);

R_Date("UBE_1962.009.00", 6141, 72);

R_Date("LOK_1981.024.05", 6133, 74);

R_Date("LOK_1980.009", 6128, 73);

R_Date("LOK_1981.023", 6118, 76);

R_Date("GAL_Grave05-1", 6095, 73);

R_Date("GAL_Grave16", 6079, 73);

R_Date("GAL_Grave04(1978)", 6049, 73);

R_Date("GAL_Grave05-2", 6044, 74);

R_Date("SHA_2004.049.01", 6041, 52);

R_Date("LOK_1985.035", 6041, 76);

R_Date("GAL_Grave03", 6033, 73);

R_Date("GAL_Grave07", 6028, 74);

R_Date("SHA_1999.007", 6001, 72);

R_Date("SHA_2004.050.01", 5981, 69);

R_Date("SHA_2008.104", 5977, 69);

R_Date("SHA_2008.108.01", 5955, 72);

R_Date("SHA_2003.030", 5953, 72);

R_Date("SHA_2004.044.01", 5952, 52);

R_Date("ROZ_2008.003", 5939, 74);

R_Date("SHA_2004.042.01", 5921, 73); 
R_Date("SHA_2008.108.03", 5915, 72);

R_Date("SHA_2005.064.01", 5902, 74);

R_Date("SHA_2003.035.01", 5877, 72);

R_Date("SHA_1998.006", 5875, 74);

R_Date("SHA_2005.059.01", 5835, 75);

Span("EN dated events");

Interval("duration EN");

;

Boundary("EN End/MN Start");

Phase("MN n=0")

\{

Interval("duration MN");

\};

Boundary("MN End/LN Start");

Phase("LN n=22")

\{

R_Date("ISA_1932.002", 4715, 71);

R_Date("UID_1989.025.03", 4710, 71);

R_Date("UID_1988.018", 4710, 71);

R_Date("UID_1991.038", 4670, 75);

R_Date("UID_1987.008", 4666, 72);

R_Date("UID_1991.041", 4663, 72);

R_Date("UID_1989.020.02", 4655, 75);

R_Date("UID_1994.052", 4644, 71);

R_Date("UID_1994.054", 4617, 74);

R_Date("UID_1989.021.02", 4597, 70);

R_Date("UID_1987.005", 4596, 73);

R_Date("UID_1989.020.01", 4584, 71);

R_Date("UID_1989.026.05", 4578, 74);

R_Date("SHM_1976.001.01", 4572, 61);

R_Date("UID_1994.053.01", 4548, 71);

R_Date("SMS_1986.019.05", 4546, 61);

R_Date("SMS_1987.029.02", 4534, 60);

R_Date("SMS_1986.019.01", 4507, 61);

R_Date("SMS_1986.017", 4412, 61);

R_Date("SMS_1986.011.01", 4363, 61);

R_Date("SMS_1986.011.04", 4359, 59);

R_Date("SMS_1986.019.02", 4283, 61);

Span("LN dated events");

Interval("duration LN"); 
\};

Boundary("LN End/EBA Start");

Phase("EBA n=91")

\{

R_Date("SHM_1975.001", 4410, 43);

R_Date("SMS_1986.009", 4350, 61);

R_Date("UID_1991.042", 4248, 71);

R_Date("GO2_1996.003", 4221, 72);

R_Date("GO2_1996.004", 4171, 71);

R_Date("GO2_1995.002", 4145, 71);

R_Date("OBK_1976.003", 4138, 51);

R_Date("KUR_2002.009", 4076, 56);

R_Date("OBK_1971.013", 4021, 51);

R_Date("MAK_1992.018", 3986, 51);

R_Date("KUR_2003.025", 3938, 60);

R_Date("KUR_2003.026", 3930, 58);

R_Date("MAK_1992.019", 3917, 50);

R_Date("OBK_1971.003.02", 3911, 50);

R_Date("BAD_1920.000", 3898, 70);

R_Date("UBE_1957.002", 3893, 67);

R_Date("OBK_1971.001.02", 3892, 35);

R_Date("MAK_1992.013.00", 3892, 50);

R_Date("KUR_2003.018", 3869, 60);

R_Date("KHA_2010.011", 3868, 60);

R_Date("OBK_1971.001.03", 3856, 50);

R_Date("MKV_1973.001", 3853, 51);

R_Date("OBK_1971.007", 3852, 50);

R_Date("KHA_2010.015", 3849, 60);

R_Date("KUR_2002.007.01", 3845, 63);

R_Date("KUL_1977.000", 3835, 60);

R_Date("KUR_2002.013", 3831, 60);

R_Date("KUR_2002.014", 3826, 59);

R_Date("OBK_1971.001.01", 3821, 44);

R_Date("KUR_2002.010", 3820, 58);

R_Date("KUR_2002.003", 3811, 61);

R_Date("KUR_2002.012", 3804, 61);

R_Date("KUR_2002.005", 3801, 60);

R_Date("OBK_1971.004.01", 3800, 50);

R_Date("UID_1991.039", 3798, 72);

R_Date("KUR_2002.007.02", 3797, 62); 
R_Date("SMS_1986.012", 3796, 60);

R_Date("OBK_1971.003.01", 3796, 51);

R_Date("KUR_2003.017", 3790, 58);

R_Date("SMS_1987.033", 3789, 58);

R_Date("KHA_2010.005", 3783, 60);

R_Date("K14_2000.077", 3776, 56);

R_Date("KUR_2002.001", 3773, 60);

R_Date("OBK_1971.004.02", 3773, 50);

R_Date("KUR_2003.019", 3759, 58);

R_Date("KUR_2002.006", 3757, 61);

R_Date("SHM_1973.001", 3747, 61);

R_Date("KHA_2010.009", 3745, 60);

R_Date("OBK_1971.014.02", 3742, 50);

R_Date("KUR_2002.015", 3741, 60);

R_Date("SMS_1986.013", 3737, 60);

R_Date("OBK_1971.014.01", 3736, 50);

R_Date("KHA_2010.008", 3714, 60);

R_Date("MNZ_1974.004.01", 3706, 50);

R_Date("UIA_1977.005", 3691, 50);

R_Date("K14_1998.037.01", 3690, 60);

R_Date("KUR_2002.016", 3679, 58);

R_Date("KUR_2002.004", 3667, 56);

R_Date("KHA_2010.012", 3664, 59);

R_Date("SHM_1973.002", 3657, 60);

R_Date("UIA_surface", 3641, 50);

R_Date("K14_1999.057.02", 3639, 59);

R_Date("K14_2001.087", 3637, 60);

R_Date("SHM_1972.002", 3634, 43);

R_Date("UKH_1930.000", 3619, 50);

R_Date("KHA_2003.003", 3614, 56);

R_Date("OBK_1971.005", 3608, 51);

R_Date("MNZ_1974.001", 3595, 50);

R_Date("SMS_1987.021", 3594, 58);

R_Date("SHA_2000.009", 3593, 67);

R_Date("SHM_1972.001.01", 3582, 60);

R_Date("K14_1998.036.01", 3582, 60);

R_Date("SHA_2008.103.02", 3578, 70);

R_Date("SHM_1973.004", 3575, 60);

R_Date("KHA_2010.007", 3556, 60);

R_Date("K14_1999.045", 3540, 59); 
R_Date("BO1_1971.002", 3539, 50);

R_Date("K14_1998.037.02", 3538, 56);

R_Date("OBK_1971.010", 3535, 49);

R_Date("SHA_2008.107", 3531, 67);

R_Date("BO2_1971.002", 3506, 36);

R_Date("K14_1999.049", 3506, 60);

R_Date("BO1_1971.001", 3503, 50);

R_Date("GLZ_1887.006", 3502, 70);

R_Date("KHA_2010.006", 3494, 60);

R_Date("SHA_2008.109", 3490, 72);

R_Date("SHA_2008.103.01", 3486, 70);

R_Date("BO2_1971.003", 3475, 50);

R_Date("SHM_1973.003.01", 3474, 60);

R_Date("UID_1994.048", 3437, 71);

R_Date("SHA_2008.111", 3409, 72);

Span("EBA dated events");

Interval("duration EBA");

\};

Boundary("EBA End");

;

\} 
Supplement 3. OxCal 4.2.4 input file for Bayesian analysis of middle Holocene culture history of Cis-Baikal, Siberia, using the trapezium distribution model. All dates are corrected for the freshwater reservoir effect and grouped by culture historical periods and then sorted by corrected ${ }^{14} \mathrm{C}$ date $\mathrm{BP}$.

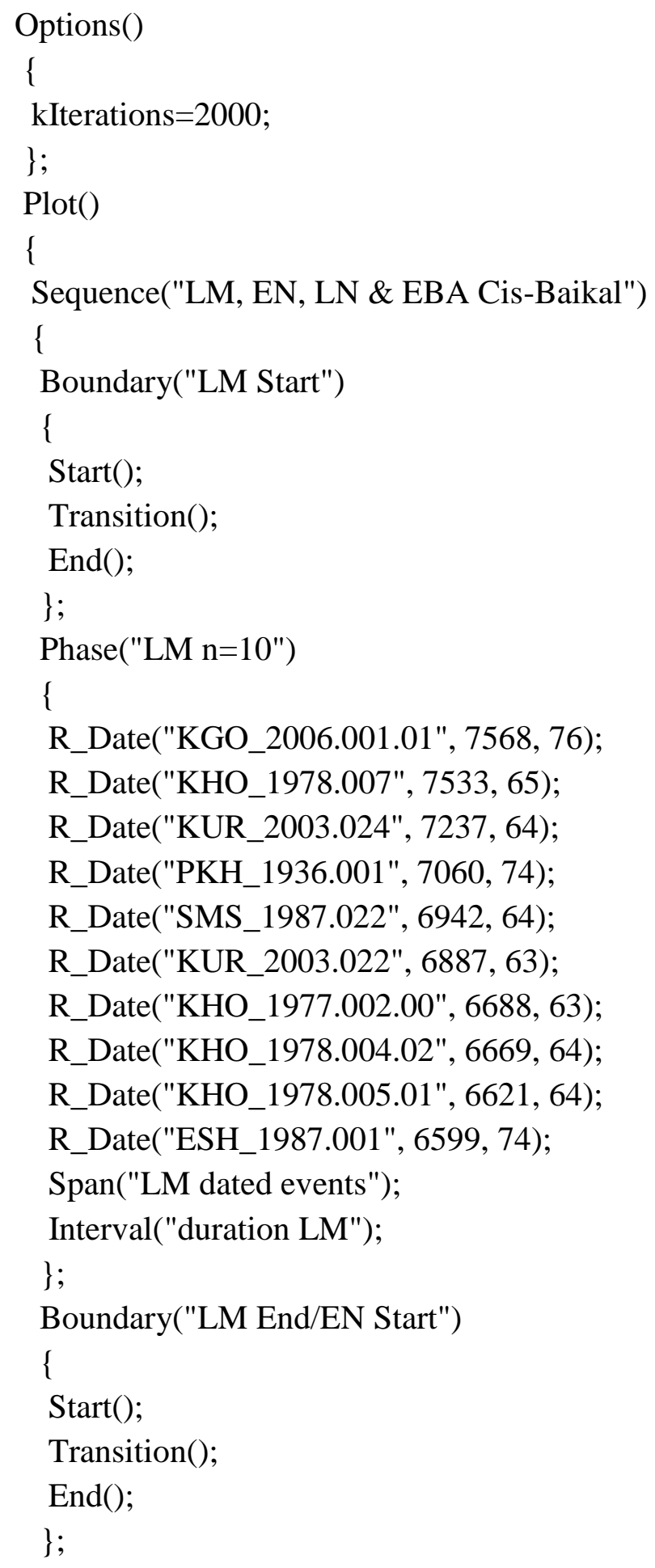




$$
\begin{aligned}
& \text { Phase("EN n=133") } \\
& \text { \{ } \\
& \text { R_Date("SHA_2005.066.01", 6653, 70); } \\
& \text { R_Date("SHA_2006.073", 6631, 78); } \\
& \text { R_Date("SHA_2004.058.01", 6628, 70); } \\
& \text { R_Date("SHA_2003.027.01", 6616, 72); } \\
& \text { R_Date("SHA_2006.076", 6614, 74); } \\
& \text { R_Date("SHA_2003.034", 6609, 73); } \\
& \text { R_Date("SHA_2007.085", 6607, 75); } \\
& \text { R_Date("SHA_2004.043", 6603, 73); } \\
& \text { R_Date("SHA_2002.021.02", 6586, 73); } \\
& \text { R_Date("SHA_2007.088", 6583, 73); } \\
& \text { R_Date("SHA_2007.093.02", 6581, 74); } \\
& \text { R_Date("SHA_2005.062.03", 6580, 75); } \\
& \text { R_Date("SHA_2006.077", 6573, 76); } \\
& \text { R_Date("SHA_2002.023.05", 6573, 73); } \\
& \text { R_Date("SHA_2004.045", 6568, 74); } \\
& \text { R_Date("SHA_2004.041", 6567, 53); } \\
& \text { R_Date("SHA_2006.079", 6565, 75); } \\
& \text { R_Date("LOR_1991.007.01", 6559, 81); } \\
& \text { R_Date("LOK_1990.043.02", 6555, 73); } \\
& \text { R_Date("SHA_2004.050.02", 6539, 69); } \\
& \text { R_Date("LOK_1990.041.02", 6535, 73); } \\
& \text { R_Date("SHA_2004.044.02", 6533, 73); } \\
& \text { R_Date("SHA_2005.065", 6529, 78); } \\
& \text { R_Date("SHA_2004.057.00", 6528, 81); } \\
& \text { R_Date("UID_1993.043", 6526, 78); } \\
& \text { R_Date("SHA_2003.033", 6522, 73); } \\
& \text { R_Date("SHA_2005.062.04", 6521, 75); } \\
& \text { R_Date("SHA_2007.092", 6518, 73); } \\
& \text { R_Date("SHA_2006.074", 6516, 75); } \\
& \text { R_Date("SHA_2005.061.02", 6513, 75); } \\
& \text { R_Date("SHA_2006.069.02", 6488, 75); } \\
& \text { R_Date("SHA_2002.022", 6512, 52); } \\
& \text { R_Date("SHA_1998.004", 6506, 75); } \\
& \text { R_Date("SHA_2005.062.01", 6505, 74); } \\
& \text { R_Date("SHA_2004.039", 6500, 42); } \\
& \text { R_Date("SHA_2005.067", 6499, 76); }
\end{aligned}
$$


R_Date("LOK_1990.042", 6484, 70);

R_Date("SHA_2002.024.02", 6479, 73);

R_Date("SHA_2005.063.02", 6474, 72);

R_Date("SHA_2004.055.02", 6472, 75);

R_Date("SHA_2004.048.01", 6469, 51);

R_Date("SHA_2005.060.02", 6456, 75);

R_Date("LOR_1998.014", 6448, 76);

R_Date("SHA_2007.090", 6445, 76);

R_Date("SHA_2004.055.01", 6440, 75);

R_Date("SHA_2004.050.03", 6439, 69);

R_Date("SHA_2006.069.01", 6436, 73);

R_Date("LOK_1980.022.03", 6435, 54);

R_Date("SHA_2004.056.02", 6433, 70);

R_Date("SHA_2004.047", 6432, 51);

R_Date("SHA_2006.075", 6431, 74);

R_Date("LOK_1984.029", 6430, 74);

R_Date("SHA_2002.025.01", 6429, 73);

R_Date("LOK_1980.002.02", 6428, 74);

R_Date("LOK_1980.002.03", 6421, 73);

R_Date("SHA_2004.054.01", 6417, 75);

R_Date("SHA_2004.053.02", 6412, 75);

R_Date("LOR_1980.003.01", 6411, 74);

R_Date("SHA_2004.046", 6411, 53);

R_Date("SHA_2006.083.02", 6402, 74);

R_Date("SHA_2005.061.01", 6399, 76);

R_Date("SHA_2005.062.02", 6391, 74);

R_Date("LOK_1981.024.01", 6388, 74);

R_Date("LOK_1985.033", 6388, 73);

R_Date("SHA_2006.071", 6384, 70);

R_Date("LOK_1988.038.02", 6383, 75);

R_Date("LOR_1998.013.01", 6380, 76);

R_Date("SHA_2006.070", 6374, 74);

R_Date("SHA_2003.026.02", 6373, 73);

R_Date("LOK_1981.025.05", 6369, 78);

R_Date("LOK_1981.024.04", 6367, 76);

R_Date("SHA_2005.068", 6367, 74);

R_Date("SHA_2004.051", 6356, 76);

R_Date("LOK_1988.038.01", 6355, 74);

R_Date("SHA_2004.053.01", 6347, 74);

R_Date("KIT_surface", 6344, 74); 
R_Date("SHA_2004.052.02", 6341, 74);

R_Date("LOK_1981.025.01", 6329, 73);

R_Date("LOR_1980.001", 6320, 76);

R_Date("SHA_2004.052.01", 6320, 76);

R_Date("LOK_1985.034", 6298, 74);

R_Date("SHA_2005.059.02", 6296, 75);

R_Date("SHA_2001.016", 6292, 69);

R_Date("SHA_2008.108.02", 6286, 72);

R_Date("LOK_1980.022.02", 6285, 70);

R_Date("SHA_2007.096.02", 6282, 69);

R_Date("SHA_2005.063.01", 6278, 75);

R_Date("LOK_1980.007", 6274, 73);

R_Date("SHA_2008.112", 6272, 75);

R_Date("KIT_1880.004", 6269, 73);

R_Date("LOK_1981.025.03", 6267, 73);

R_Date("GAL_Grave17-2", 6266, 74);

R_Date("LOK_1988.039", 6250, 73);

R_Date("SHA_2007.086.02", 6244, 73);

R_Date("SHA_2006.083.01", 6240, 76);

R_Date("KIT_1880.011", 6233, 73);

R_Date("LOK_1980.006", 6229, 73);

R_Date("UBE_1962.005", 6224, 72);

R_Date("LOK_1985.030.01", 6217, 73);

R_Date("SHA_2005.060.01", 6206, 75);

R_Date("SHA_2007.086.01", 6205, 75);

R_Date("UBE_1962.008", 6188, 73);

R_Date("GAL_Grave18", 6176, 74);

R_Date("GAL_Grave17-1", 6172, 73);

R_Date("SHU_1972.002.01", 6167, 74);

R_Date("LOK_1981.025.02", 6161, 73);

R_Date("UBE_1962.009.00", 6141, 72);

R_Date("LOK_1981.024.05", 6133, 74);

R_Date("LOK_1980.009", 6128, 73);

R_Date("LOK_1981.023", 6118, 76);

R_Date("GAL_Grave05-1", 6095, 73);

R_Date("GAL_Grave16", 6079, 73);

R_Date("GAL_Grave04(1978)", 6049, 73);

R_Date("GAL_Grave05-2", 6044, 74);

R_Date("SHA_2004.049.01", 6041, 52);

R_Date("LOK_1985.035", 6041, 76); 
R_Date("GAL_Grave03", 6033, 73);

R_Date("GAL_Grave07", 6028, 74);

R_Date("SHA_1999.007", 6001, 72);

R_Date("SHA_2004.050.01", 5981, 69);

R_Date("SHA_2008.104", 5977, 69);

R_Date("SHA_2008.108.01", 5955, 72);

R_Date("SHA_2003.030", 5953, 72);

R_Date("SHA_2004.044.01", 5952, 52);

R_Date("ROZ_2008.003", 5939, 74);

R_Date("SHA_2004.042.01", 5921, 73);

R_Date("SHA_2008.108.03", 5915, 72);

R_Date("SHA_2005.064.01", 5902, 74);

R_Date("SHA_2003.035.01", 5877, 72);

R_Date("SHA_1998.006", 5875, 74);

R_Date("SHA_2005.059.01", 5835, 75);

Span("EN dated events");

Interval("duration EN");

\};

Boundary("EN End/MN Start")

\{

Start();

Transition();

End();

\};

Phase("MN n=0")

\{

Interval("duration MN");

\};

Boundary("MN End/LN Start")

\{

Start();

Transition();

End();

\};

Phase("LN n=22")

\{

R_Date("ISA_1932.002", 4715, 71);

R_Date("UID_1989.025.03", 4710, 71);

R_Date("UID_1988.018", 4710, 71);

R_Date("UID_1991.038", 4670, 75); 
R_Date("UID_1987.008", 4666, 72);

R_Date("UID_1991.041", 4663, 72);

R_Date("UID_1989.020.02", 4655, 75);

R_Date("UID_1994.052", 4644, 71);

R_Date("UID_1994.054", 4617, 74);

R_Date("UID_1989.021.02", 4597, 70);

R_Date("UID_1987.005", 4596, 73);

R_Date("UID_1989.020.01", 4584, 71);

R_Date("UID_1989.026.05", 4578, 74);

R_Date("SHM_1976.001.01", 4572, 61);

R_Date("UID_1994.053.01", 4548, 71);

R_Date("SMS_1986.019.05", 4546, 61);

R_Date("SMS_1987.029.02", 4534, 60);

R_Date("SMS_1986.019.01", 4507, 61);

R_Date("SMS_1986.017", 4412, 61);

R_Date("SMS_1986.011.01", 4363, 61);

R_Date("SMS_1986.011.04", 4359, 59);

R_Date("SMS_1986.019.02", 4283, 61);

Span("LN dated events");

Interval("duration LN");

\};

Boundary("LN End/EBA Start")

\{

Start();

Transition();

End();

\};

Phase("EBA n=91")

\{

R_Date("SHM_1975.001", 4410, 43);

R_Date("SMS_1986.009", 4350, 61);

R_Date("UID_1991.042", 4248, 71);

R_Date("GO2_1996.003", 4221, 72);

R_Date("GO2_1996.004", 4171, 71);

R_Date("GO2_1995.002", 4145, 71);

R_Date("OBK_1976.003", 4138, 51);

R_Date("KUR_2002.009", 4076, 56);

R_Date("OBK_1971.013", 4021, 51);

R_Date("MAK_1992.018", 3986, 51);

R_Date("KUR_2003.025", 3938, 60); 
R_Date("KUR_2003.026", 3930, 58);

R_Date("MAK_1992.019", 3917, 50);

R_Date("OBK_1971.003.02", 3911, 50);

R_Date("BAD_1920.000", 3898, 70);

R_Date("UBE_1957.002", 3893, 67);

R_Date("OBK_1971.001.02", 3892, 35);

R_Date("MAK_1992.013.00", 3892, 50);

R_Date("KUR_2003.018", 3869, 60);

R_Date("KHA_2010.011", 3868, 60);

R_Date("OBK_1971.001.03", 3856, 50);

R_Date("MKV_1973.001", 3853, 51);

R_Date("OBK_1971.007", 3852, 50);

R_Date("KHA_2010.015", 3849, 60);

R_Date("KUR_2002.007.01", 3845, 63);

R_Date("KUL_1977.000", 3835, 60);

R_Date("KUR_2002.013", 3831, 60);

R_Date("KUR_2002.014", 3826, 59);

R_Date("OBK_1971.001.01", 3821, 44);

R_Date("KUR_2002.010", 3820, 58);

R_Date("KUR_2002.003", 3811, 61);

R_Date("KUR_2002.012", 3804, 61);

R_Date("KUR_2002.005", 3801, 60);

R_Date("OBK_1971.004.01", 3800, 50);

R_Date("UID_1991.039", 3798, 72);

R_Date("KUR_2002.007.02", 3797, 62);

R_Date("SMS_1986.012", 3796, 60);

R_Date("OBK_1971.003.01", 3796, 51);

R_Date("KUR_2003.017", 3790, 58);

R_Date("SMS_1987.033", 3789, 58);

R_Date("KHA_2010.005", 3783, 60);

R_Date("K14_2000.077", 3776, 56);

R_Date("KUR_2002.001", 3773, 60);

R_Date("OBK_1971.004.02", 3773, 50);

R_Date("KUR_2003.019", 3759, 58);

R_Date("KUR_2002.006", 3757, 61);

R_Date("SHM_1973.001", 3747, 61);

R_Date("KHA_2010.009", 3745, 60);

R_Date("OBK_1971.014.02", 3742, 50);

R_Date("KUR_2002.015", 3741, 60);

R_Date("SMS_1986.013", 3737, 60); 
R_Date("OBK_1971.014.01", 3736, 50);

R_Date("KHA_2010.008", 3714, 60);

R_Date("MNZ_1974.004.01", 3706, 50);

R_Date("UIA_1977.005", 3691, 50);

R_Date("K14_1998.037.01", 3690, 60);

R_Date("KUR_2002.016", 3679, 58);

R_Date("KUR_2002.004", 3667, 56);

R_Date("KHA_2010.012", 3664, 59);

R_Date("SHM_1973.002", 3657, 60);

R_Date("UIA_surface", 3641, 50);

R_Date("K14_1999.057.02", 3639, 59);

R_Date("K14_2001.087", 3637, 60);

R_Date("SHM_1972.002", 3634, 43);

R_Date("UKH_1930.000", 3619, 50);

R_Date("KHA_2003.003", 3614, 56);

R_Date("OBK_1971.005", 3608, 51);

R_Date("MNZ_1974.001", 3595, 50);

R_Date("SMS_1987.021", 3594, 58);

R_Date("SHA_2000.009", 3593, 67);

R_Date("SHM_1972.001.01", 3582, 60);

R_Date("K14_1998.036.01", 3582, 60);

R_Date("SHA_2008.103.02", 3578, 70);

R_Date("SHM_1973.004", 3575, 60);

R_Date("KHA_2010.007", 3556, 60);

R_Date("K14_1999.045", 3540, 59);

R_Date("BO1_1971.002", 3539, 50);

R_Date("K14_1998.037.02", 3538, 56);

R_Date("OBK_1971.010", 3535, 49);

R_Date("SHA_2008.107", 3531, 67);

R_Date("BO2_1971.002", 3506, 36);

R_Date("K14_1999.049", 3506, 60);

R_Date("BO1_1971.001", 3503, 50);

R_Date("GLZ_1887.006", 3502, 70);

R_Date("KHA_2010.006", 3494, 60);

R_Date("SHA_2008.109", 3490, 72);

R_Date("SHA_2008.103.01", 3486, 70);

R_Date("BO2_1971.003", 3475, 50);

R_Date("SHM_1973.003.01", 3474, 60);

R_Date("UID_1994.048", 3437, 71);

R_Date("SHA_2008.111", 3409, 72); 
Span("EBA dated events");

Interval("duration EBA");

\};

Boundary("EBA End")

\{

Start();

Transition();

End();

; ;

\}

\} 
November 30, 2015

Dear Editor,

We have just submitted our revised paper "Chronology of Middle Holocene hunter-gatherers in the Cis-Baikal region of Siberia: Corrections based on examination of the freshwater reservoir effect".

The paper has been reworked following the suggestions and comments provided by the two reviewers. We found both assessments very helpful and we agree with most recommendations. We would like to note that it is clear that both reviewers support the general approach and appreciate the changes made to the previous draft. We understand, however, that the paper still needed some work although not as much as after the original submission.

The following is a list of changes made to the current manuscript:

1. The method of combining radiocarbon dates has been changed slightly and now follows the suggestion of Reviewer 1. The method is now explained in a new section dedicated to this matter (4.3. Combining radiocarbon dates).

2. The use of a new method of combining dates required running the entire statistical analysis again. This, as expected, didn't make much difference to the overall results but all numbers (e.g., the "r" and "p" values) changed slightly and were accordingly updated in the text, figures, tables, and supplements.

3. We explained and justified why the R_Combine function was preferred over the Combine function to combine radiocarbon dates.

4. We also explained why using the trapezium distribution for the Bayesian modeling in some instances produces Spans that are longer than the Intervals.

5. We decided not to make the case for the presence of two phases of cemetery use at Shamanka II stronger, as implicitly suggested by Reviewer 1 . We believe that we dealt with this matter adequately and that the paper was already long enough to expand this matter further. Besides, there are sufficient references in the paper that the matter is discussed in more detail in a separate study soon to appear in print too.

6. Regarding the point by Reviewer 1 that "the interpretation seems back-to-front" (p.18, para.3), we agree and the interpretation was changed.

7. Regarding the general comment made by Reviewer 1 that correlations between date and isotope values need to address the matter of diet composition, we added a new paragraph to the section discussing the EN Angara and the section on the EN Southwest Baikal was revised too. The section on the EBA Little Sea already had enough information about this matter.

8. Since much of the work reported in the paper was completed prior to the conception of the Baikal-Hokkaido Archaeology Project, in some places we use 'Baikal Archaeology Project' - our former name. We agree that this may confuse some readers a little, but to credit BHAP for the work done by BAP would not be fair.

9. The Conclusions were somewhat revised, including the statement pointed out by Reviewer 2. 
10. The entire paper was screened for minor errors including those identified by the reviewers.

In addition to the above changes, one entirely new section was added to the paper. In the light of the discussion in the section on dietary patterns in the EBA Little Sea sample, in which the Upper Lena micro-region is mentioned quite frequently, we considered it useful to add a section on the EBA Upper Lena. This new section expands and clarifies some of the points made in the section on the EBA Little Sea. In a way, these two sections complement one another.

We trust that these changes are satisfactory to proceed to the production stage.

Kind regards,

Andrzej Weber 